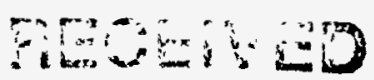

Final Evaluation of the Acoustics of thie2 61996 APS Conference Center OSTI

by

Juan Mario Restrepo

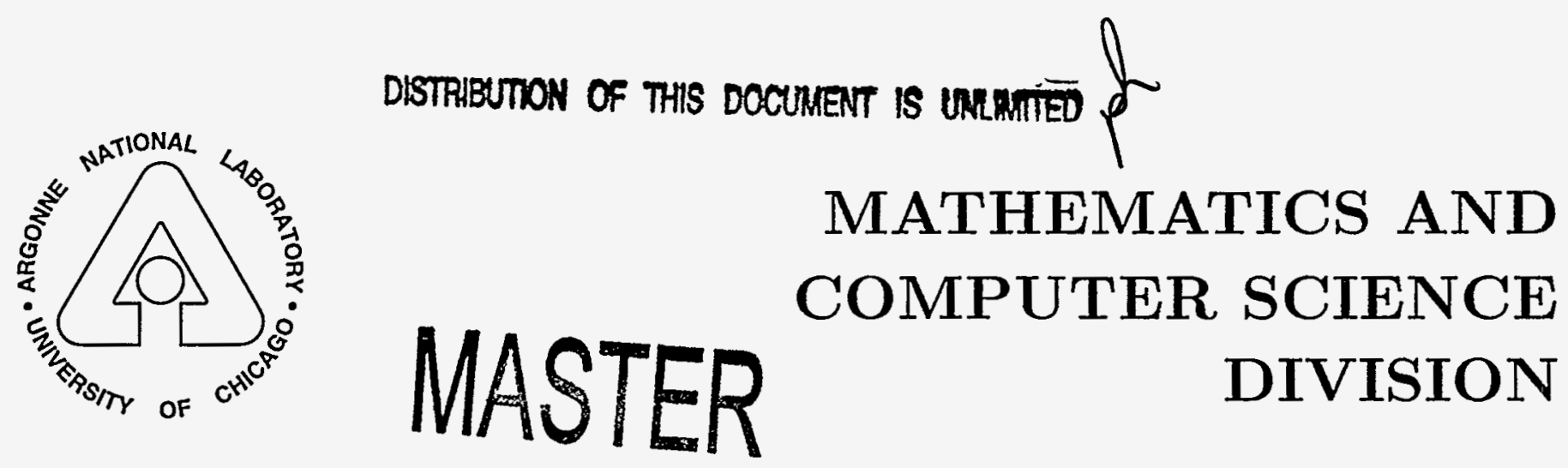


Argonne National Laboratory, with facilities in the states of Illinois and Idaho, is owned by the United States government, and operated by The University of Chicago under the provisions of a contract with the Department of Energy.

\section{DISCLAIMER}

This report was prepared as an account of work sponsored by an agency of the United States Government. Neither the United States Government nor any agency thereof, nor any of their employees, makes any warranty, express or implied, or assumes any legal liability or responsibility for the accuracy, completeness, or usefulness of any information, apparatus, product, or process disclosed, or represents that its use would not infringe privately owned rights. Reference herein to any specific commercial product, process, or service by trade name, trademark, manufacturer, or otherwise, does not necessarily constitute or imply its endorsement, recommendation, or favoring by the United States Government or any agency thereof. The views and opinions of authors expressed herein do not necessarily state or reflect those of the United States Government or any agency thereof.

Reproduced from the best available copy.

Available to DOE and DOE contractors from the Office of Scientific and Technical Information

P.O. Box 62

Oak Ridge, TN 37831.

Prices available from (423) 576-8401

Available to the public from the National Technical Information Service

U.S. Department of Commerce 5285 Port Royal Roac Springfield, VA 22161 
ARGONNE NATIONAL LABORATORY

9700 South Cass Avenue

Argonne, IL 60439

ANL/MCS-TM-212

\title{
Final Evaluation of the Acoustics of the APS Conference Center
}

\author{
by \\ Juan Mario Restrepo \\ Mathematics and Computer Science Division
}

Technical Memorandum No. 212

November 1995

This work was supported in part by the Mathematical, Information, and Computational Sciences Division subprogram of the Office of Computational and Technology Research, U.S. Department of Energy, under Contracat W-31-109-Eng-38. 


\section{DISCLAIMER}

Portions of this document may be illegible in electronic image products. Images are produced from the best available original document. 


\section{CONTENTS}

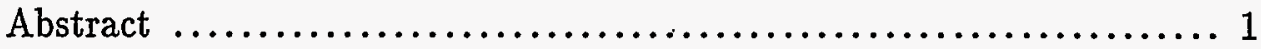

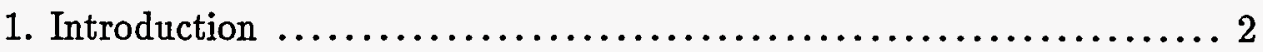

2. Changes on the Original Design $\ldots \ldots \ldots \ldots \ldots \ldots \ldots \ldots \ldots \ldots$

3. Summary of Work Performed $\ldots \ldots \ldots \ldots \ldots \ldots \ldots \ldots \ldots \ldots \ldots \ldots \ldots$

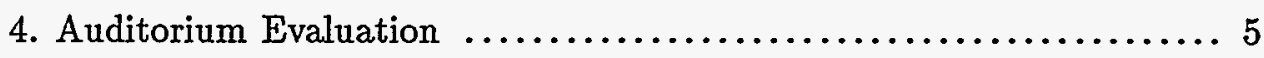

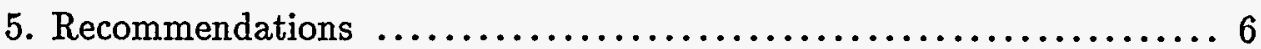

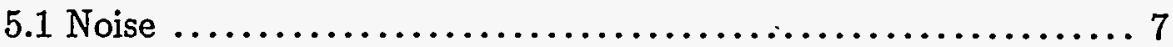

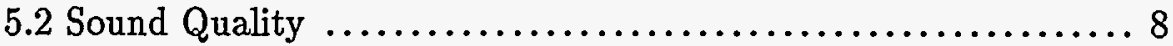

5.3 Lighting $\ldots \ldots \ldots \ldots \ldots \ldots \ldots \ldots \ldots \ldots \ldots \ldots \ldots \ldots \ldots \ldots \ldots, 8$

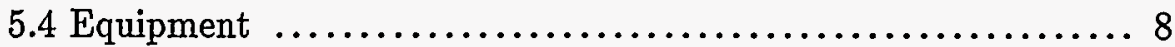

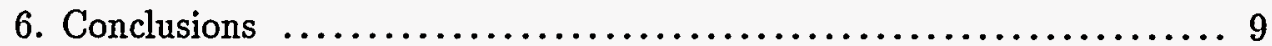

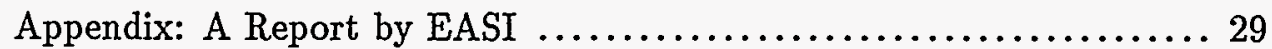




\title{
Final Evaluation of the Acoustics of the APS Conference Center
}

by

\author{
Juan Mario Restrepo
}

\begin{abstract}
Along with a description of the changes that I prescribed on the original design, this report is an evaluation of the acoustical properties of the new Advanced Photon Source Auditorium at Argonne National Laboratory. Acoustical deficiencies in the hall are presented with

several options for their expedient and economical solution.
\end{abstract}




\section{INTRODUCTION}

In addition to making final recommendations regarding further improvements on the auditorium, I will include in this report a brief description of the ways in which my input to this project affected in a significant way the eventual qualities of the auditorium.

My involvement with this project began when I was invited as an observer to a design review meeting which was held about a year-and-a-half ago at the Chicago offices of the architects, from Knight and Assoc. Present at the meeting were the architects, construction contractors, the acoustics consultant, audio/video contractors, and several people representing Argonne. The meeting's purpose was to review the acoustic design as well as some aesthetic details of the hall. At the time of the meeting most of the blue-prints and schedules were already drawn up. At this meeting, I took issue with the following design decisions:

(1) Overall elliptical shape of the auditorium: shape produces severe sound focusing (and poor sound diffusion). Shape presents problems for several performing activities, such as dance, musical theater, etc. The elliptical shape has poor space utilization characteristics and makes any future expansions of the auditorium costly.

(2) Gypsum-wall construction: very poor noise transmission abatement qualities. Leads to poor bass response (owing to diaphragmatic effects of walls). Aesthetically displeasing construction material.

(3) Extremely low reverberant times, poor diffusion, poor use of natural acoustic energy, poor projection, poor initial time delay, near-certain possibility of echoes and flutter, poor high frequency response, low intimacy and warmth, speech intelligibility problems.

(4) Stage area too small. The stage would be uncomfortable and its shape was not checked out for overhead projector use.

(5) Stage wings too small. Also, stage wings do not have double doors.

(6) Poor line-of-site for seating area under the balcony.

(7) Poor acoustic coupling between stage and orchestra due to proscenium structure.

(8) Poor acoustics for seating area under the balcony owing to bad aspect ratios

(i.e., the depth/height ratio is unacceptably high).

(9) Excessive acoustic treatment.

It should be noted that I had a meeting with Dr. David Moncton in which items (1)(7) were brought to his attention. This meeting occurred a few days after my very first design meeting. Since my involvement in the project began after the designing and bidding stages were completed, several of the items listed above could not be changed: consensus between the builders and client had already been reached. Several of these items were beyond discussion, namely, items $(1),(5),(6)$, and (8). On the other items some of my suggestions were considered, others were considered but ultimately not implemented Item (4): the stage 
was enlarged marginally. Item(7): the proscenium was to be eliminated, but ultimately the suggestion was ignored. For items (2) and (3), I agreed to formulate a design and a testing strategy that would significantly improve the acoustics with regards to abating poor diffusion and focusing, raising the reverberation time, reducing loss of low frequencies, taking advantage of available natural acoustic energy, improve speech intelligibility, straighten out as much as possible the elliptical walls. Details of the design changes will be discussed later in this report. During the same meeting, I had the opportunity to get an overview of the noise control plans of the acoustics consultant. He was not terribly forthcoming with the design details, and most likely annoyed with me since I changed substantially his design specifications for the halls' internal surfaces. The Noise Criteria ( $\mathrm{NC}$ rating) for the hall was guaranteed by the acoustics consultant to be no greater than $\mathrm{NC}=30-35$, higher than the criteria I preferred, which was $\mathrm{NC}=20-25$. We reviewed the details of the construction of the roof, which I was satisfied with, and I asked the acoustics consultant to specify low velocity air-handling equipment with large unobstructed air-supply ducts. These ducts would bring air into the hall in the area above the acoustic reflectors that I agreed to design. He was supposed to send me details of the noise control design, but I never received them. While acoustic (sound) quality is still a matter of art and experience, noise abatement design is standard engineering: noise control is a straightforward affair that can be achieved through careful design and any acoustics expert is expected to succeed in this aspect of design. Since he was a paid expert (and I was of the unpaid variety), I left this area of concern in his hands. Presently, noise is the single worse problem of the present auditorium. At the end of this report I will present several recommendations that will improve significantly the signal to noise ratio in the hall.

The standard practice in hall design dictates that matters of aesthetics and sound perception cannot be well defined or perfectly predicted. With regards to these aspects, the acoustics consultant is not liable unless some fundamental feature is grossly executed. However, with regards to noise abatement, the acoustics expert is expected and liable for delivering a completed building to within specifications. It is also good practice for the noise control expert to make very frequent visits to the sight to oversee all matters relevant to attaining the noise specifications. I do not know of any instance in which the acoustics consultant ever visited the site. While I came late to the project, beyond the design discussion stage, it was the acoustics expert's responsibility to warn the architects regarding the perils of auditoriums of pathological shape.

\section{CHANGES ON THE ORIGINAL DESIGN}

Of the items listed previously, the design changes improved considerably items (1), (2), (3), and (4). Items (4) and (7) were supposed to be taken care of by removing the proscenium walls, but this recommendation was being ignored. I recommended that most of the originally-specified surfaces of the walls and ceiling be changed: most of the walls would be covered with acoustic diffusers of my design, the lower part of the side walls lined with hardwood. The balcony area would be straightened out to reduce the effects of the curved 
walls. Most of the acoustic treatment which was originally specified was eliminated. The side-wall acoustic diffusers were designed to increase sound balance and diffusion and to better utilize the available acoustic energy by deflecting it either to the audience or to the free field. The diffusers also mitigated the effects of the elliptical shape of the hall for the mid to high frequencies, the diaphragmatic effect of gypsum wall construction, and significantly decreased noise transmission. The original design of the wall diffusers were to come in two different sizes, which would have increased diffusion to even lower frequencies, but cost and aesthetics would only allow for the smaller-sized diffusers. The diffusers would affect sound in frequencies above $1200 \mathrm{~Hz}$. The acoustic diffusers appear in Figure 1. The hardwood lining on the lower portion of the side walls had not been installed when these pictures were. taken. The hardwood panels further remove the diaphragmatic nature of the gypsum walls, thus increasing the bass response, particularly of high powered sound sources. In my last visit to the auditorium, on Dec 6 1995, I noticed that a hollow cavity exists behind the wall panels: this was specifically to be avoided in the installation since these cavities will tend to filter mid-low frequencies. Hence, the effect is opposite of what was expected. The effect, however is not very deleterious. Further comments on these structures appear in a section below.

I designed and helped install a system of reflectors on the ceiling. These reflectors increase. the amount of energy in the first reflections, primarily in the mid-high frequency range, and increase low frequency diffusion. The reflectors were designed so as to allow optional adjustment for maximum energy utilization. Figure 2a shows the acoustic reflector system. These reflectors were supposed to be roller/brush-painted rather than air-brushed. A slight decrease of high frequency reflections from these panels results in a noticeable decrease in high frequency reverberant sound. Fig.2b shows the coverage pattern that was achieved by adjusting every single reflector for optimal energy utilization. A design strategy was adopted which called for most surfaces to be treated acoustically, but other surfaces to be left bare until tested during the construction phase. The test would ultimately determine whether the remaining acoustic treatment was needed and if so, what type. Our October 12 test showed that most of the treatment originally specified by the acoustics engineer for the balcony area was unnecessary and was not installed.

During that first meeting, I also reviewed the audio/video design. The originally-specified equipment was very sophisticated. My primary concern was that no fail-safe mechanisms were in place for any of this equipment. Failure of this equipment, coupled with the poor acoustics of the original design would have paralized a talk or a conference. I made the recommendation that all the equipment should have by-pass capabilities, so that the auditorium could be used unaided by the equipment and expert operators. For the most part this recommendation was adopted. Between myself and other A/V representatives from Argonne, we were able to make substantial changes in the specified equipment to either remove. unnecessary expenses or to increase the flexibility of the equipment to suit Argonne's needs.

Several other meetings were organized with the architects and contractors to review my design changes and calculations as well as to review my design strategy. Other meetings dealt with aspects related to audio equipment and facilities. I was personally involved with 
the installation of the acoustic reflectors and acoustic testing of the facility In one instance, I tried in vain to dissuade the purchase and improper installation of the lateral loudspeakers which I deemed an unnecessary expense.

\section{SUMMARY OF WORK PERFORMED}

The following is an itemized list of the work I performed in connection to the design and construction of the APS auditorium:

- Evaluation of designs.

- Acoustic quality calculations.

- Re-design of treatment.

- Design of diffusers.

- Design of reflectors.

- Installation of reflectors.

- High-frequency field test, initial time delay tests, frequency response.

- Low-frequency, speaker performance test, noise measurements, flutter identification.

- Speech intelligibility test.

- Construction oversight.

- Audio design evaluation.

- Drafting of final'recommendations.

A total of $150-200$ hours of work.

\section{AUDITORIUM EVALUATION}

Several acoustic tests were performed. Among the most revealing are those conducted by Mr. Doug Jones of EASI and myself on October 12, 1995. Details of our measurement procedure and equipment appears in the appended EASI report. Our initial evaluation and measurement analysis preface the data. Overall, the auditorium has a higher reverberation time than was originally specified. This is a very welcomed result. The reverberation time is around 1.5 seconds. Lower reverberation times occur at lower frequencies, which is somewhat unusual. Initial time delays were, overall very adequate, except in the lateral seats in the front of the orchestra section. The elliptical shape of the auditorium produces a non-dense 
decay of reflections. However, the frequency of reflection has been greatly enhanced by the diffusers and reflectors. There is an extremely severe focusing problem in the center front seats and in the center stage area owing to the parabolic shape of the back wall of the stage. The frequency response for the auditorium is fairly flat, somewhat deficient in the high frequencies. An informal speech intelligibility (RASTI) showed a "fair" rating. The intelligibility test was performed with the air-handler in operation. The main reason for the fair speech intelligibility rating is the noise problem. The main source of noise is turbulence originating at the diffusers of the air-handling system. A statistical test on speech intelligibility was performed on Dec 12, 1995, in which data from 100 listeners was evaluated. Rather than using the standard Fletcher and Steinberg method for the rating of speech intelligibility, a more informal statistical test was performed. The outcome confirms the rating by the RASTI method, and the relative intelligibility was 0.82 for the center front seats, 0.64 for lateral front seats, 0.63 for the anterior orchestra section, and 0.55 for the bacony area. These figures are lower bounds. They represent speech intelligibility ratings for a non-native English speaker in a situation typical of a seminar talk. For a native speaker, the speech intelligibility rating was 0.94 for the center front seats and all other locations dropped approximately in the same amounts for the other locations. Both tests were conducted without the aid of sound reinforcement and with the air-handler turned off.

Overall, the acoustics in the balcony were most uniform and balanced for music but less satisfactory for speech. The orchestra section could be improved considerably with regards to the acoustics if the back wall of the stage could be straightened out and the proscenium removed. By far, the most serious problem is the air-handling noise. The noise criteria should have been no greater that $\mathrm{NC}=25$, The current figure is about NCC=40-45.

The testing did not include the seating area under the balcony. All measurement were made with this area sealed off by the divider panels. For performances, it will make little or no difference on the acoustics to close off this seating area elsewhere in the hall.

Aside from evaluating the auditorium acoustically, it was also inspected visually. The most salient problem I found was the choice of doors throughout the hall. None of them are acoustically rated, none of the are satisfactory in this application.

Testing also showed that the lateral loudspeakers are not to be used in the public address system on speech-oriented events owing to severe comb-filtering. This is documented in the EASI report.

Measurements on stage and in the rest of the hall confirmed the deleterious effect of the proscenium walls in decoupling the stage acoustically from the rest of the auditorium. The proscenium walls also enhance a severe flutter echo which is focused in the near and center seating area.

\section{RECOMMENDATIONS}

The main problem that needs to be addressed is the noise from the air-handling system. In order of seriousness, there are problems related to noise, sound quality, lighting, equipment, and aesthetics. 


\subsection{Noise}

1. Air-Handling System: Noise is primarily turbulence-induced by diffusers and is affected by high-velocity flow and improper placement of air supply locations.

Solution: Reduce flow speed. Remove the internal dampers on all the ducts. Remove diffusers from site in Figure 3. Expand (by a factor of 2 or 3 ) the air supply ducts in Figure 4 and remove the diffuser grills. Seal every other air supply in Figure 5, and remove diffuser grills of ducts that are not sealed. It would be even better if all air supply ducts in Figure 5 were sealed. This judgment needs to be made based on comfort, but I think it would work if the air supply ducts in Figure 4 are enlarged considerably. The proscenium wall should be removed; see Figure 6a. However, if this proscenium wall is not removed, the air supply ducts should be moved as high as possible from the floor and the diffuser grill removed; see Figure 6b.

2. Doors: None of the doors are acoustically adequate. They have poor noise transmission characteristics, are very noisy when operated, and have noisy handles. Outside doors do not stay closed. See Figure 7.

Solution: Short of replacing all of the doors, replace door handles with acousticallyrated handles on all doors that lead directly into the hall. See Figure 8. On doors such as shown in Figures 9a and 9b, high density gaskets should be installed between doors. All door frames, as in Figure 10, should be fitted with strips of acoustic gasketing, as shown in Figure 11. Door drop-bars needs to be installed on all doors. See Figure 12.

3. Balcony: Staircase leading to balcony is a serious noise source as people gain access or talk in this area. 13.

Solution: Treat all walls of this area with Novowall ${ }^{1}$ or similar acoustic tiles. See Figure

4. Exterior Doors (immediately off-state): Source of external noise.

Solution: Fix or replace doors. See Figure 7. Also, need to install another set of doors in the off-stage area.

5. Balcony Wall: Hollow wall makes noise when kicked.

Solution: Install heavy carpet along the whole wall. See Figure 14.

${ }^{1}$ Novowall is available from the Huff Company. Contact Steve Mitchell (708) 362-7440. 


\subsection{Sound Quality}

1. Proscenium Frame Walls (Figure 6): Decouples stage acoustically from the rest of the hall. There is an extremely annoying flutter echo between inside walls and the back wall of the stage. Walls take up useful stage space. It reinforces the negative qualities of an elliptical auditorium.

Solution: Remove altogether. If this is not possible, it is suggested that the inside walls be coated with acoustic tiles or Novowall. This ia a poor compromise, since it will reduce the amount of energy delivered to the hall.

2. Parabolic Shape of the Back of the Stage: There is severe focusing of sound on the first few seats in the orchestra. Also, it is responsible for poor sound on lateral seats in the orchestra area. Audience members are also capable of distracting speaker. It contributes to poor energy spreading.

Solution: Straighten the back wall. As an experiment, place the acoustic baffles from the 362 auditorium so that a straighter wall can be assessed. Putting a couple of these panels in the center of the stage can be considered as permanent fixtures. Another possibility is to hang straight solid panels on several areas of the back wall.

3. Bass Response: There is poor bass response from gypsum wall construction.

Solution: In addition to the help produced by the diffusers, the lower part of the side walls are laminated with hardwood paneling. In my last inspection, I noticed that these panels are of significant distance away from the wall. There is an airspace which was supposed to be avoided. To mitigate the improper installation, drill holes on the panel upper sides and fill space with sand. Do not fill the space with foam.

\subsection{Lighting}

Poor Lighting: There is poor lighting toward the front of the stage area.

Solution: More lighting is required. See Figure 15.

\subsection{Equipment}

1. Center Speaker Cluster: There is poor coverage; see Figure 16. Also, there is limited service access.

Solution: Remove fabric since it is not acoustically transparent. Redirect speakers; the center cluster is composed of two speakers. One of them is left untouched. The other is redirected so that more coverage is achieved. See Figure 17. 
2. Lateral Speakers: There is limited utility and poor coverage.

Solution: Use only for movies or to support center cluster in popular music events. Redirect speakers to improve coverage toward auditorium. Remove nontransparent fabric covering.

3. Lobby Public-Address: Need to wire lobby speakers so that audio access from the sound booth is possible.

\section{CONCLUSIONS}

The present report emphasizes the poor qualities of the APS auditorium, since it is written specifically to alert the users of its problems and of its solutions. An equally-long report could be written to highlight the good qualities of the auditorium. This report specifies several solutions to the most salient problems in the hall which, if acted upon, would elevate the acoustical quality of the hall to levels comparable to any other auditorium of similar class in the region.

Clearly, noise is the most significant problem and should be addressed before any other problem is tackled. It is reasonable to expect the NC rating can be decreased from 45 to 35 if all the noise problems discussed in this report are addressed. A lower NC than 35 is only possible with a major redesign of the auditorium and the air-handling system.

The next most significant problem is related to the hall's shape. Although my design changes were able to ameliorate the shape's contribution on the acoustics, the focusing of the stage back wall cannot be treated without either a stage redesign or by the placement of structures on the stage area that would compromise the already small available useful space on stage.

I am told that one of the senior architects at Knight and Assoc. has offered to redesign the stage area at no most. My candid opinion on this suggestion is that an expert steam boiler designer is not qualified to design nuclear reactors. An alternative is for me to design a reasonably-priced structure that would be attached to the present stage back wall. This would require that the stage area and the front of the orchestra section be resurveyed, since the existing blueprints differ in several important ways from these portions of the current auditorium. The new design would include calculations with which to estimate its effectiveness.

To conclude, elevating the acoustical qualities of the APS auditorium significantly is both feasible and worthwhile and can be accomplished at reasonable costs. 


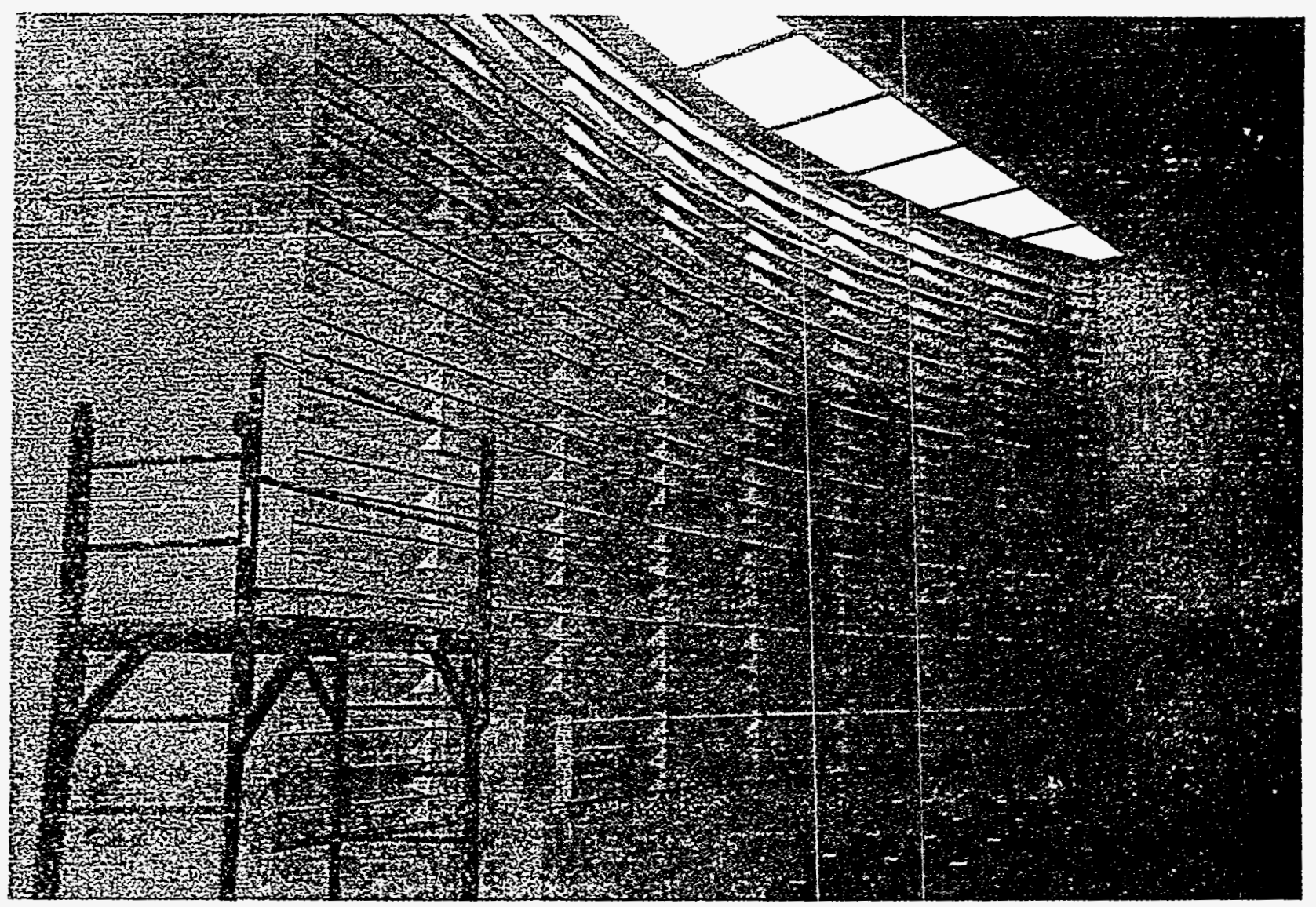

Figure 1. Diffusers on side walls. These structures provide high-frequency diffusion and counteract effects of elliptic hall geometry in this frequency range. 


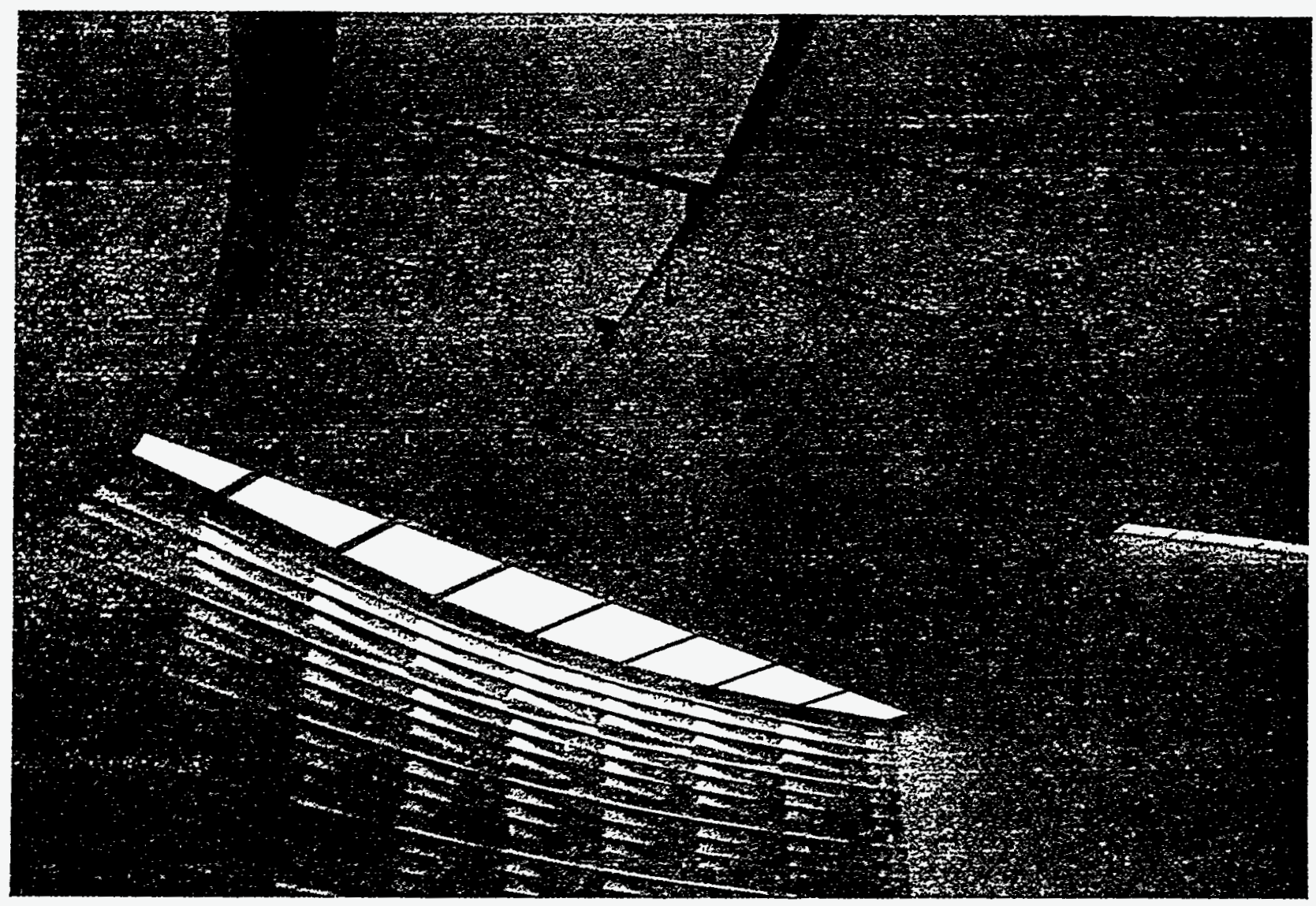

Figure 2a. Acoustic reflectors. Provide high-frequency reflections, increasing the density of secondary reflections at listening locations. They also provide low-frequency diffusion. 


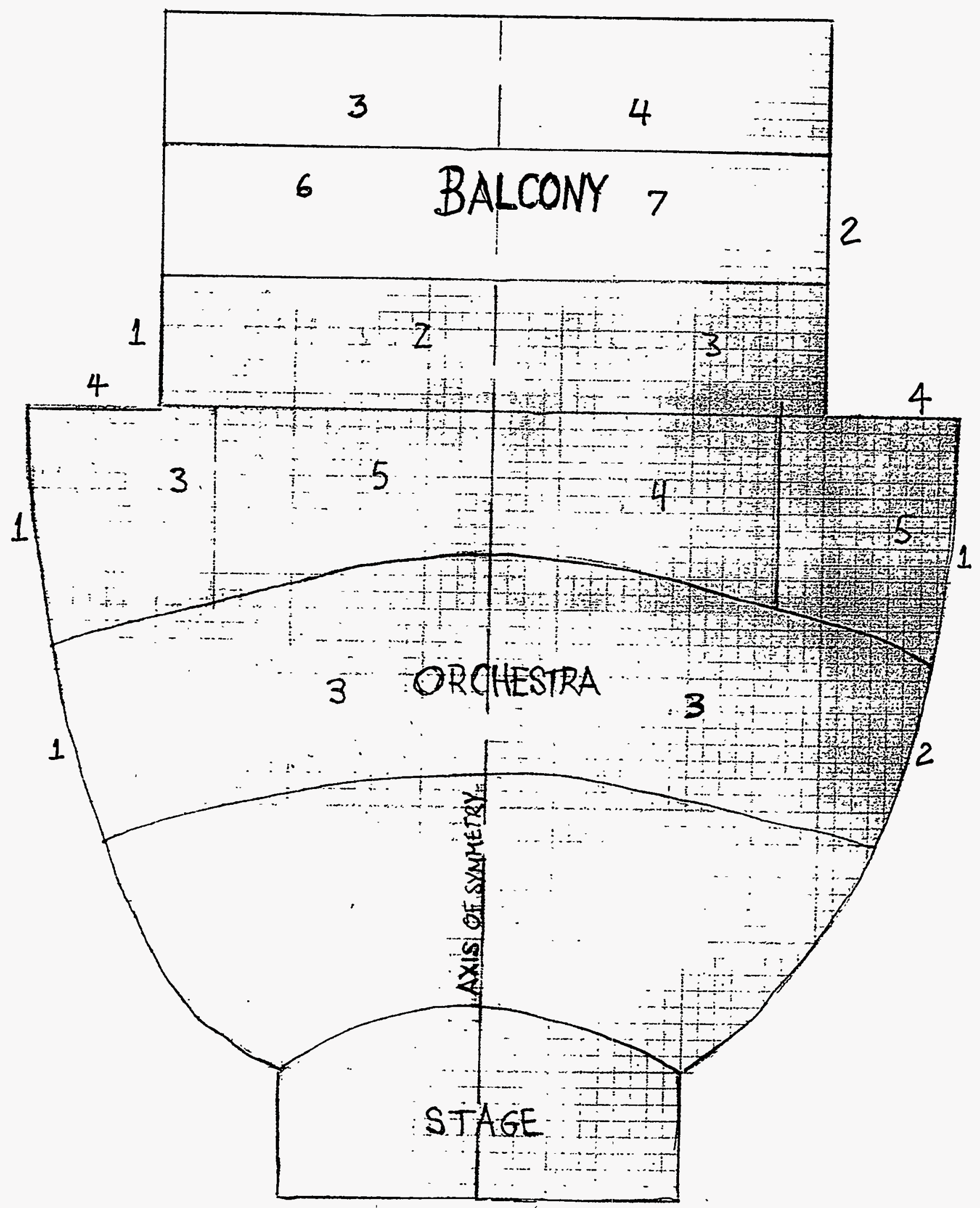

Figure 2b. Pattern of first reflections on audience area due to acoustic reflectors. Number describes the number of reflections. Left of axis of symmetry corresponds to source on axis. Right of axis corresponds to source left of axis. 


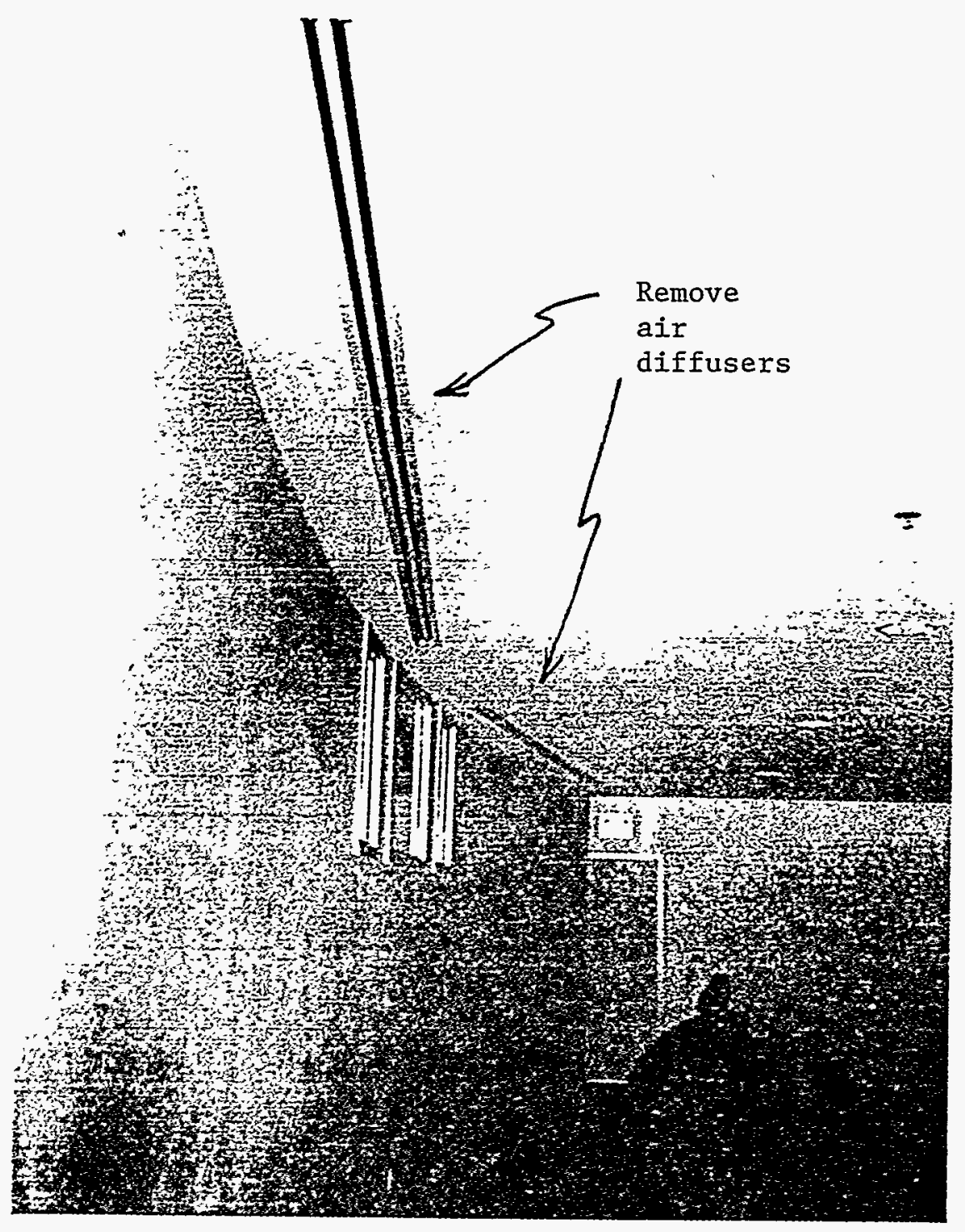

Figure 3. 


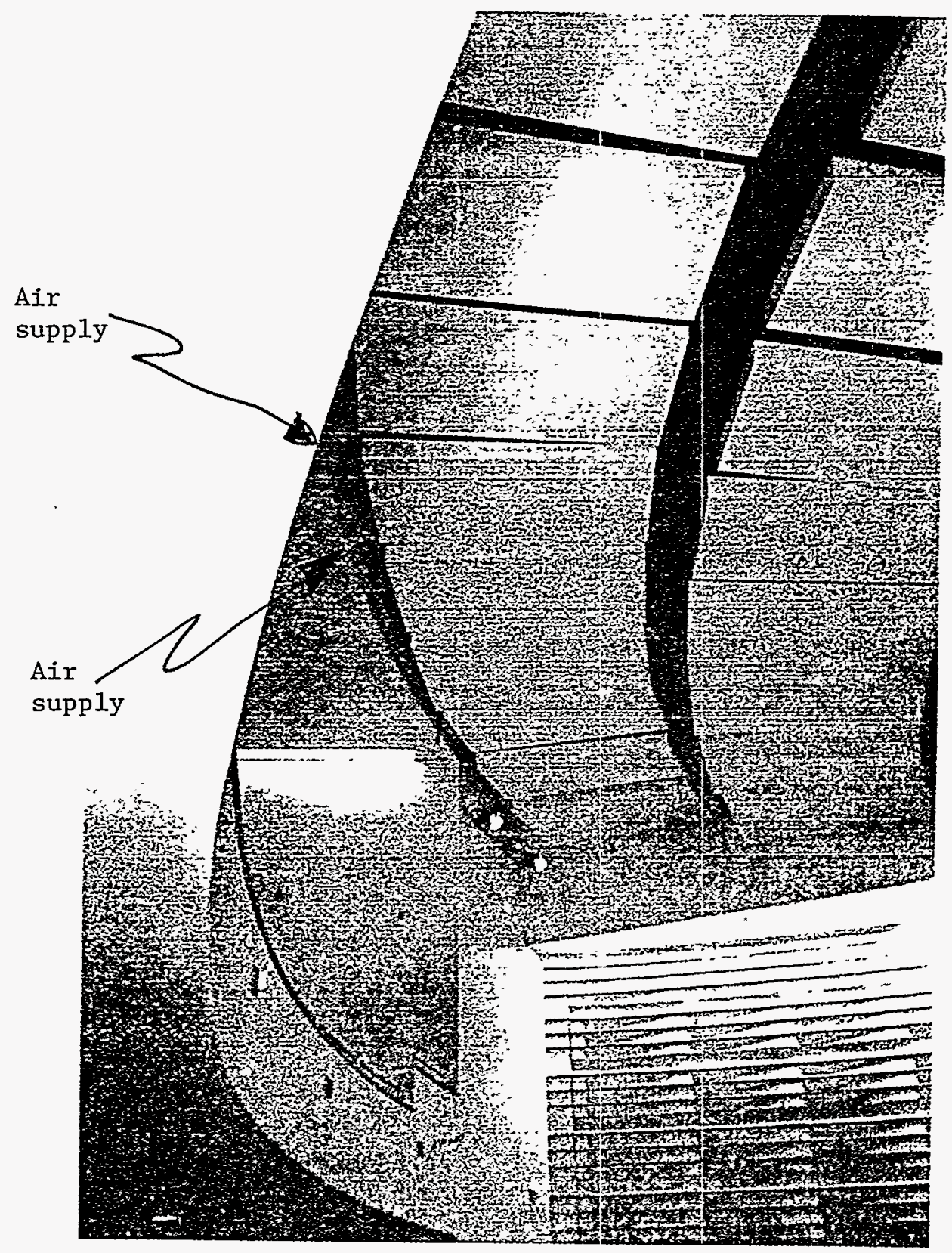

Figure 4. Remove air diffusers and enlarge air supply ducts 


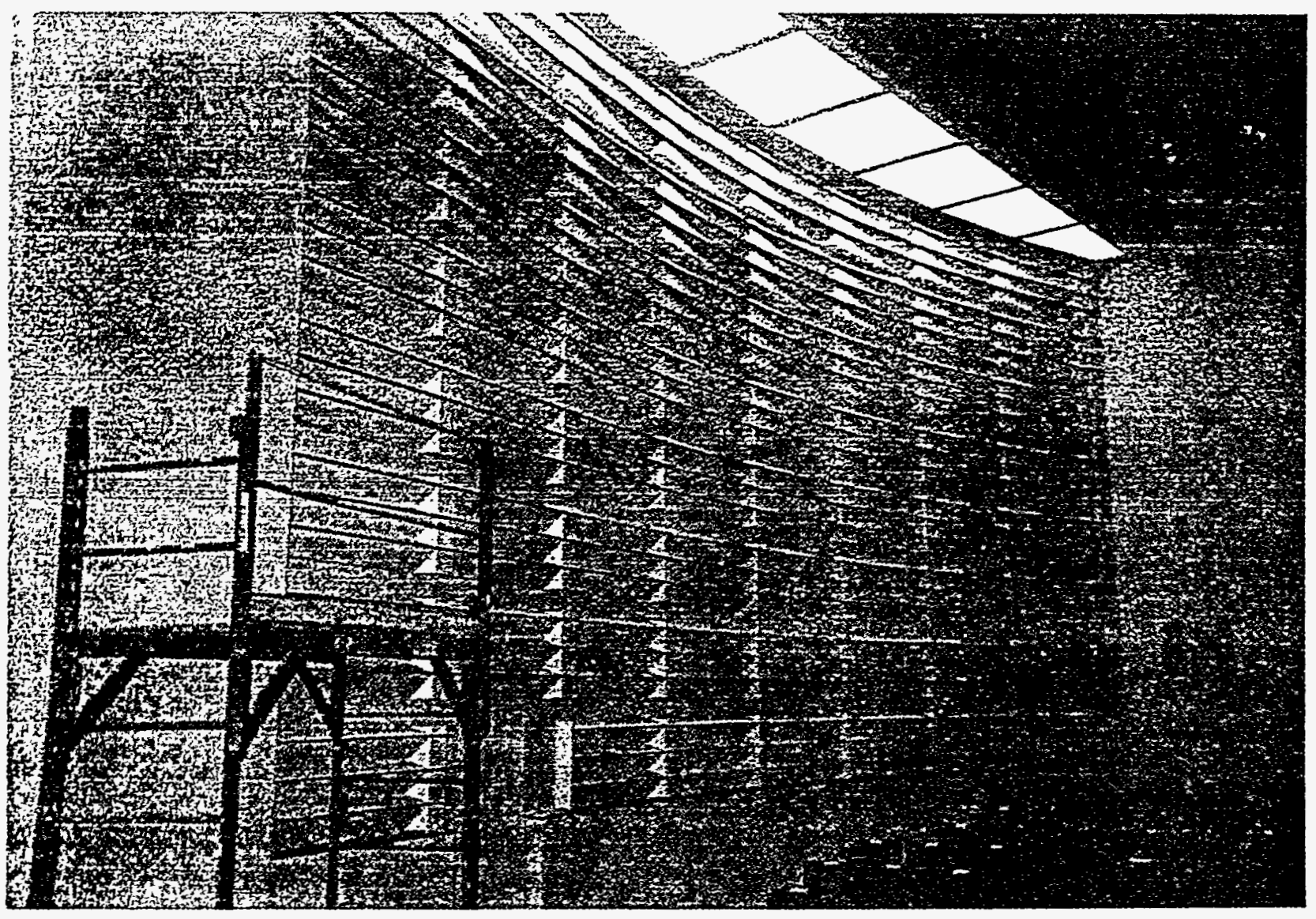

Figure 5. Seal air supply ducts on side walls 


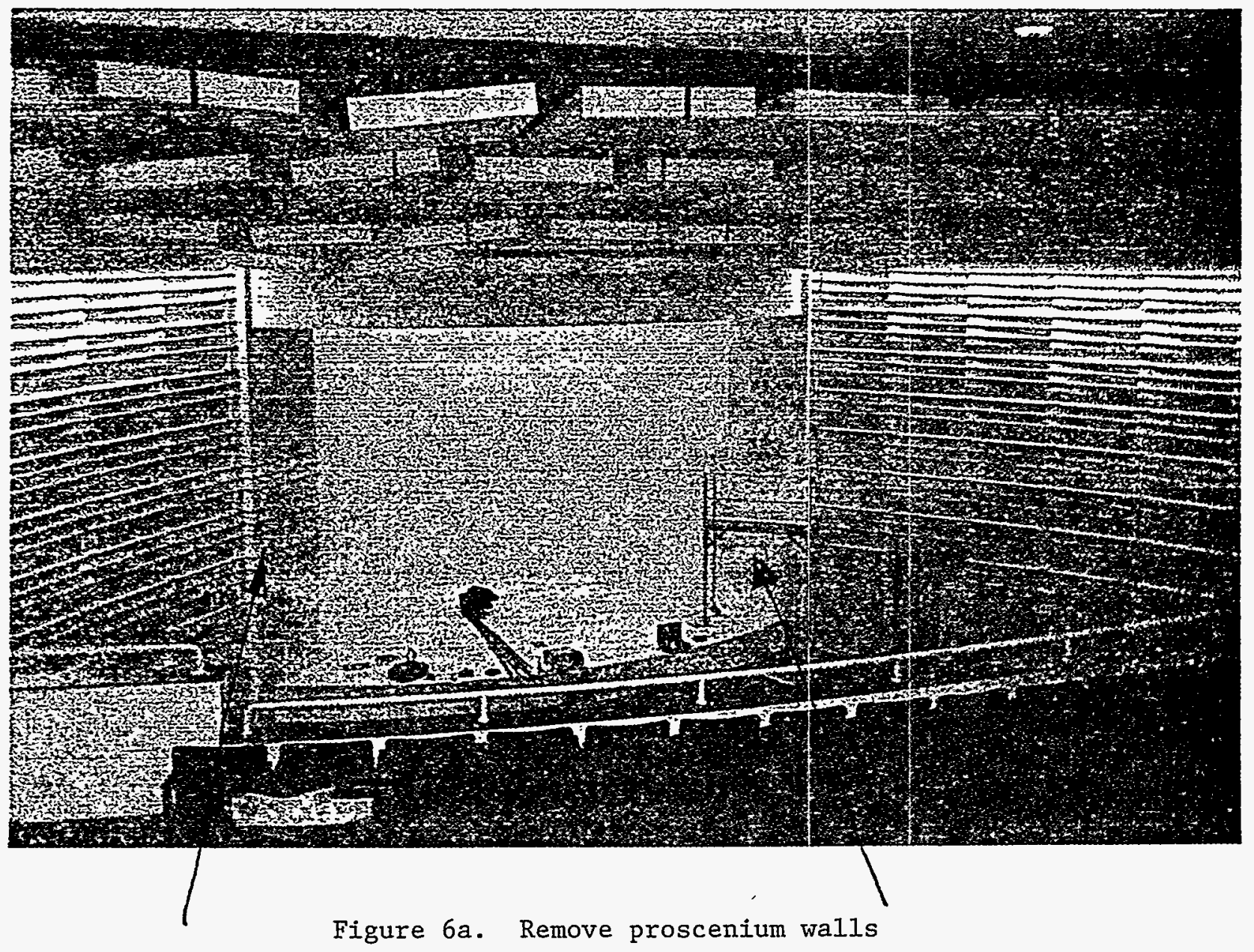




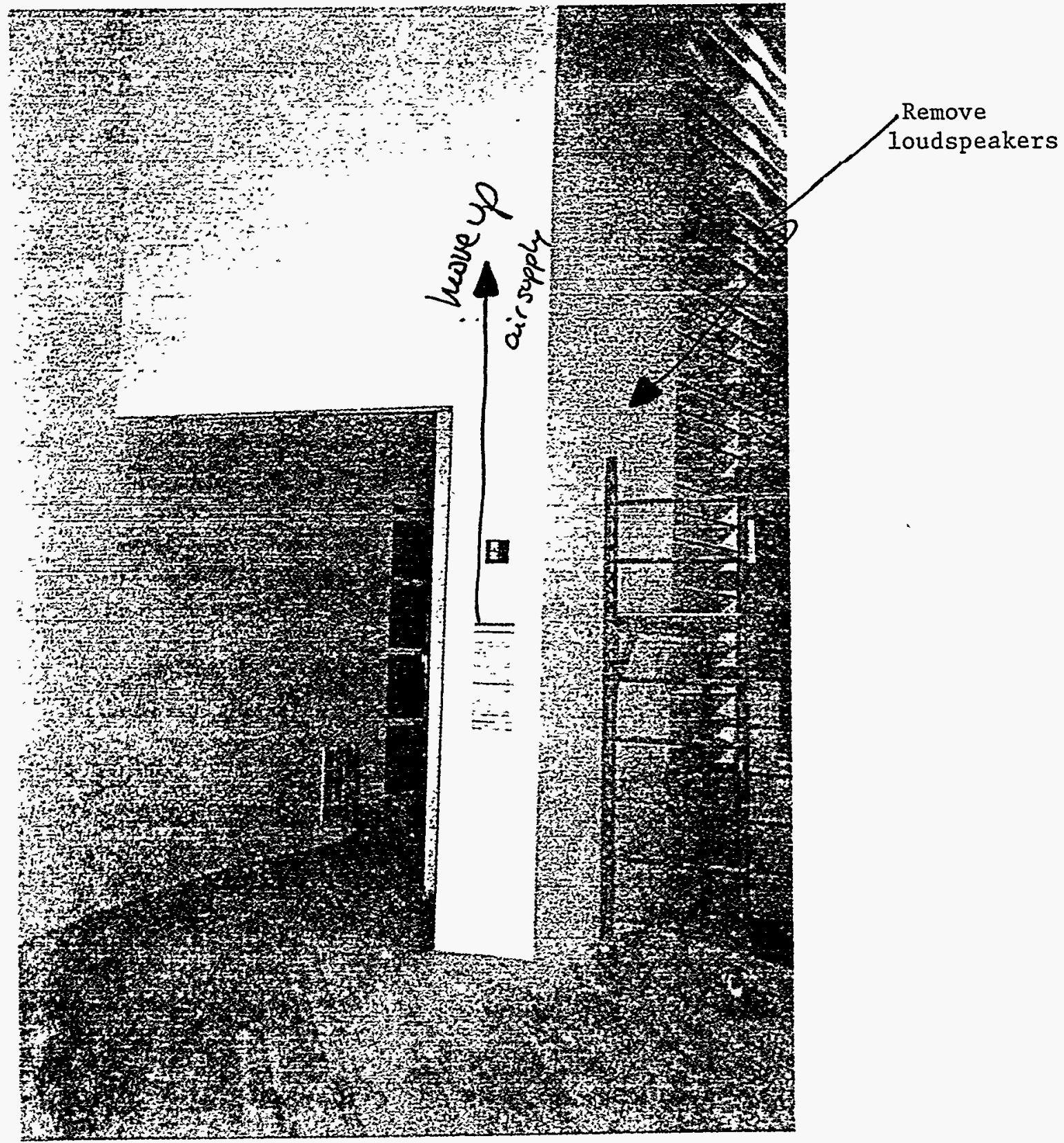

Figure 6b. Move air supply duct as high as possible. Remove lateral loudspeakers. 


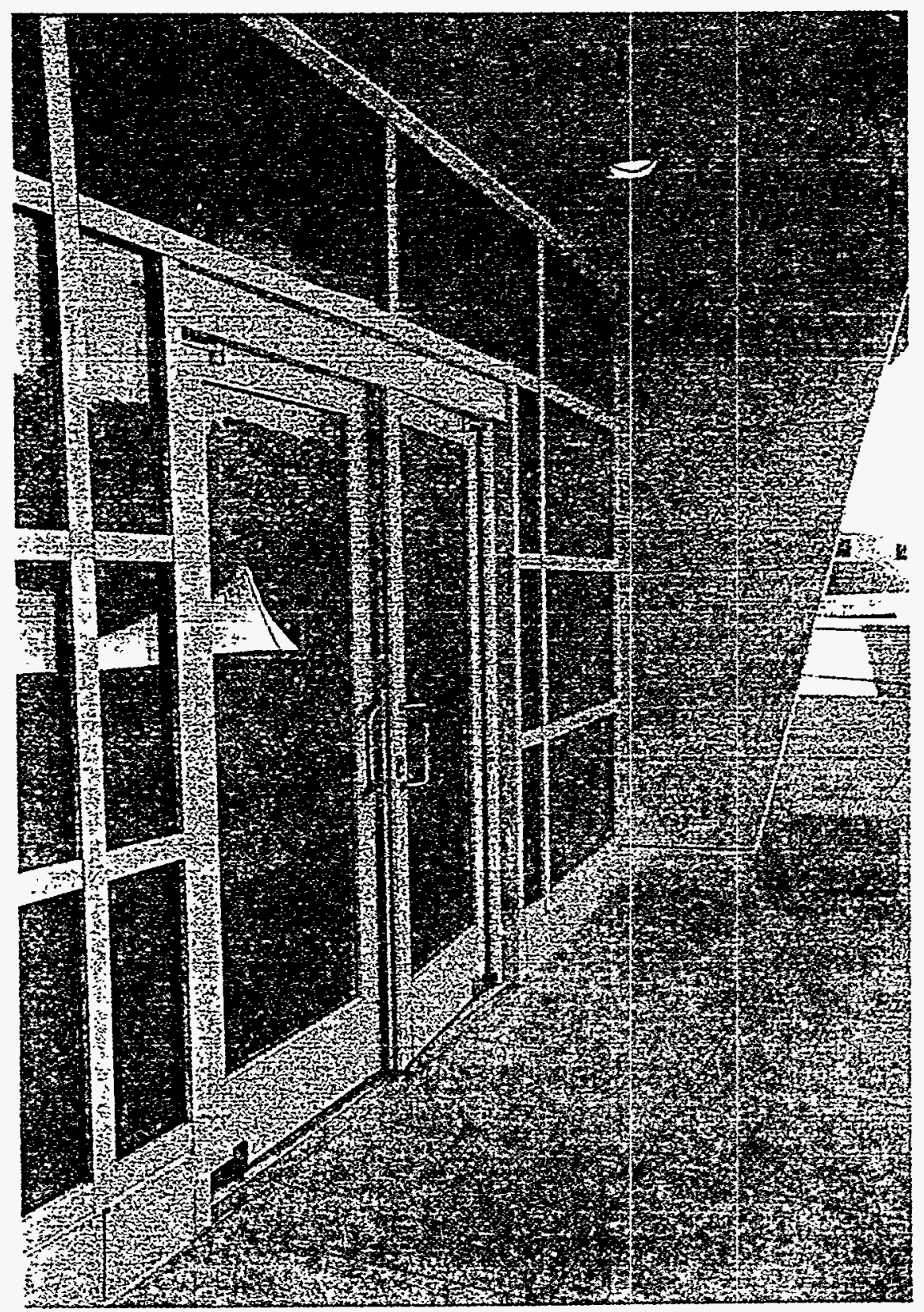

Figure 7. Exterior door 


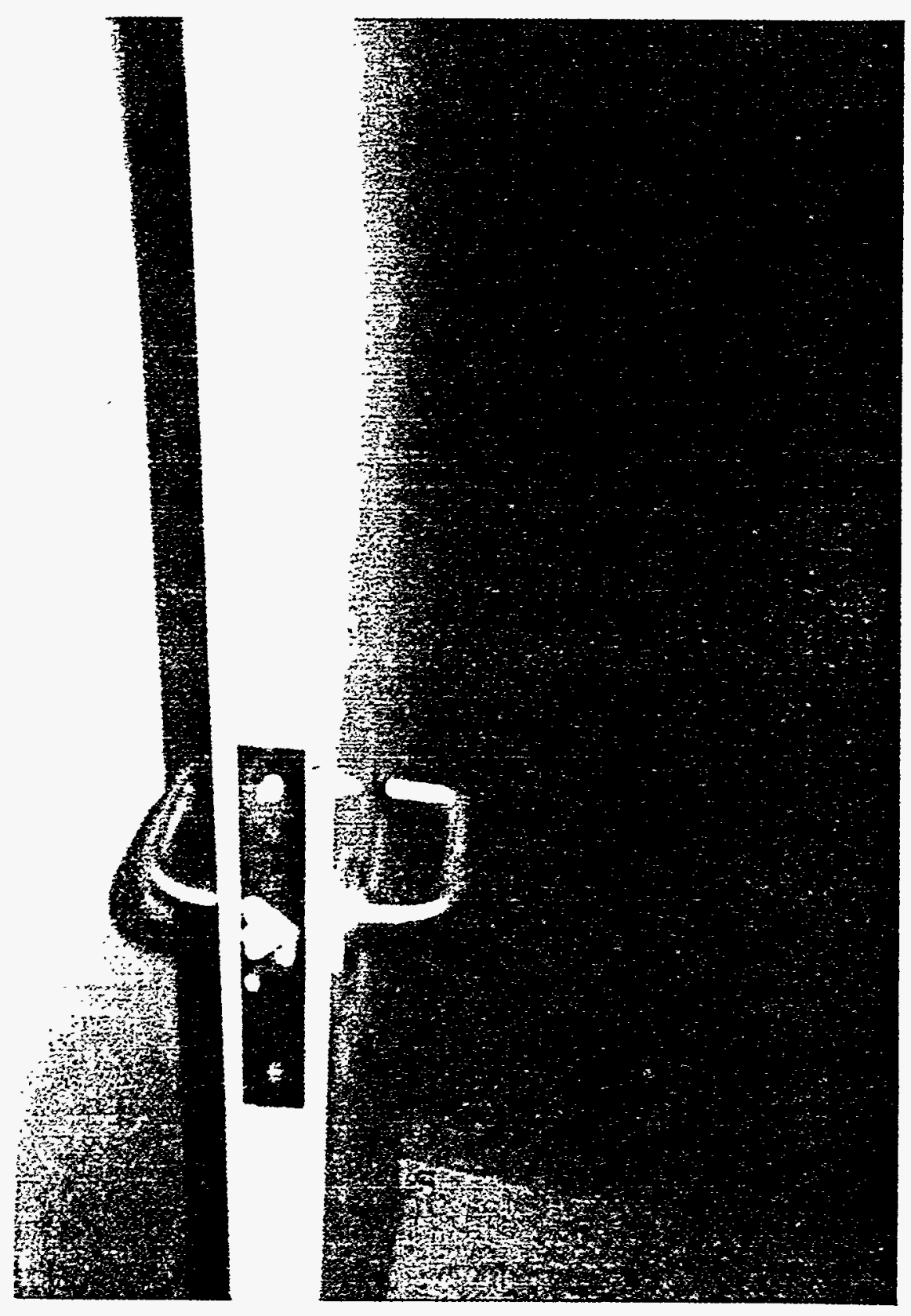

Figure 8. Door handle detail 


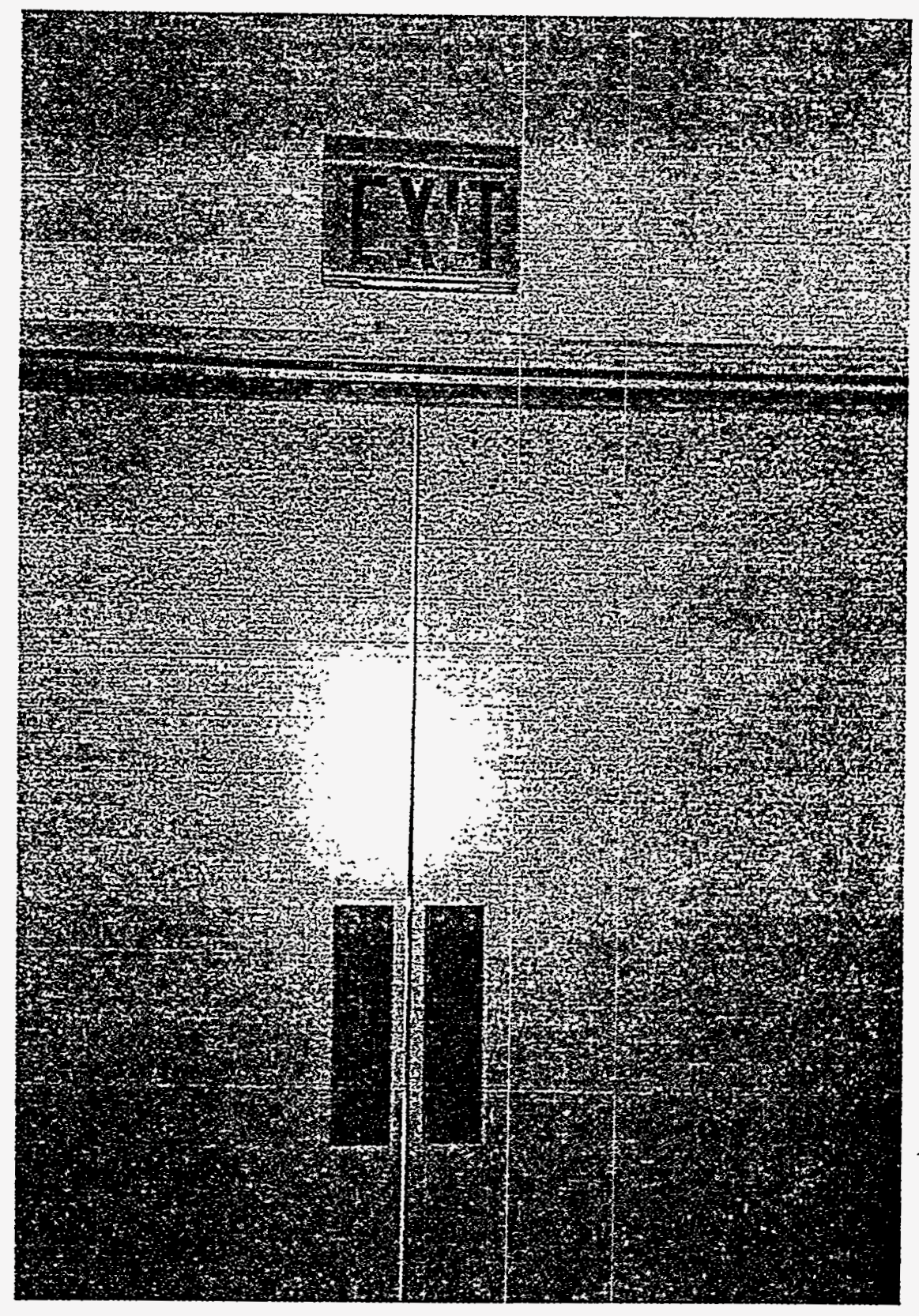

Figure 9a. Notice large gap in between doors 


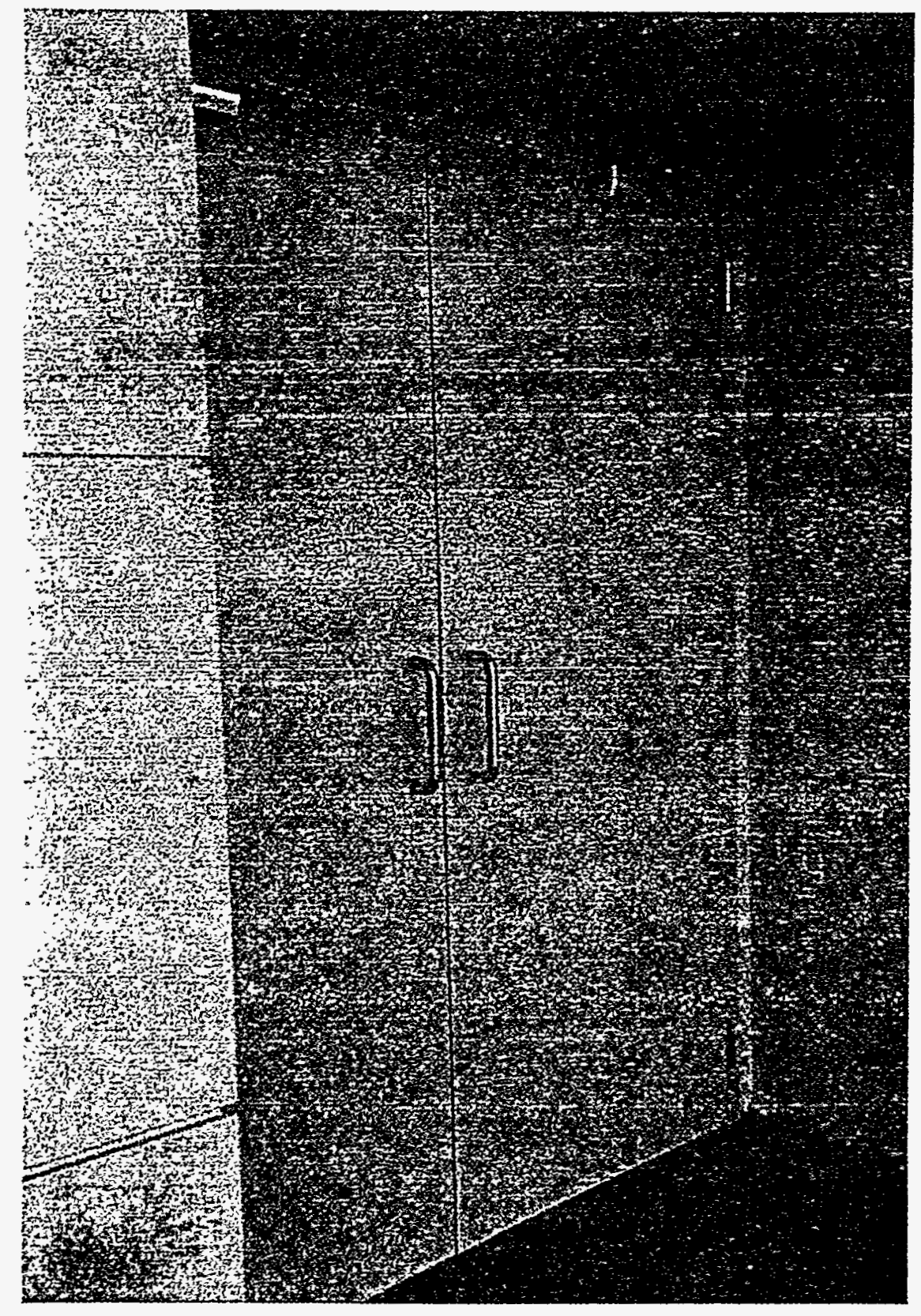

Figure 9b. Doors need gaskets 


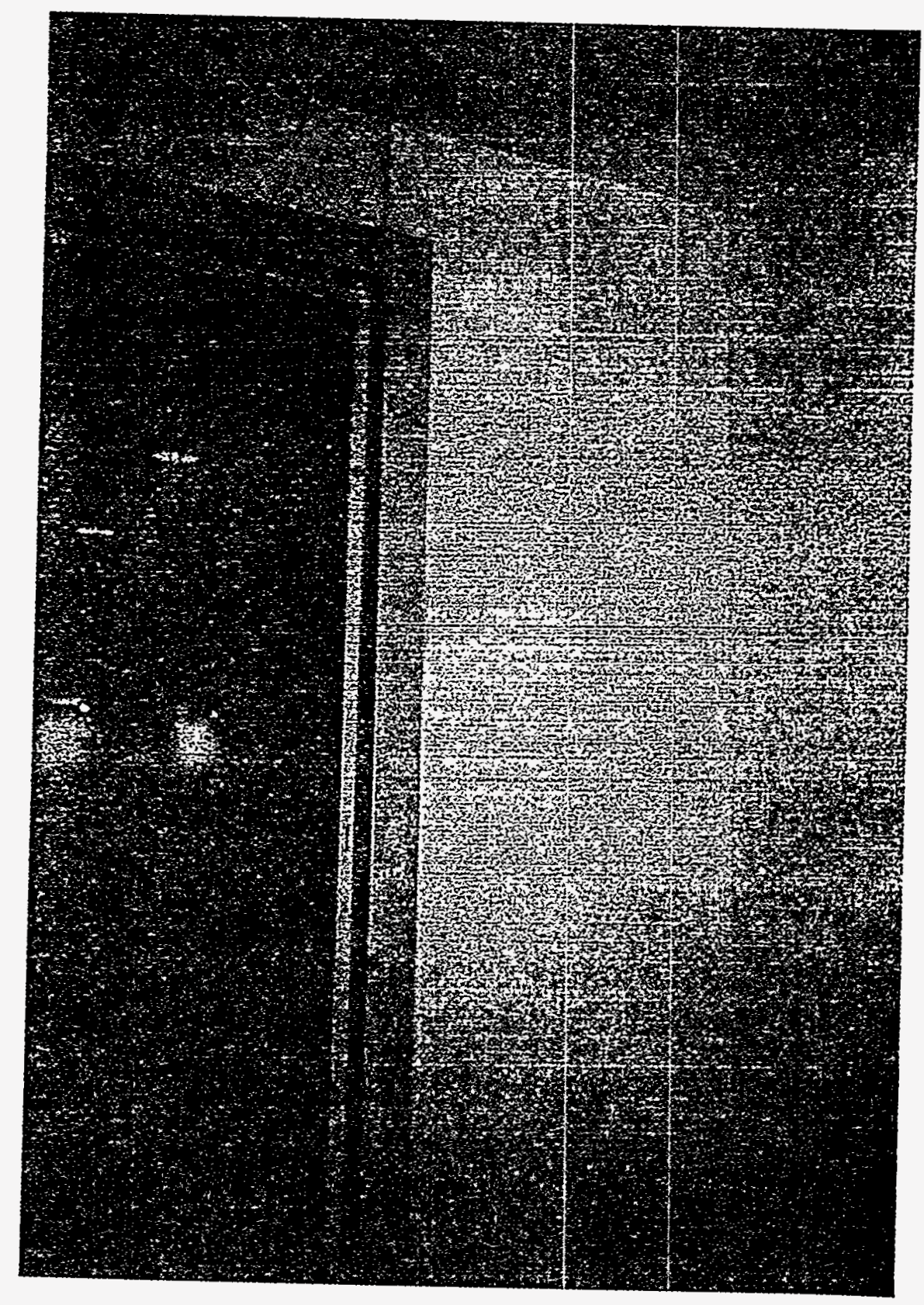

Figure 10. 


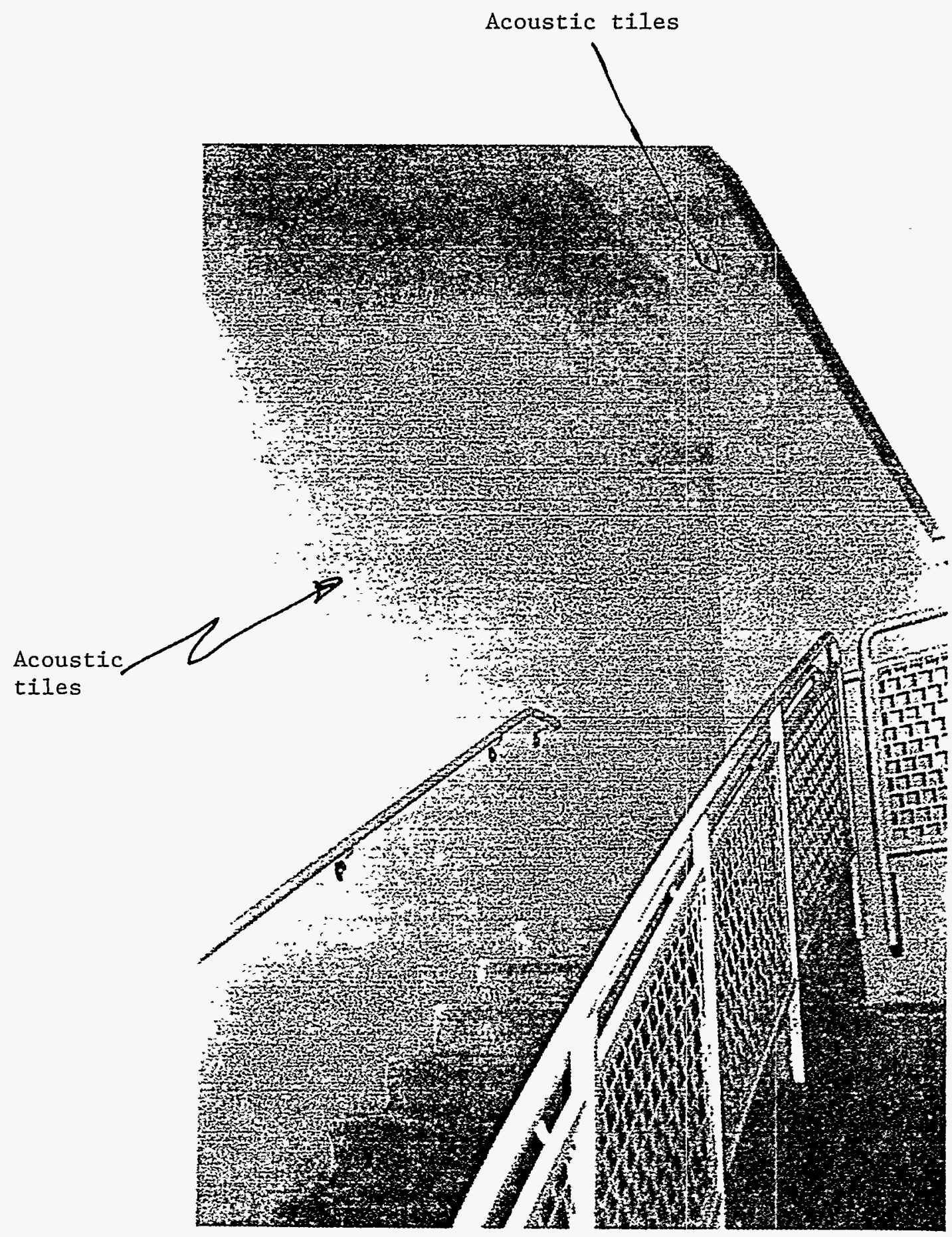

Figure 13. Access to the balcony 


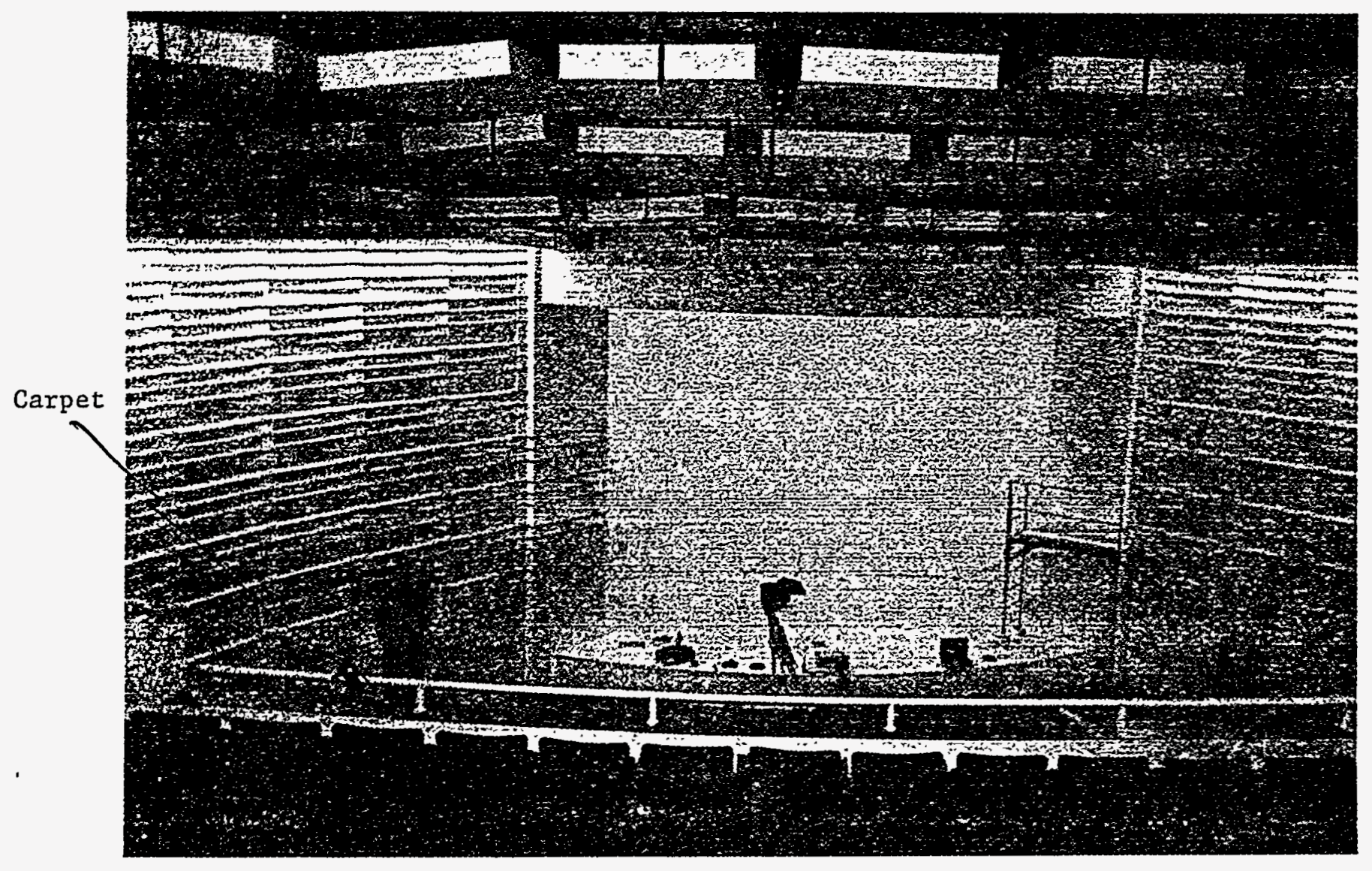

Figure 14. Front balcony wa11. Carpet faces opposite stage. 


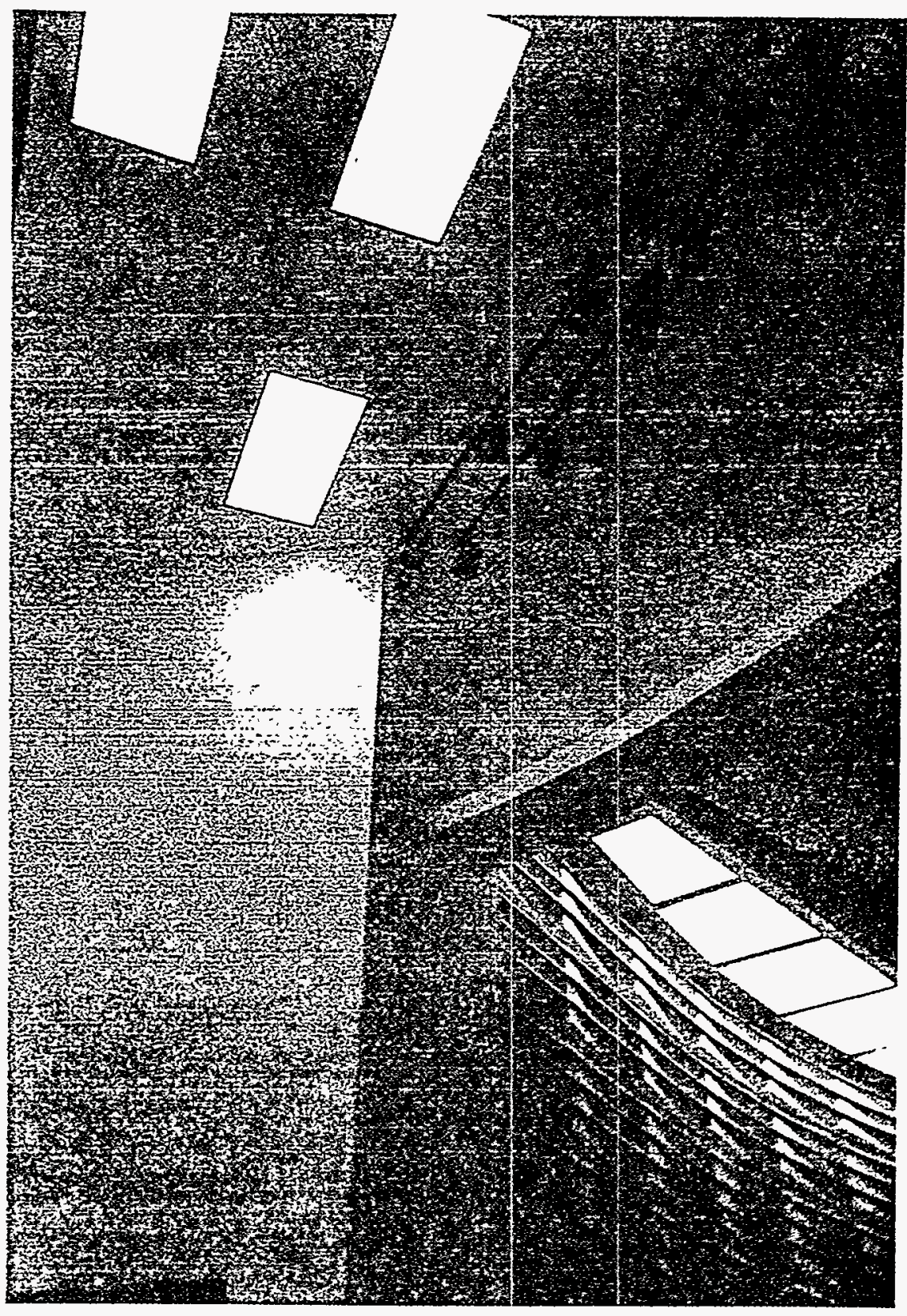

Figure 15. Poor lighting toward front of stage 


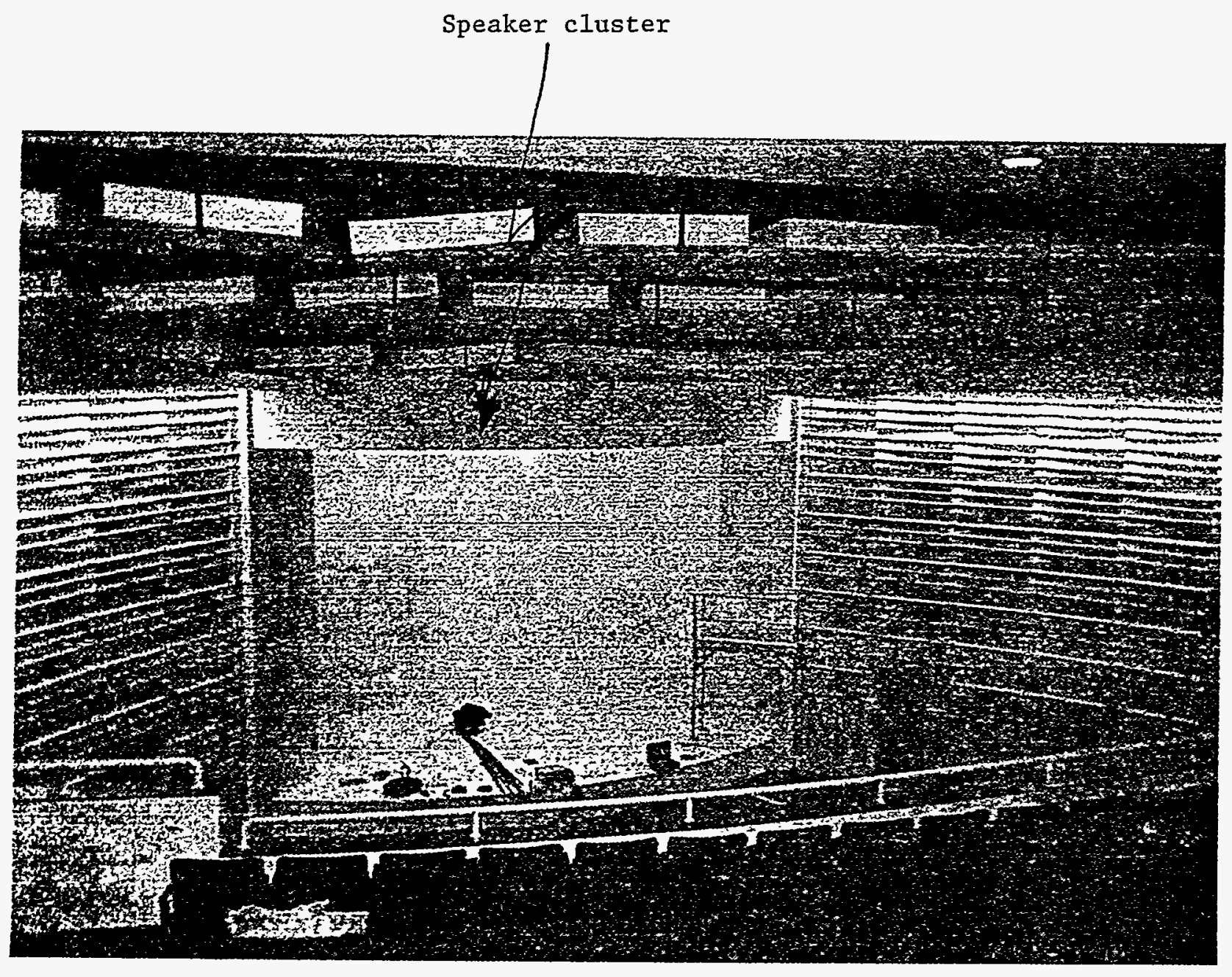

Figure 16. Center speaker cluster 


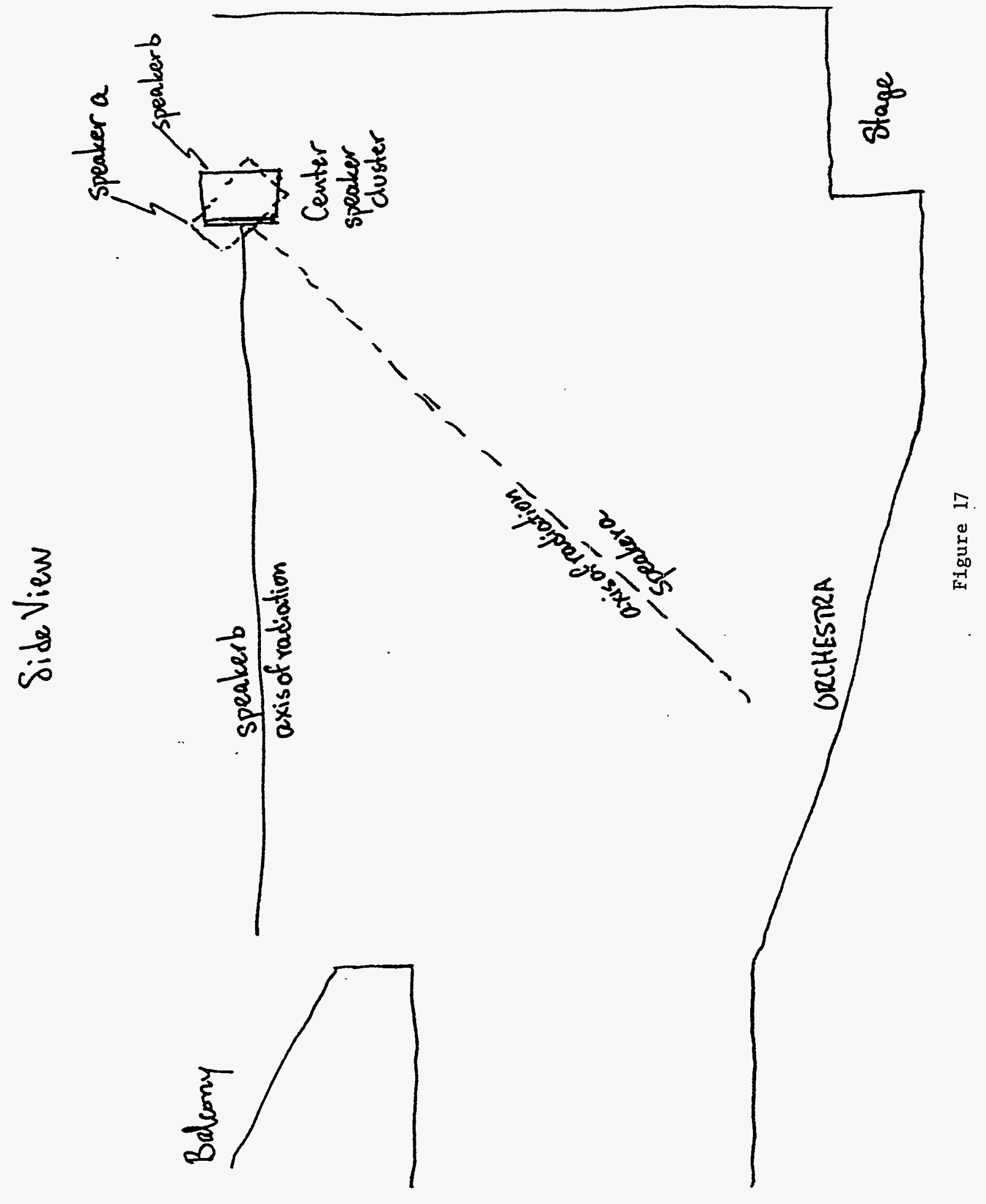




\section{The Acoustics of Advanced Photon Source Auditorium A Report}

\section{Scope}

EASI was engaged to perform three types of measurements on the Auditorium; noise measurements, reverb time measurements and an evaluation of the performance of the sound reinforcement system. The measurements were performed using a TEF 20 system with a Macintosh Powerbook 170 host and a Bruel \& Kjaer model 4007 microphone.

\section{The Measurements}

Noise

To perform the noise measurements, the measurement mic is placed in a number of locations in the auditorium and on stage The computer takes samples in each octave band and integrates the levels for 4 seconds. The data are then displayed on a standard Noise Criterion graph. In addition to the graph, a one number score is displayed indicating what Noise Criterion is met. In addition to the NC measurements we performed a fast response spectral analysis of the noise to see if there were any specific frequencies present that might indicate the cause or source of the noise.

\section{Reverb Time}

The measurement of reverberation is a controversial topic. We use a technique called Time Delay Spectrometry to measure the Energy Time Curve in specific frequency bands. A Schroeder integration is performed on the ETC and from that the slope of the decay is measured and extrapolated out to $60 \mathrm{~dB}$. This is a somewhat cumbersome approach to Rt measurement, and it requires subject to some subjective interpretation of the data to remove the energy of the direct sound. We believe, however, that this approach gives us the best correlation with the subjective impression of the room. The other problem with measuring $R t$ is that very few small auditoria actually have statistical reverberant fields. This means that if one were to take 50 measurements in the space, one would receive 50 different numbers. Since it was not the purpose of this test to be exhaustive, we made RT measurements in 2 locations that were felt to be representative of ine whole space.

\section{Evaluation of the PA System.}

When these measurements were performed the central cluster was apparently not operative. It should be noted that the preferred way to cover an auditorium is from a centra! cluster and not from speakers on the sides of the proscenium.

We made 3 different kinds of measurements in 5 seats in the auditorium. Two seats were in the balcony and three on the main floor. The first set of measurements were Energy Time Curves (ETC) made using the Time Delay Spectrometry algorithms running on the TEF 20. These measurements show the first 20 to 30 milliseconds of the energy that arrives at each of the seats. Ideally, ${ }^{1}$ each seat should receive the direct sound from the loud-speaker followed by a gap, the early reflections and then the reverberant field.

The next set of measurements were frequency response measurements. This is a way to look at the coverage of the system. Again these were made using the Time Delay Spectrometry algorithms running on the TEF 20. The measurement are of the direct sound arriving at the listeners ears. The frequency response curves do not include contribution from the room.

${ }^{1}$ This is the ideal in a speech reinforcement system. In a performance environment it is desirable to have the direct sound closely followed by a richly diffuser early sound field followed by a reverberant field. 
The final set of measurements that were made to evaluate the performance of the sound system are the intelligibility measurements. These measurements were made using the RASTI (RApid Speech Transmission Index) method of predicting speech intelligibility. This is a technique that measures the modulation transfer function of the system once again using Time Delay Spectrometry to collect the data. It should be noted that the RASTI measurements that we made are not "calibrated" measurements. As such they cannot be used for absolute comparison to other systems. They are valid for comparing the relative intelligibility in different parts of the room.

\section{Analysis}

Noise

The noise measurements consistently show that the room meets a Noise Criterion of 40-45. This is, in our opinion, excessive. In auditoria that are used for either lecture or performance, NC s of 25-30 are expected. The spectrum of the noise indicates that the source of the noise is the face diffusers. The noise is due to turbulence induced in the flow by the slot diffusers as the air enters the room. The solution is to either reduce the velocity of the air ${ }^{2}$ or use a different form of diffuser that maintains a laminar air flow. The subjective effects of noise levels this high include speech that is difficult to understand, lecturers finding it difficult to talk over the noise floor, and the noise masking the more delicate passages of a performance.

RT60

The reverb measurements are quite interesting in what they reveal. First there was no evidence of a well integrated homogenous reverberant field. At most this room would be classified as semi-reverberant. The interesting feature of the reverb curve shown below is that the reverb time climbs as the frequency increases.

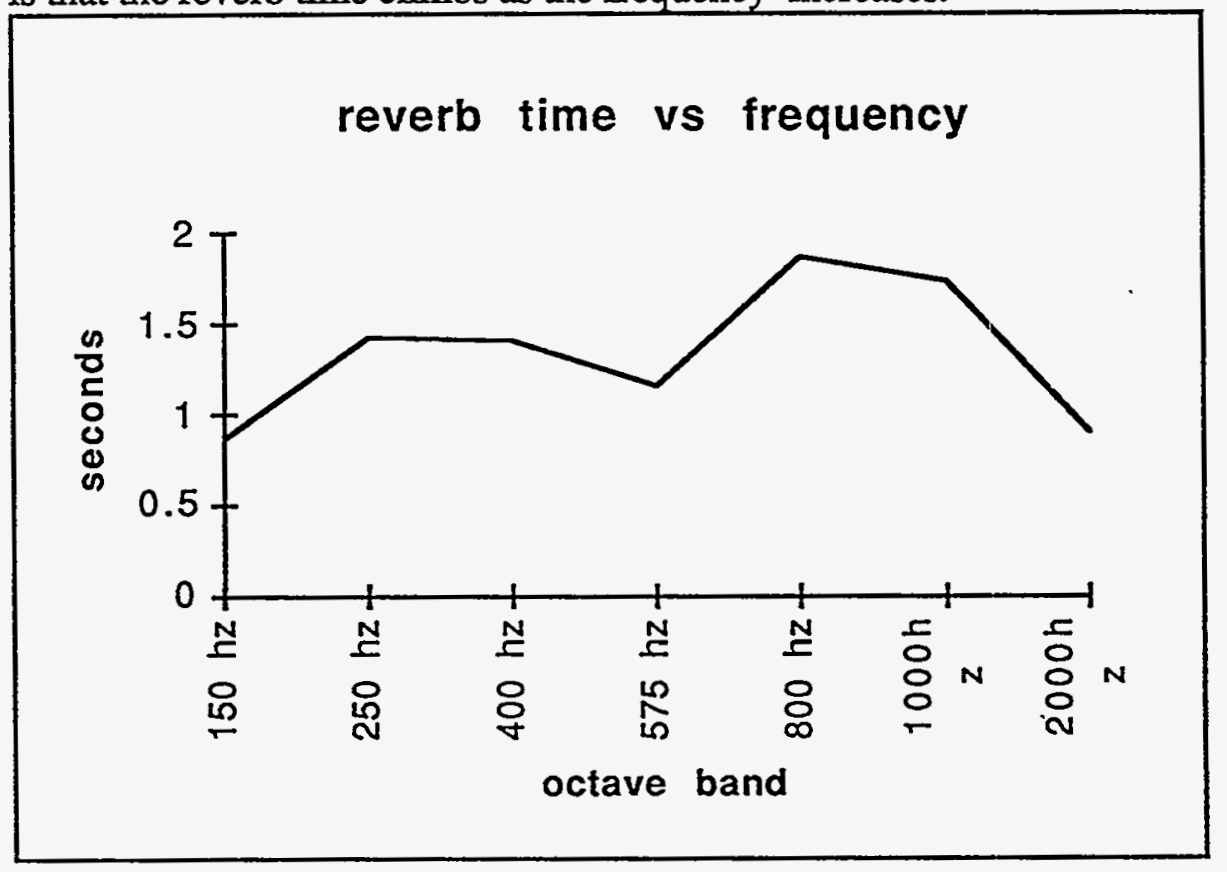

${ }^{2}$ Typically systems that need to meet stringent NC limits use velocities of less than 500 CFM. 
This is most likely due to the construction of the walls which is quite diaphragmatic and thus absorbent in the low end. It is also likely to be the result of the diffusers that are use on the walls. These diffusers are doing a good job from $800 \mathrm{hz}$ on up and they contribute to a pleasing midrange and high end. The subjective effects of this kind of reverb curve include a feeling that there is not enough support to the low registers of music performed there. The room will feel rather "live" but never "boomy".

\section{PA Evaluation}

The final set of measurements were made to try to evaluate the performance of the PA system. As was noted earlier, the central cluster was not operative so the results are not surprising. The ETCs, Freq. response and RASTI measurements all agree that intelligibility and coverage from the speakers in the side walls is marginal.

\section{RECOMMENDATIONS}

It is our recommendation that the noise be addressed. Even if it can only be reduced to an NC 35, this would be a great improvement. We would not recommend any attempt at changing the acoustics other then trying to reduce the effect of having a curved wall behind the podium. We did not measure this feature, but the subjective effects of standing in the focus of this curve are severe. We recommend some sort of absorber placed on the front wall. Finally we can only assume that the central cluster will perform better than the speakers mounted in the side walls. We do recommend however, that the side speakers be aimed out towards the audience more and that some method to access the speakers in case of failure be devised. 
Test Title: Noise tests

User Name: Doug Jones

Date: Thursday, October 12, 1995 at 8:47 PM

Location: Argonne APS

Job description: Stage noise

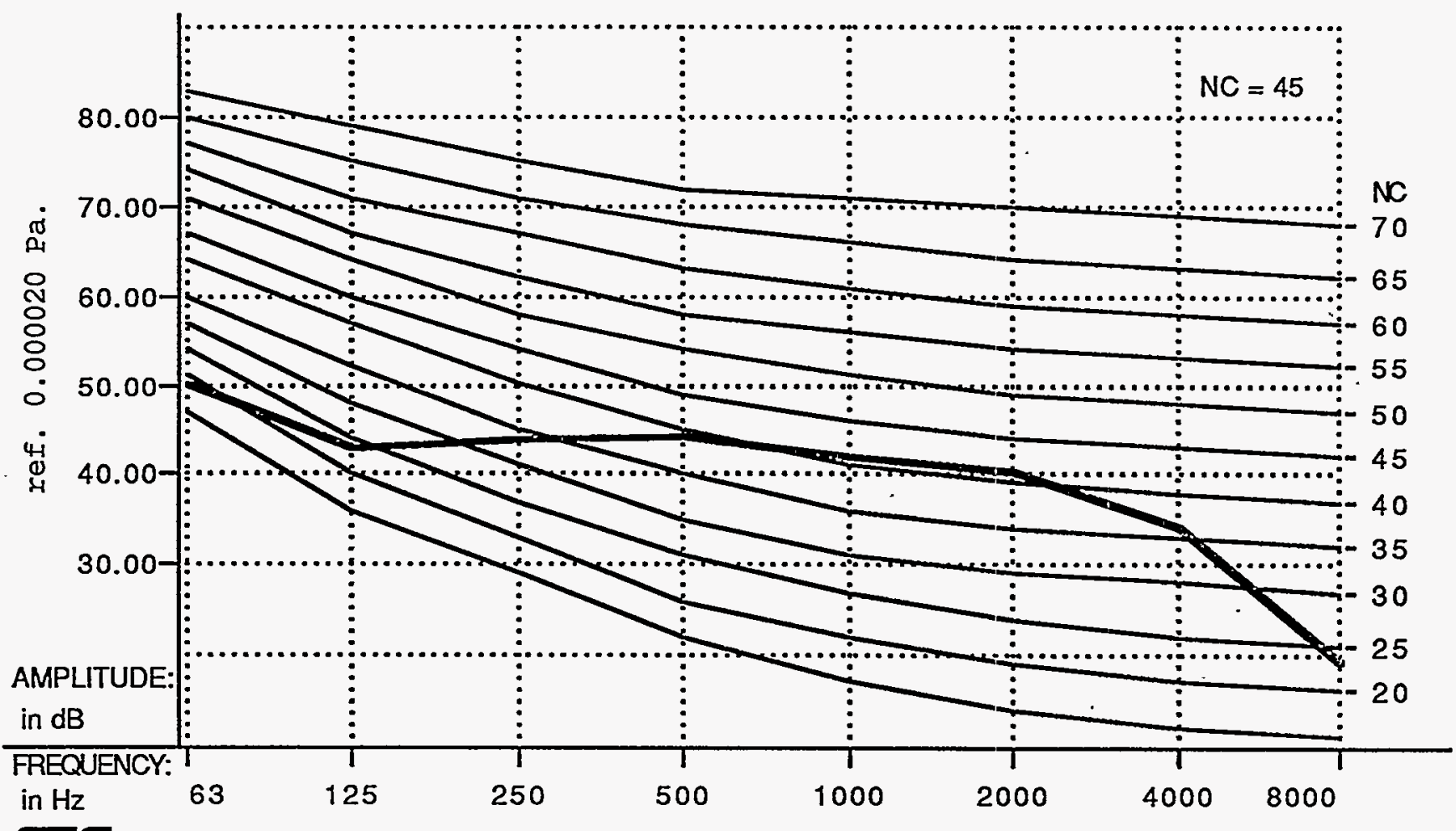

IEF

Test Parameters

Integration Time 4 Seconds
Calibration

Reference Unit Pascal

Volts Per Reference Unit 0.002500

Zero dB Reference Value $\mathbf{0 . 0 0 0 0 2 0}$

Preamp Input: A

Input

Preamp Gain Channel A: 56dB 
Test Title: Noise tests

User Name: Doug Jones

Date: Thursday, October 12, 1995 at 8:48 PM

Location: Argonne APS

Job description: Down Stage noise

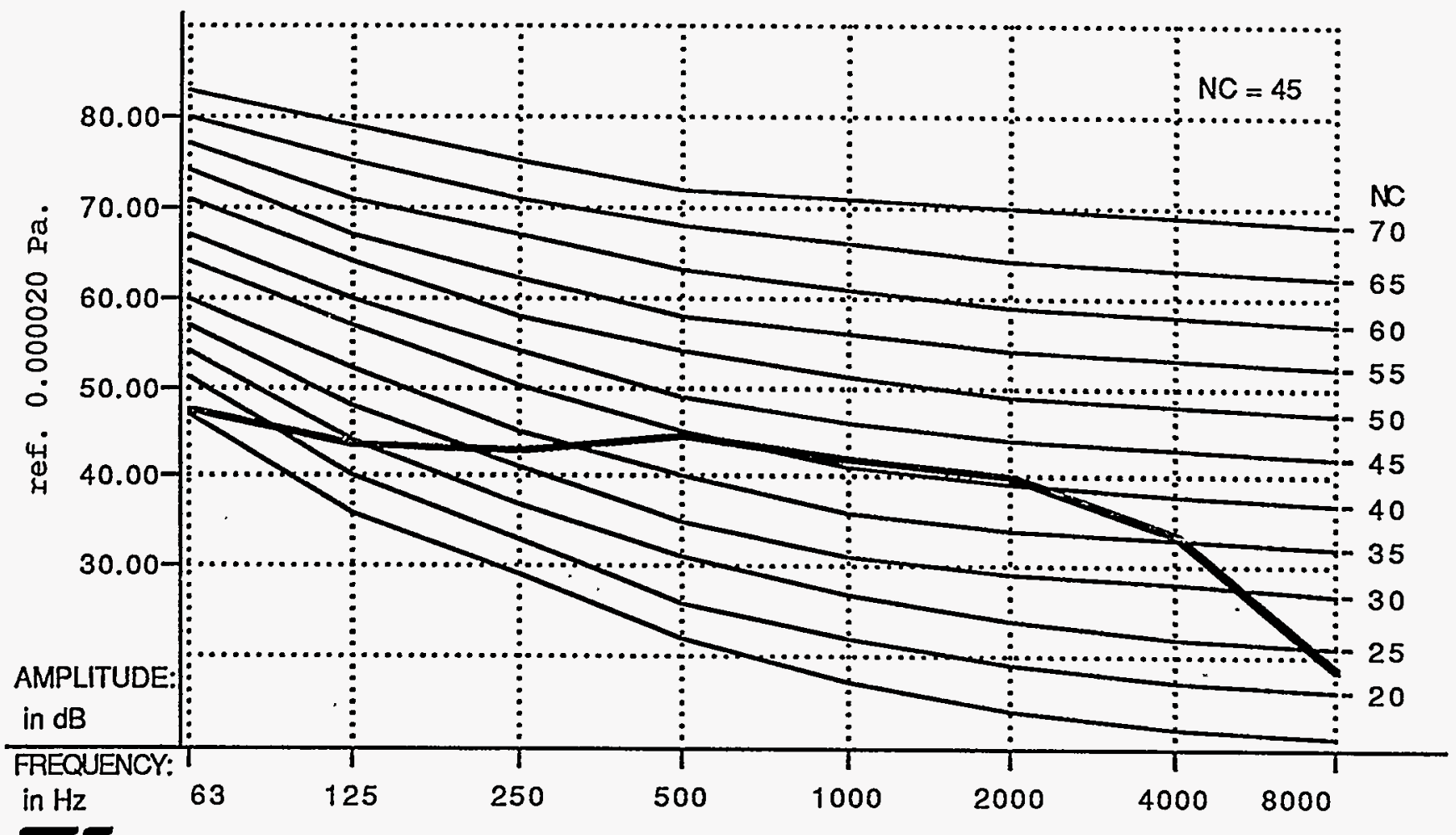

TEF

Test Parameters

Integration Time 4 Seconds
Calibration

Reference Unit Pascal

Volts Per Reference Unit $\mathbf{0 . 0 0 2 5 0 0}$

Zero dB Reference Value 0.000020

Preamp Input: A

Input

Preamp Gain Channel A: $56 \mathrm{~dB}$ 
Test Title: Noise tests

User Name: Doug Jones

Date: Thursday, October 12, 1995 at 8:57 PM

Location: Argonne

Job description: Orch. Center

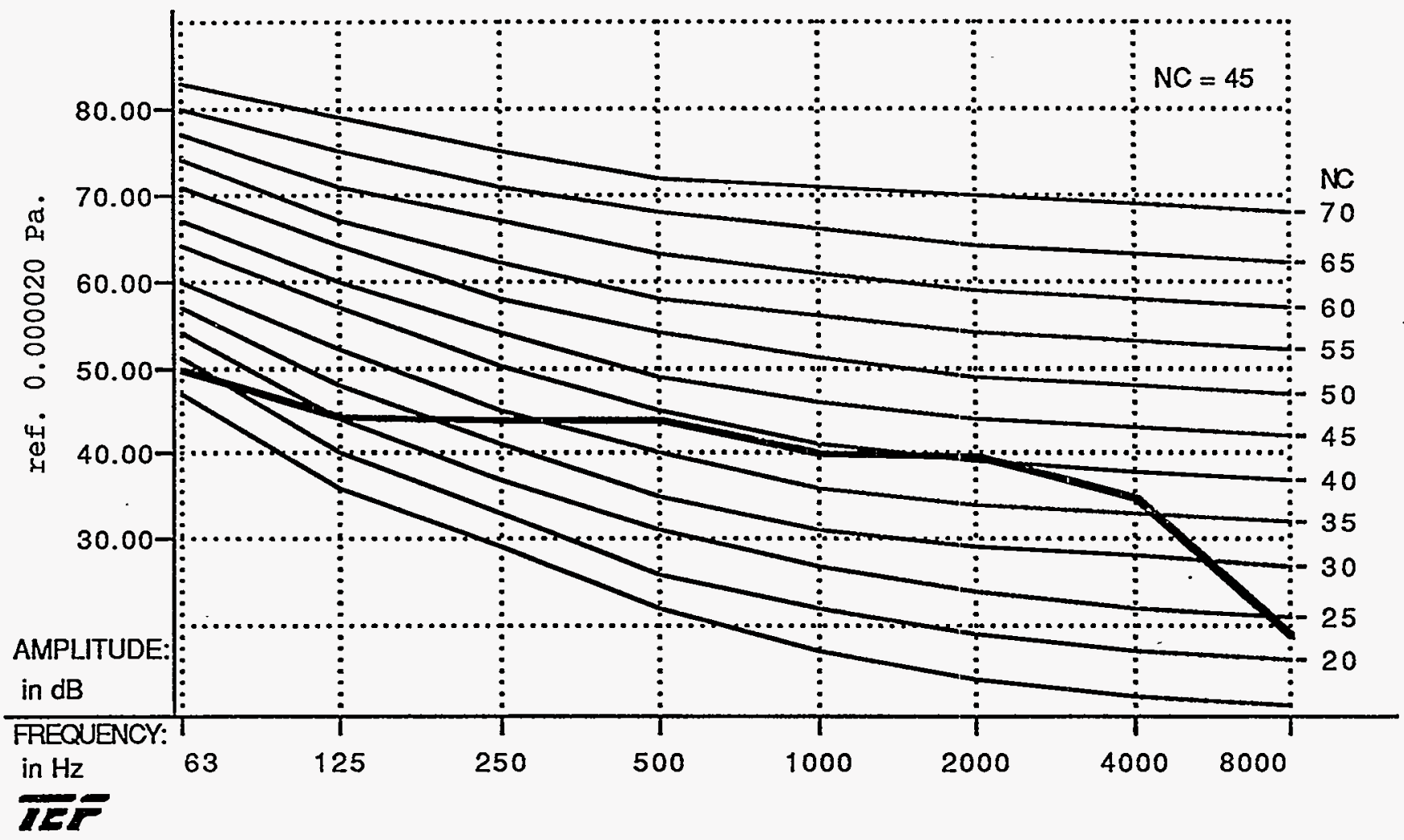

Test Parameters

Integration Time 4 Seconds

Calibration

Reference Unit Pascal

Volts Per Reference Unit 0.002500

Zero dB Reference Value 0.000020

Preamp Input: A

$$
\text { Input }
$$

Preamp Gain Channel A: 56dB 
Test Title: Noise tests

User Name: Doug Jones

Date: Thursday, October 12, 1995 at 9:06 PM

Location: Argonne

Job description: Balcony Center

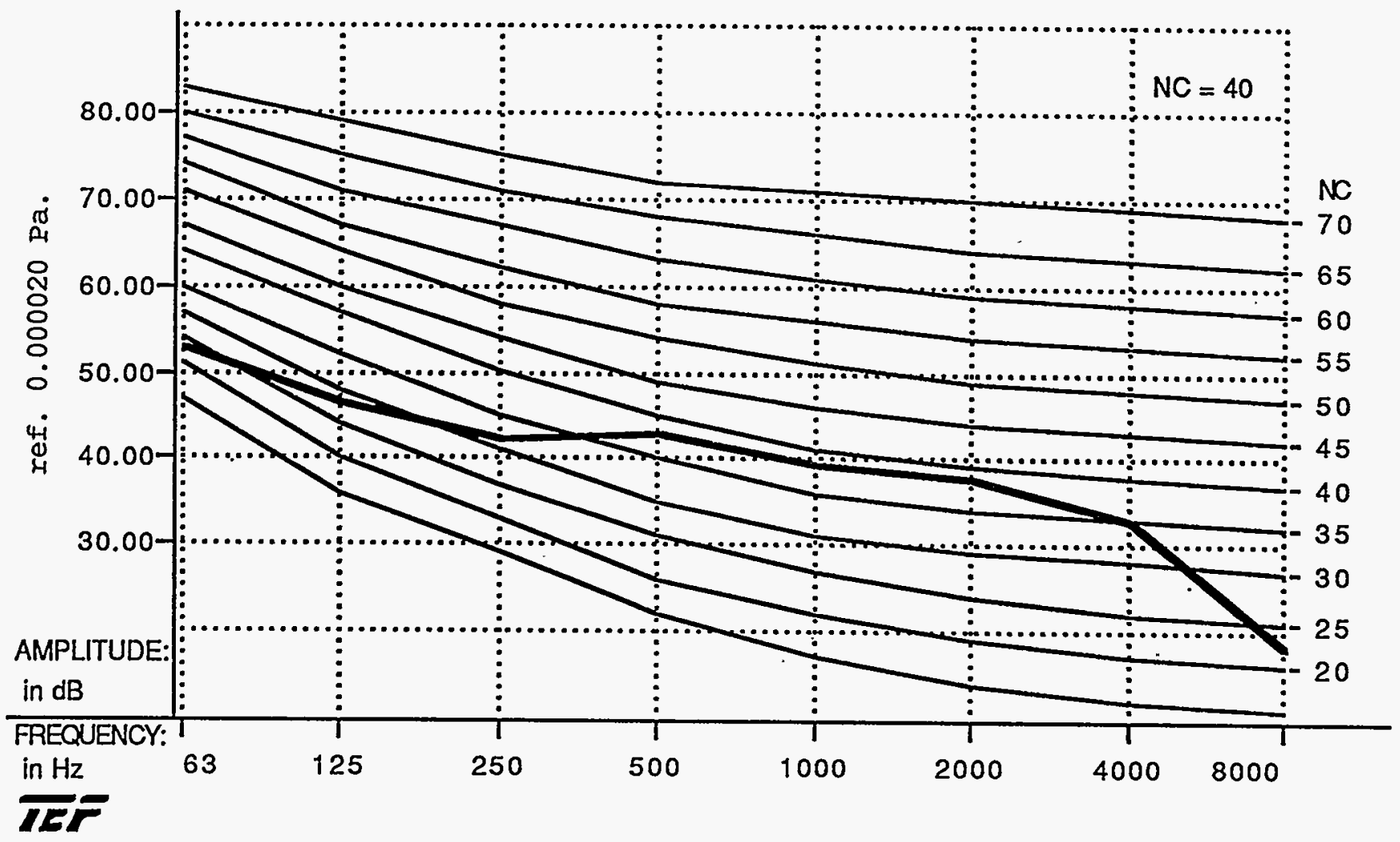

Test Parameters

Integration Time 4 Seconds

\section{Calibration}

Reference Unit Pascal

Volts Per Reference Unit 0.002500

Zero dB Reference Value 0.000020

Preamp Input: A

\section{Input}

Preamp Gain Channel A: $56 \mathrm{~dB}$ 
Test Title: Noise tests

User Name: Doug Jones

Date: Thursday, October 12, 1995 at 10:14 PM

Location: Argonne

Job description: Orch. Center, with air handler on per engineer

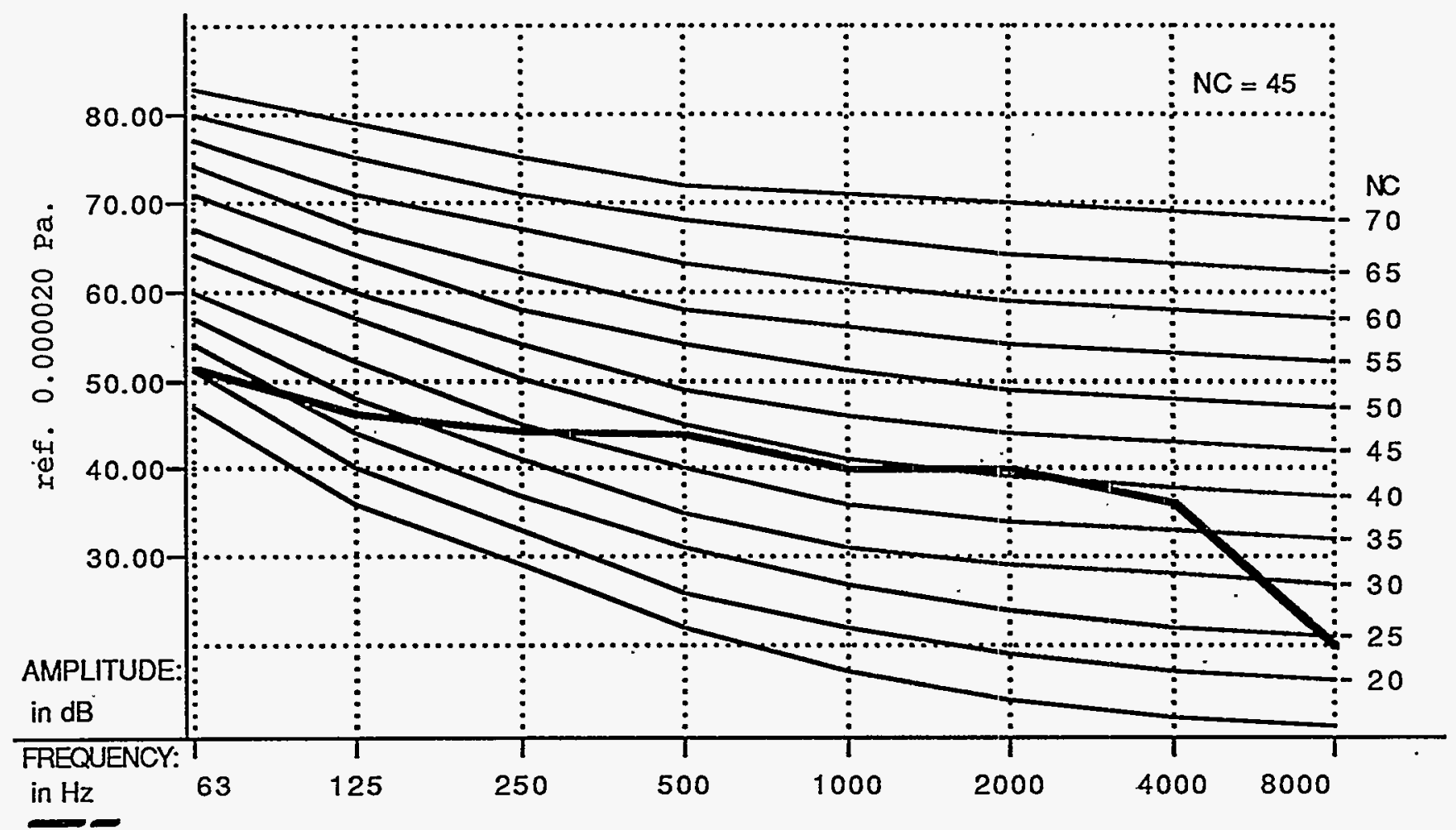

TEF

Test Parameters

Integration Time 4 Seconds

\section{Calibration}

Reference Unit Pascal

Volts Per Reference Unit 0.002500

Zero dB Reference Value 0.000020

Preamp Input: A

$$
\text { Input }
$$

Preamp Gain Channel A: $56 \mathrm{~dB}$ 
Test Title: Argonne noise User Name: Doug Jones

Date: Thursday, October 12, 1995 at 8:55 PM

Location: Front of procenium

Job description: Average spectrum

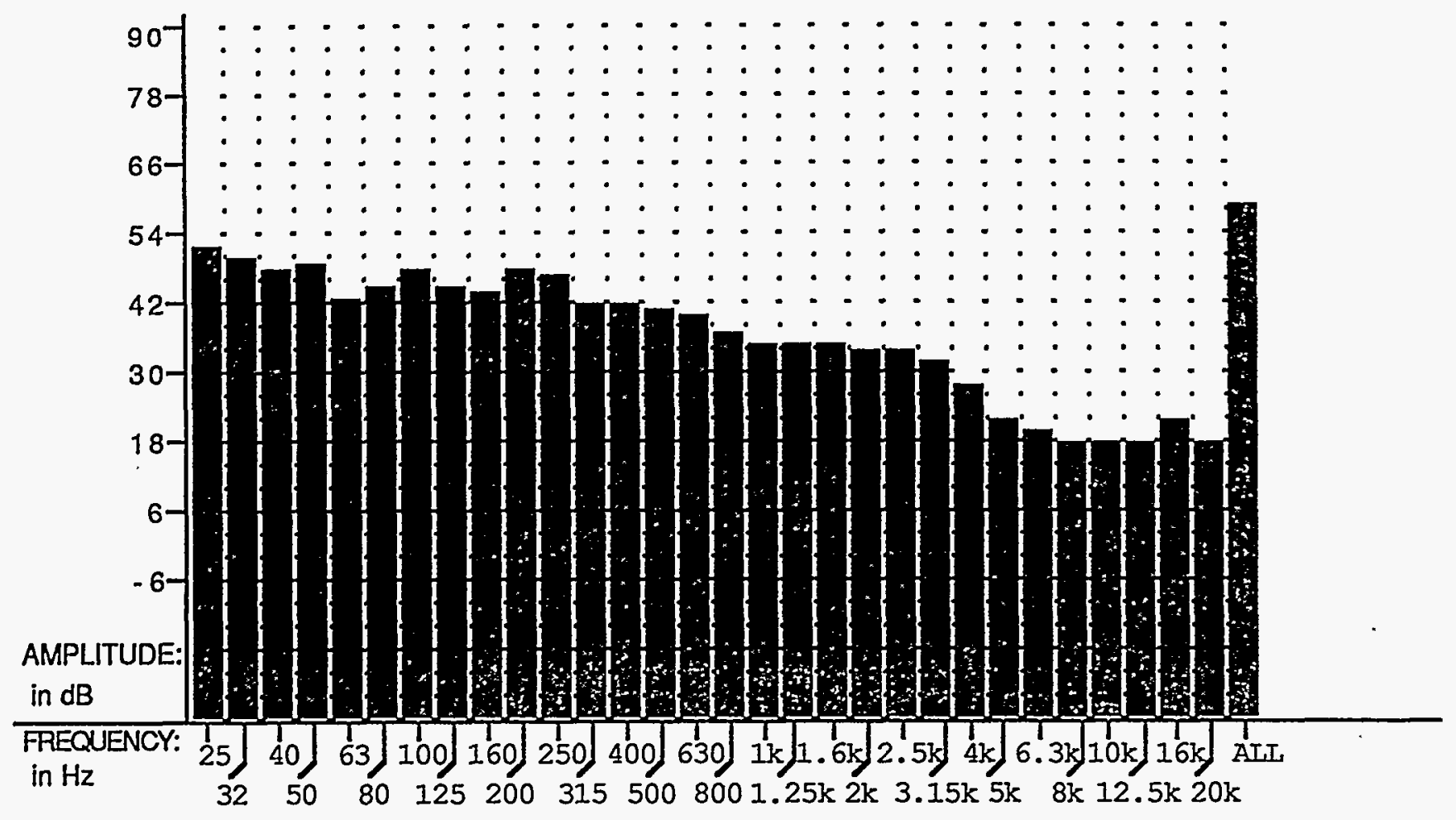

TEF

Test Parameters

Response Time = Fast

Signal Type $=$ Noise

\begin{abstract}
Calibration
Reference Unit Pascal

Volts Per Reference Unit 0.002500

Zero dB Reference Value $\mathbf{0 . 0 0 0 0 2 0}$

Input
\end{abstract}

Preamp Input: A

Preamp Gain Channel A: 56dB 
Test Title: Noise tests

User Name: Doug Jones

Date: Thursday, October 12, 1995 at 9:10 PM

Location: Argonne

Job description: Balcony noise, HVAC on

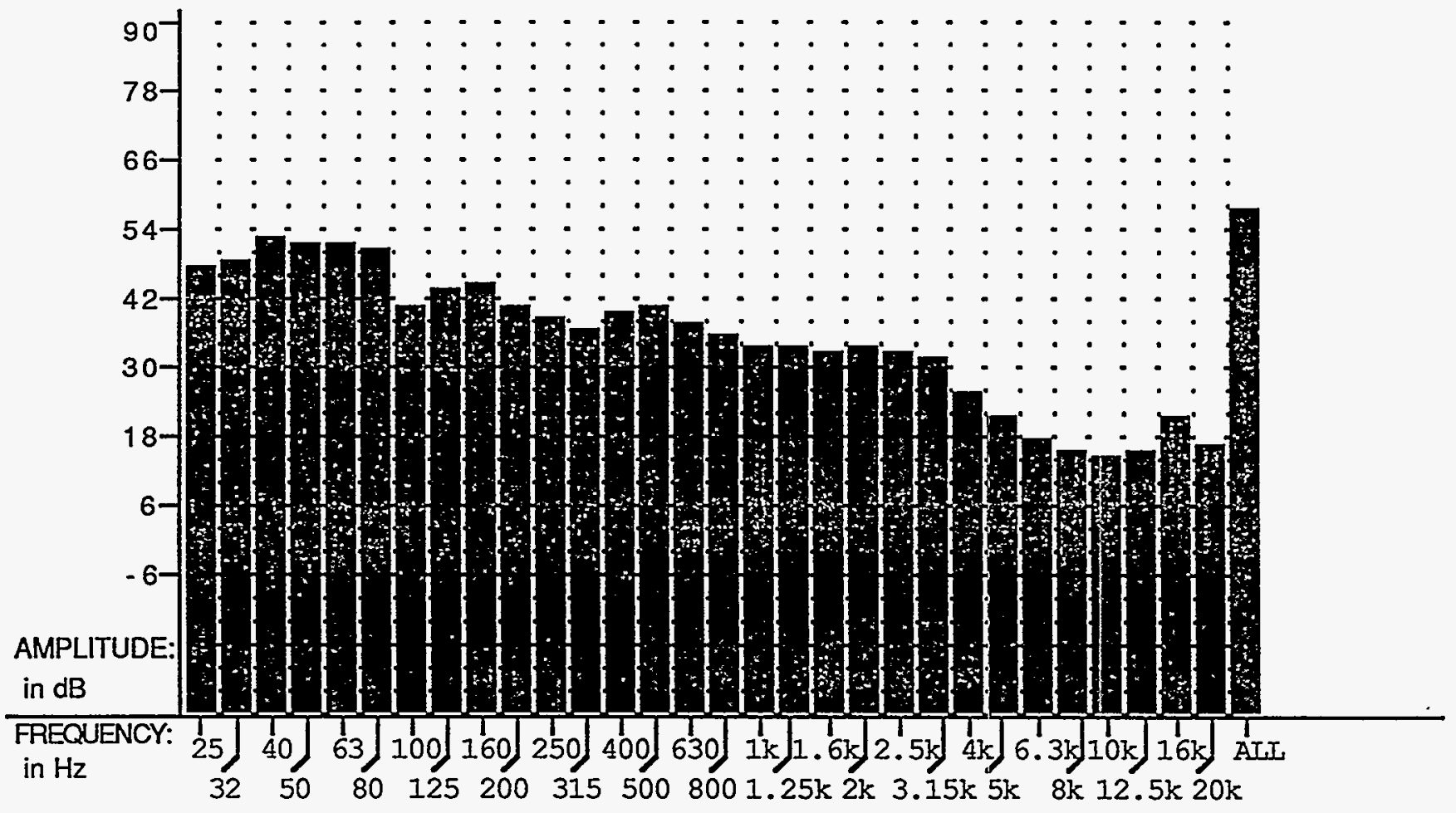

TEF

Test Parameters

Response Time $=$ Fast

Signal Type $=$ Noise

\section{Calibration}

Reference Unit Pascal

Volts Per Reference Unit 0.002500

Zero dB Reference Value 0.000020

Input

Preamp Input: A

Preamp Gain Channel A: 56dB 
Test Title: Sound System Analysis

User Name: Doug Jones

Date: Thursday, October 12, 1995 at 7:45 PM

Location: Argonne APS

Job description: Mic in 3rd row, center seat, no eq

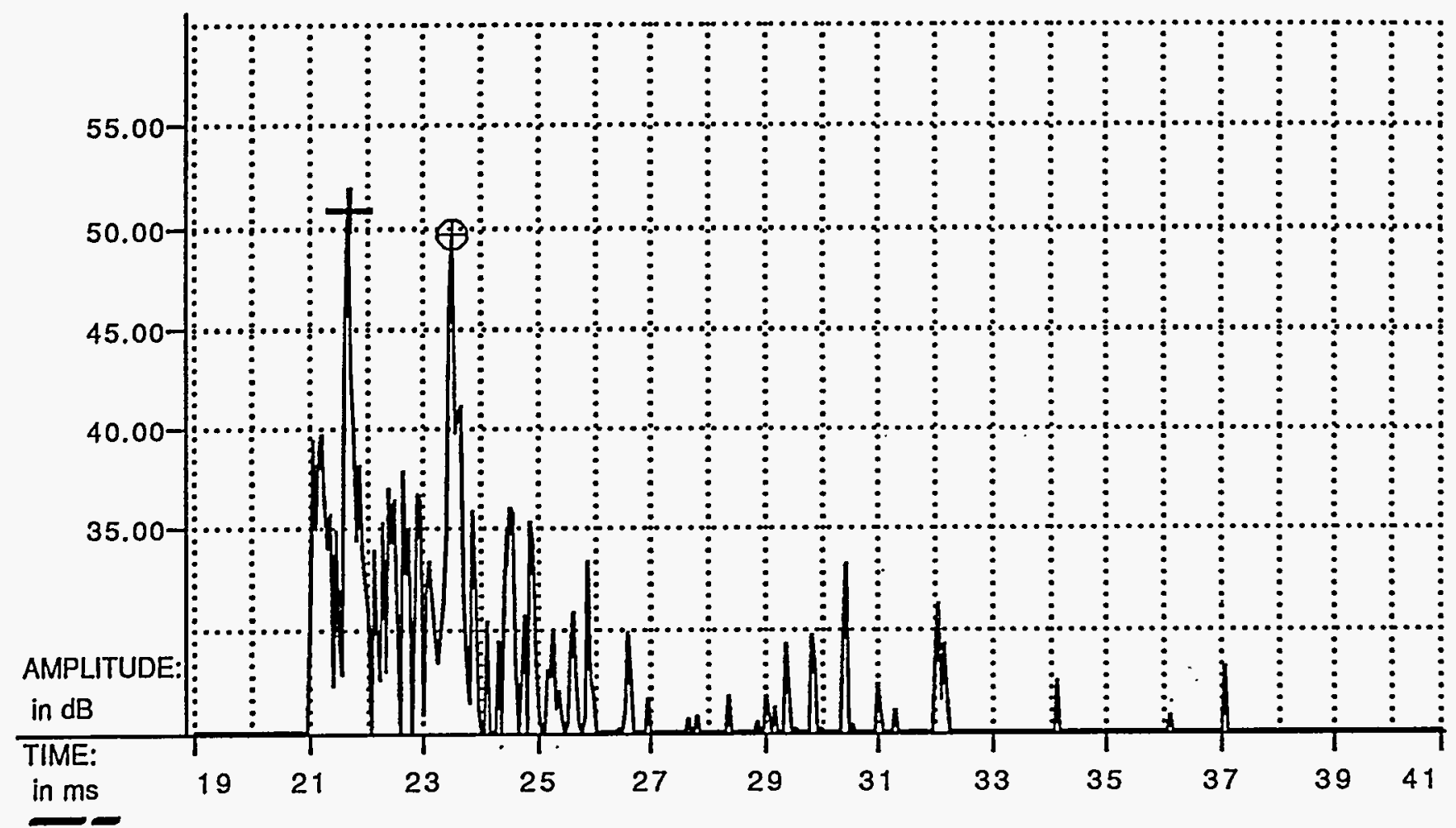

TEF

\section{Test Parameters}

\begin{tabular}{|c|c|c|}
\hline Start Frequency & (Hz) 1 & 100.0 \\
\hline Stop Frequency & $(H z) 2$ & 20000.0 \\
\hline Center Frequency & $(H z)$ & 10050.0 \\
\hline Frequency Span & $(H z)$ & 19900.0 \\
\hline Sweep Time & (Secs) 4 & 4.01 \\
\hline Receive Delay & (mSecs) & 19.0000 \\
\hline ETC Time Span & (mSecs) & 21.87 \\
\hline \multicolumn{3}{|c|}{ Number of Samples : 1024} \\
\hline & & \\
\hline
\end{tabular}

\section{Cursor}

$\begin{aligned} & 21.663 \mathrm{~ms} \\ & \begin{array}{l}24.458 \mathrm{ft} . \\ 50.87 \mathrm{~dB}\end{array}\end{aligned} \begin{array}{cc}23.472 \mathrm{~ms} & \Delta 1.809 \mathrm{~ms} \\ 26.500 \mathrm{ft} & \Delta 2.042 \mathrm{ft} . \\ 49.69 \mathrm{~dB} & \Delta-1.18 \mathrm{~dB}\end{array}$
Calibration
Reference Unit Pascal
Volts Per Reference Unit 0.002500
Zero dB Reference Value 0.000020
Propagation Speed 1129.00
$\quad$ Input
Preamp Input: A
Preamp Gain Channel A: $52 \mathrm{~dB}$


Test Title:

User Name:

Date:

Location:

Job description:

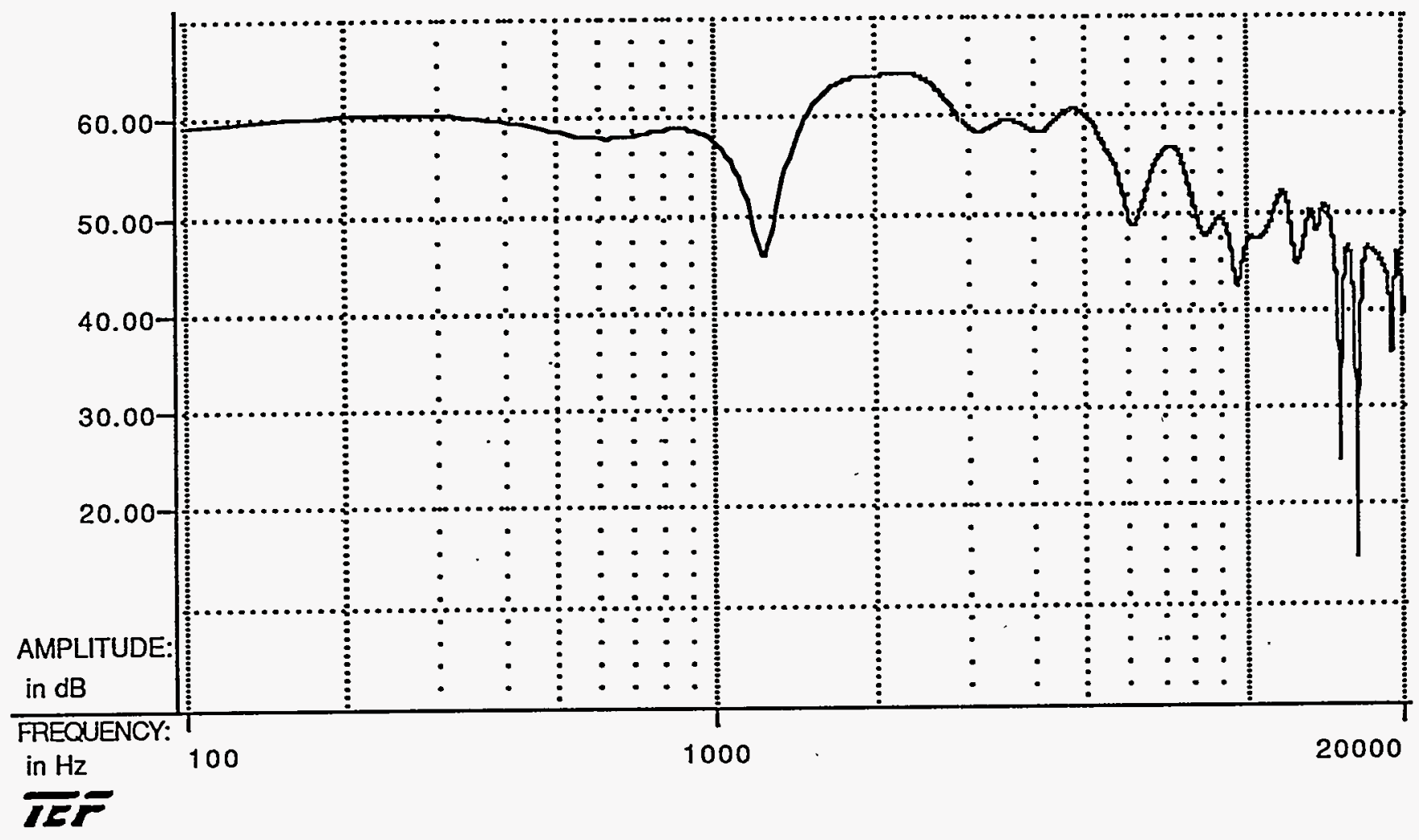

Test Parameters

$\begin{array}{ll}\text { Start Frequency } & (\mathrm{Hz}) 100.0 \\ \text { Stop Frequency } & (\mathrm{Hz}) 20000.0 \\ \text { Sweep Time } & \text { (Secs) } 4.05 \\ \text { Receive Delay } & \text { (mSecs) } 21.663317 \\ \text { RESOLUTHON: } & \\ \text { Time } & \text { (mSecs) } 1.00 \\ \text { Distance } & \text { (ft.) } 1.13 \\ \text { Frequency } & \text { (Hz) } 1000.00 \\ \text { Sweep Rate } & \text { (Hz/Sec) } 4909.54 \\ \text { Bandwidth } & \text { (Hz) } 4.910\end{array}$

Best Frequency Resolution OFF

Number of samples: 1024

\section{Calibration}

Reference Unit Pascal

Volts Per Reference Unit $\mathbf{0 . 0 0 2 5 0 0}$

Zero dB Reference Value 0.000020

Propagation Speed 1129.00

\section{Input}

Preamp Input: A

Preamp Gain Channel A: 52dB 
Test Title: Sound System Analysis

User Name: Doug Jones

Date: Thursday, October 12, 1995 at 8:01 PM

Location: Argonne APS

Job description: Mic in back row, center seat, no eq

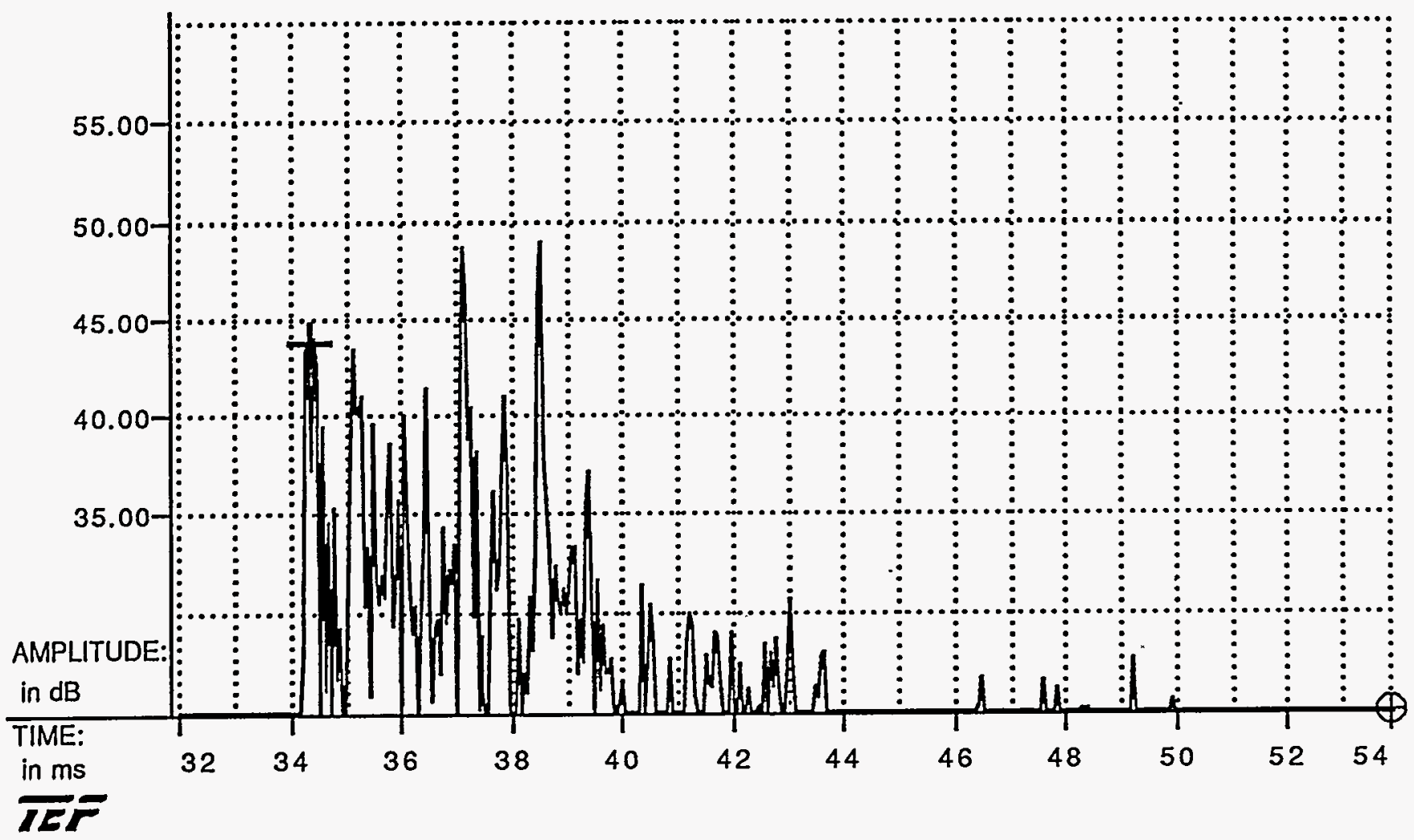

Test Parameters

\begin{tabular}{|c|c|}
\hline Start Frequency & $(\mathrm{Hz}) 100.0$ \\
\hline Stop Frequency & $(\mathrm{Hz}) \quad 20000.0$ \\
\hline Center Frequency & $(\mathrm{Hz}) \quad 10050.0$ \\
\hline Frequency Span & $(H z) \quad 19900.0$ \\
\hline Sweep Time & (Secs) 4.01 \\
\hline Receive Delay & (mSecs) 32.0000 \\
\hline ETC Time Span & (mSecs) 21.87 \\
\hline Number of Sample & les : 1024 \\
\hline Windc & NG \\
\hline
\end{tabular}

Cursor

\begin{tabular}{|c|c|}
\hline $\begin{array}{l}34.312 \mathrm{~ms} \\
38.738 \mathrm{ft} . \\
43.87 \mathrm{~dB}\end{array}$ & $\begin{array}{l}53.809 \mathrm{~ms} \\
60.750 \mathrm{ft} . \\
4.54 \mathrm{~dB}\end{array}$ \\
\hline
\end{tabular}

Calibration

Reference Unit Pascal

Volts Per Reference Unit 0.002500

Zero dB Reference Value 0.000020

Propagation Speed 1129.00

Input

Preamp Input: A

Preamp Gain Channel A: 52dB 
Test Title:

User Name:

Date:

Location:

Job description:

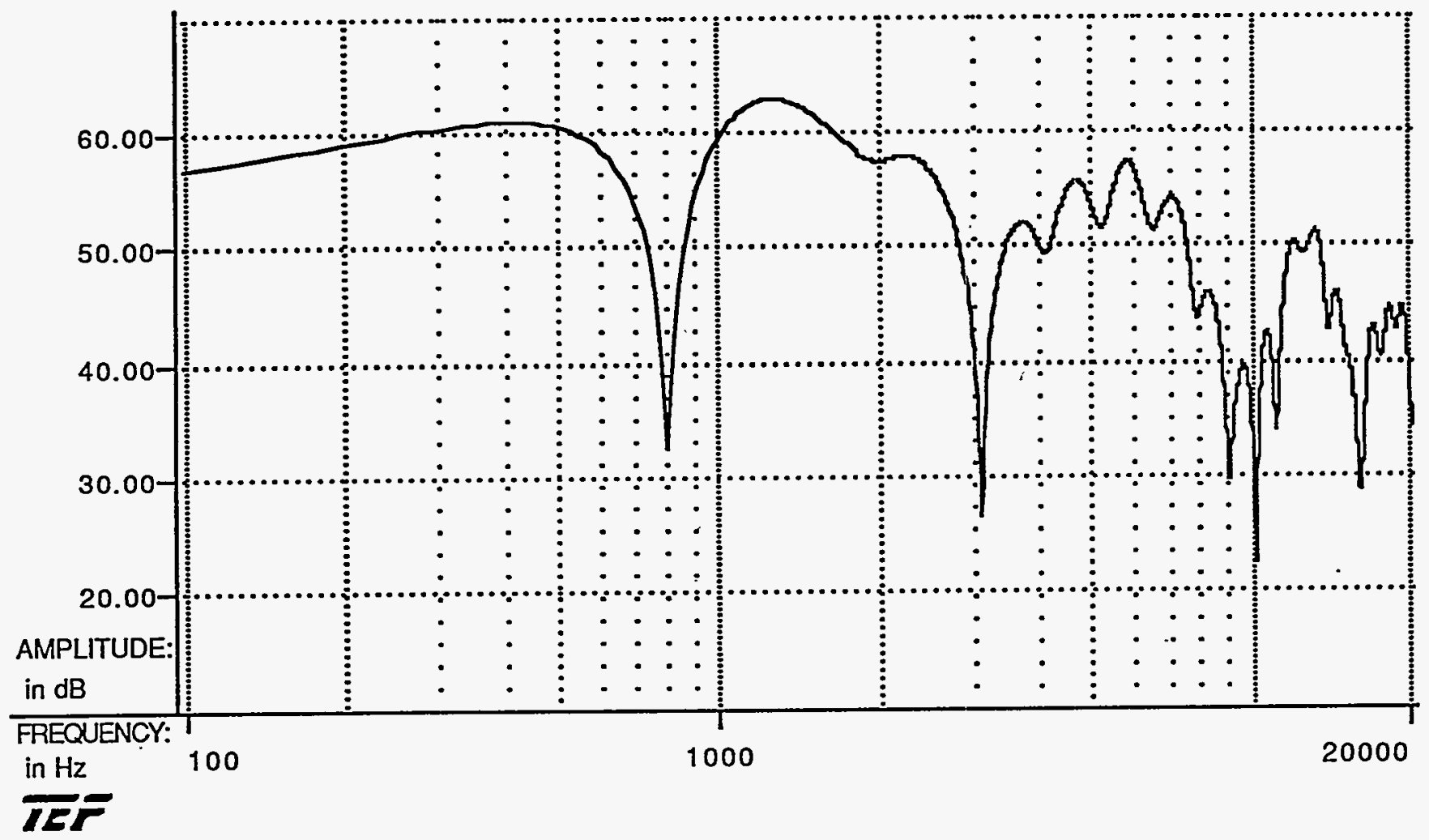

Test Parameters

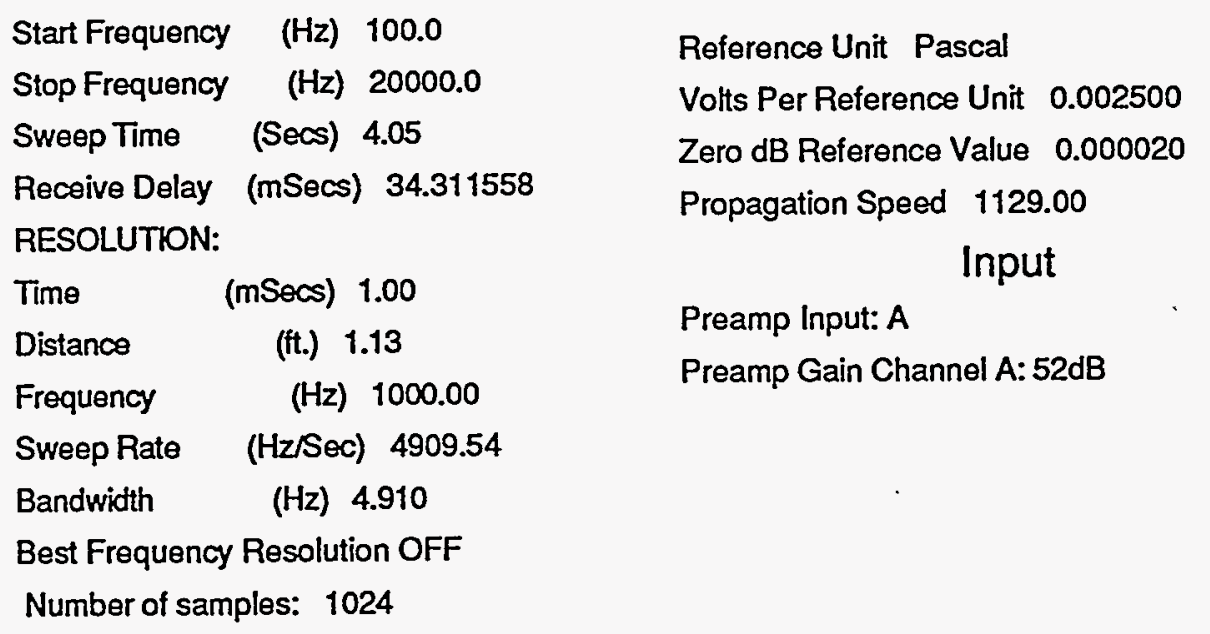


Test Title: Sound System Analysis

User Name: Doug Jones

Date: Thursday, October 12, 1995 at 8:06 PM

Location: Argonne

Job description: Stage right row 5 isle seat, no eq

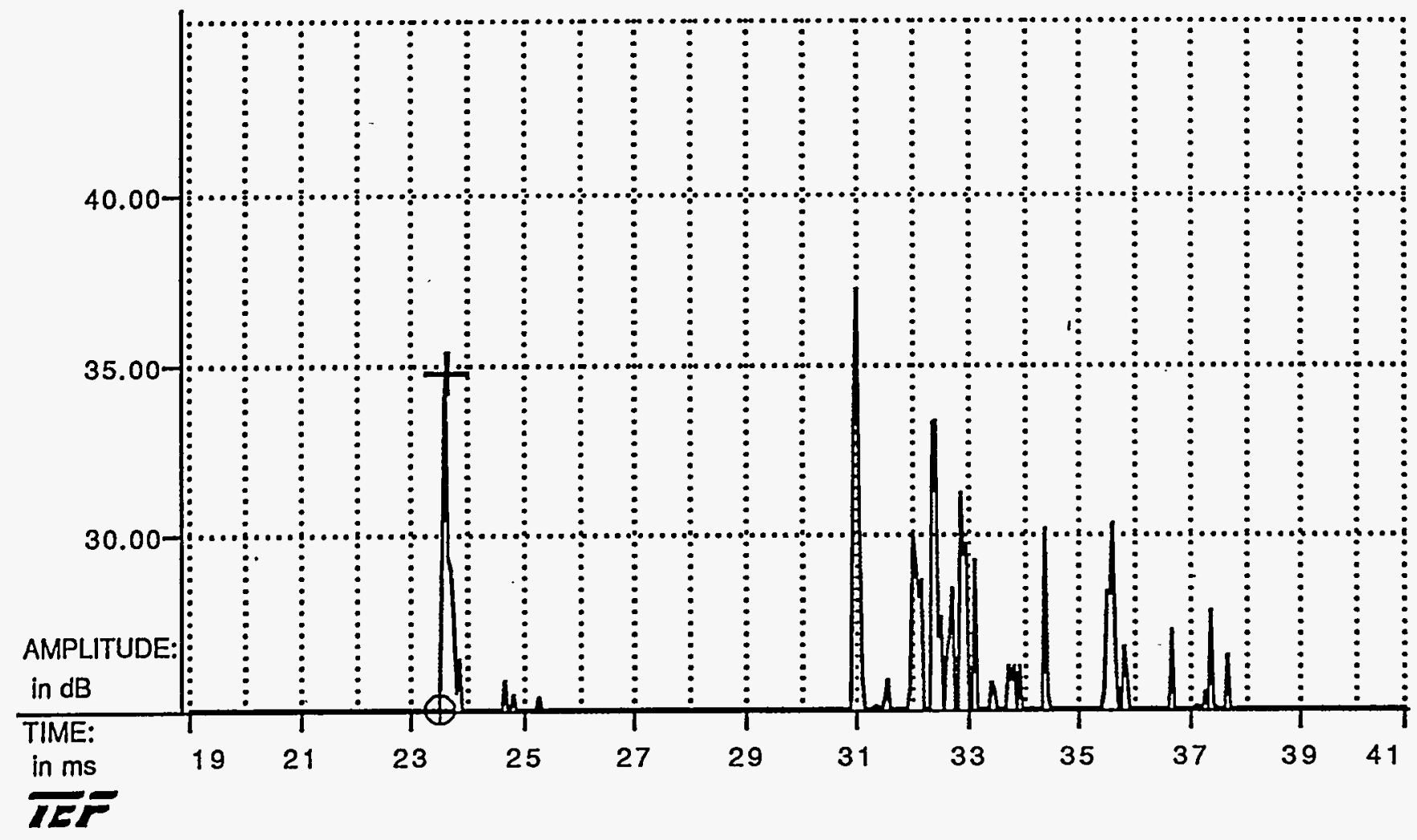

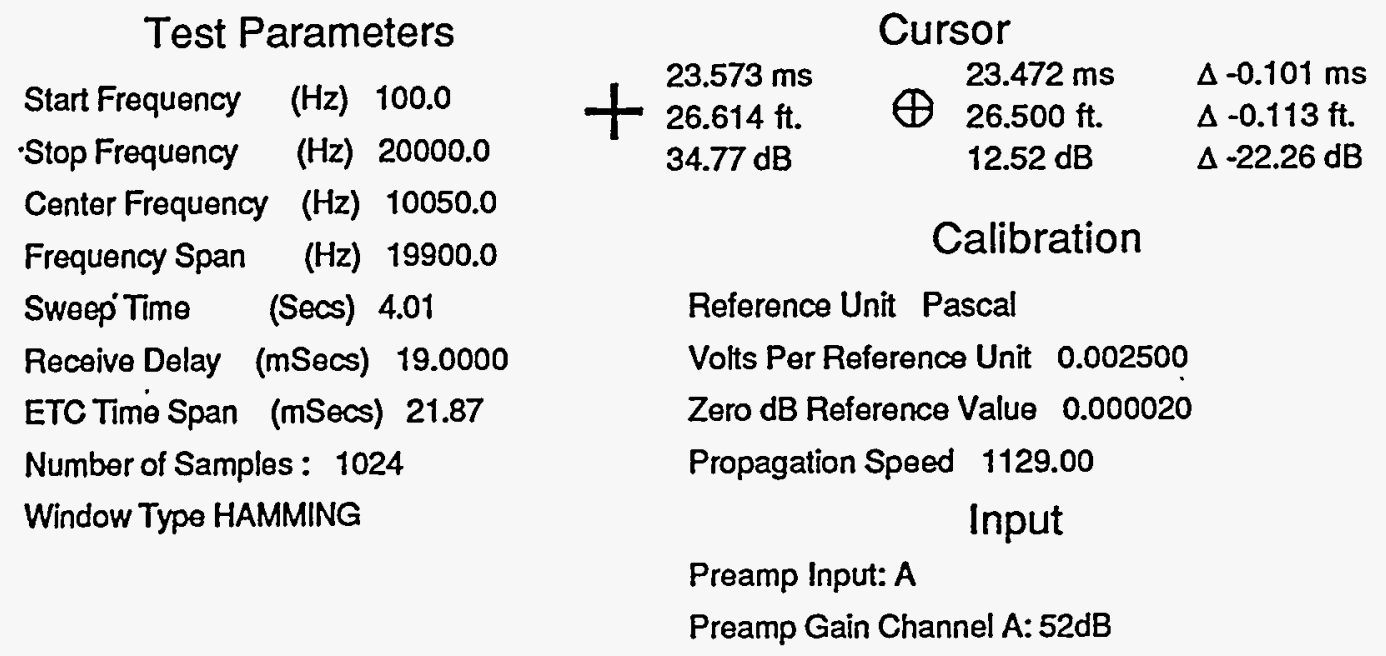


Test Title:

User Name:

Date:

Location:

Job description:

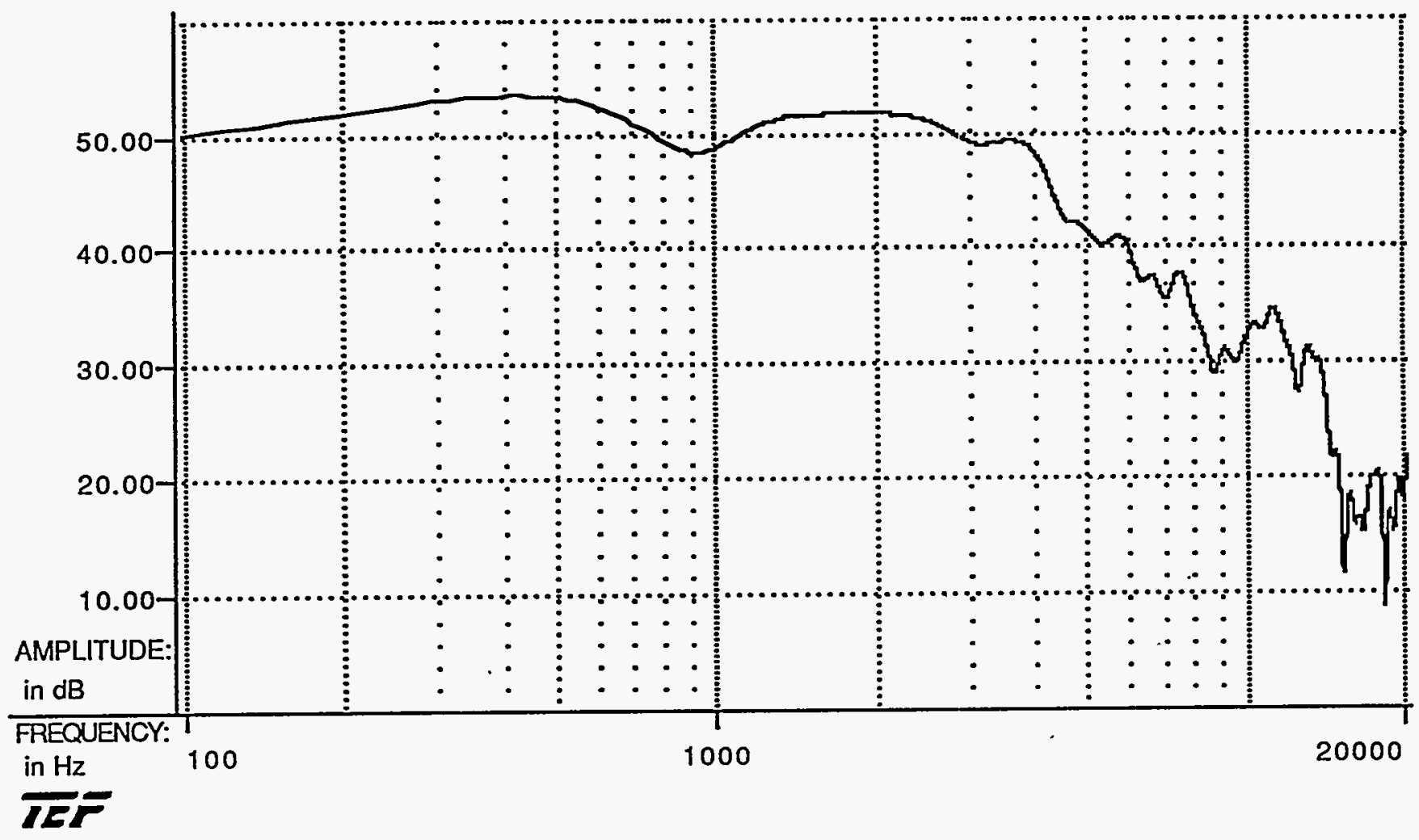

Test Parameters

$\begin{array}{ll}\text { Start Frequency } & (\mathrm{Hz}) 100.0 \\ \text { Stop Frequency } & (\mathrm{Hz}) 20000.0 \\ \text { Sweep Time } & \text { (Secs) } 4.05 \\ \text { Receive Delay } & \text { (mSecs) } 23.572865 \\ \text { RESOLUTION: } & \\ \text { Time } & \text { (mSecs) } 1.00 \\ \text { Distance } & \text { (ft.) } 1.13 \\ \text { Frequency } & \text { (Hz) } 1000.00 \\ \text { Sweep Rate } & \text { (Hz/Sec) } 4909.54 \\ \text { Bandwidth } & \text { (Hz) } 4.910\end{array}$

Calibration

Reference Unit Pascal

Volts Per Reference Unit 0.002500

Zero dB Reference Value 0.000020

Propagation Speed 1129.00

Input

Preamp Input: A

Preamp Gain Channel A: 52dB

Best Frequency Resolution OFF

Number of samples: 1024 
Test Title: Sound System Analysis

User Name: Doug Jones

Date: Thursday, October 12, 1995 at 8:18 PM

Location: Argonne

Job description: Balcony, center, center, no eq

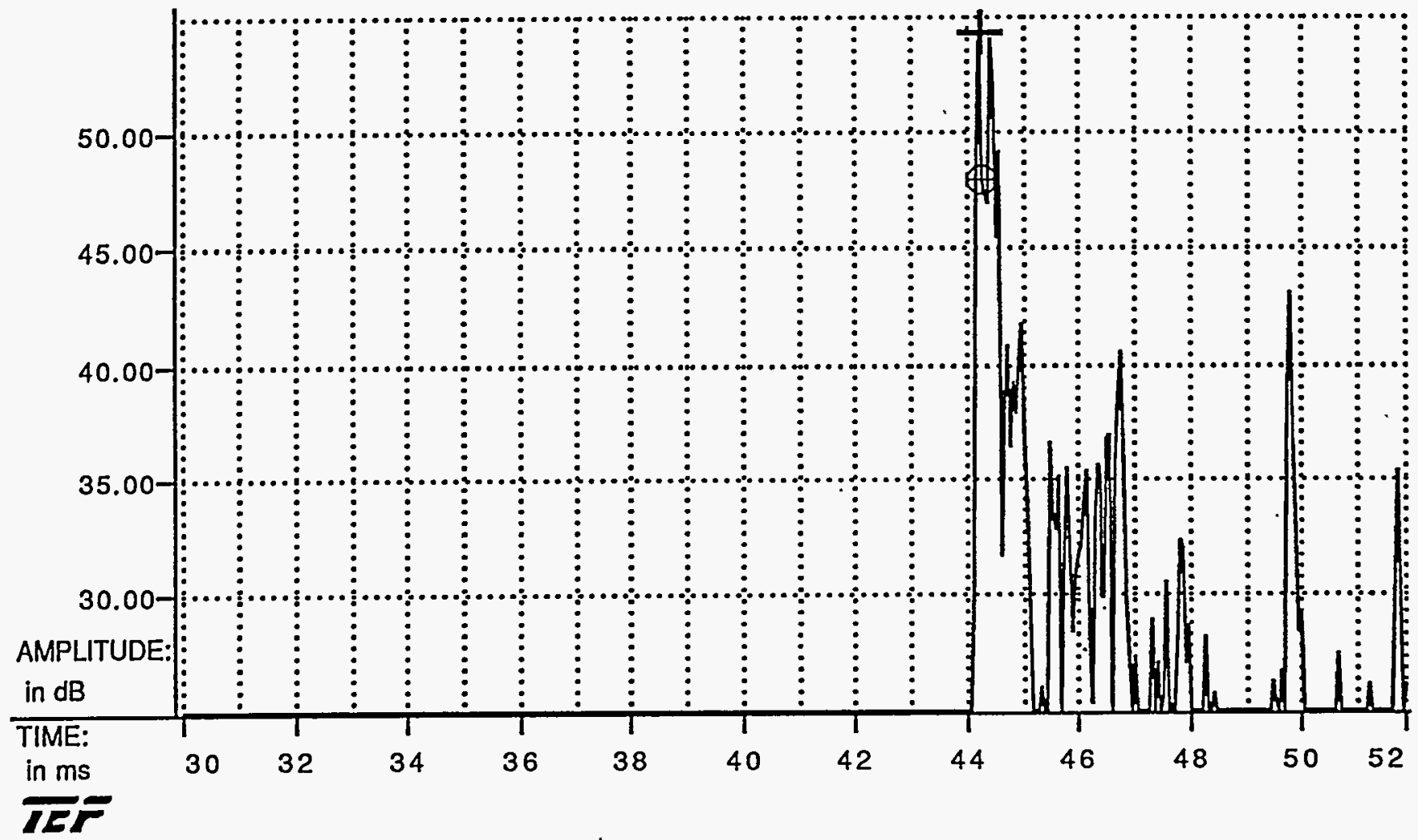

Test Parameters

\begin{tabular}{|c|c|}
\hline Start Frequency & $(H z) \quad 100.0$ \\
\hline Stop Frequency & $(\mathrm{Hz}) \quad 20000.0$ \\
\hline Center Frequency & $(\mathrm{Hz}) \quad 10050.0$ \\
\hline Frequency Span & $(H z) \quad 19900.0$ \\
\hline Sweep Time & (Secs) 4.01 \\
\hline Receive Delay & (mSecs) 30.0000 \\
\hline ETC Time Span & (mSecs) 21.87 \\
\hline Number of Sample & les : 1024 \\
\hline Window & MMING \\
\hline
\end{tabular}

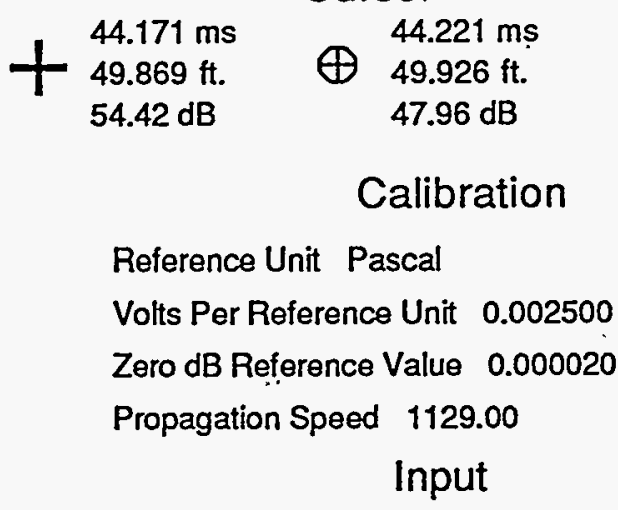

Preamp Input: A

Preamp Gain Channel A: 52dB 
Test Title: Sound System Analysis User Name: Doug Jones

Date: Thursday, October 12, 1995 at 8:16 PM Location: Argonne Job description: Balcony, center, center, no eq

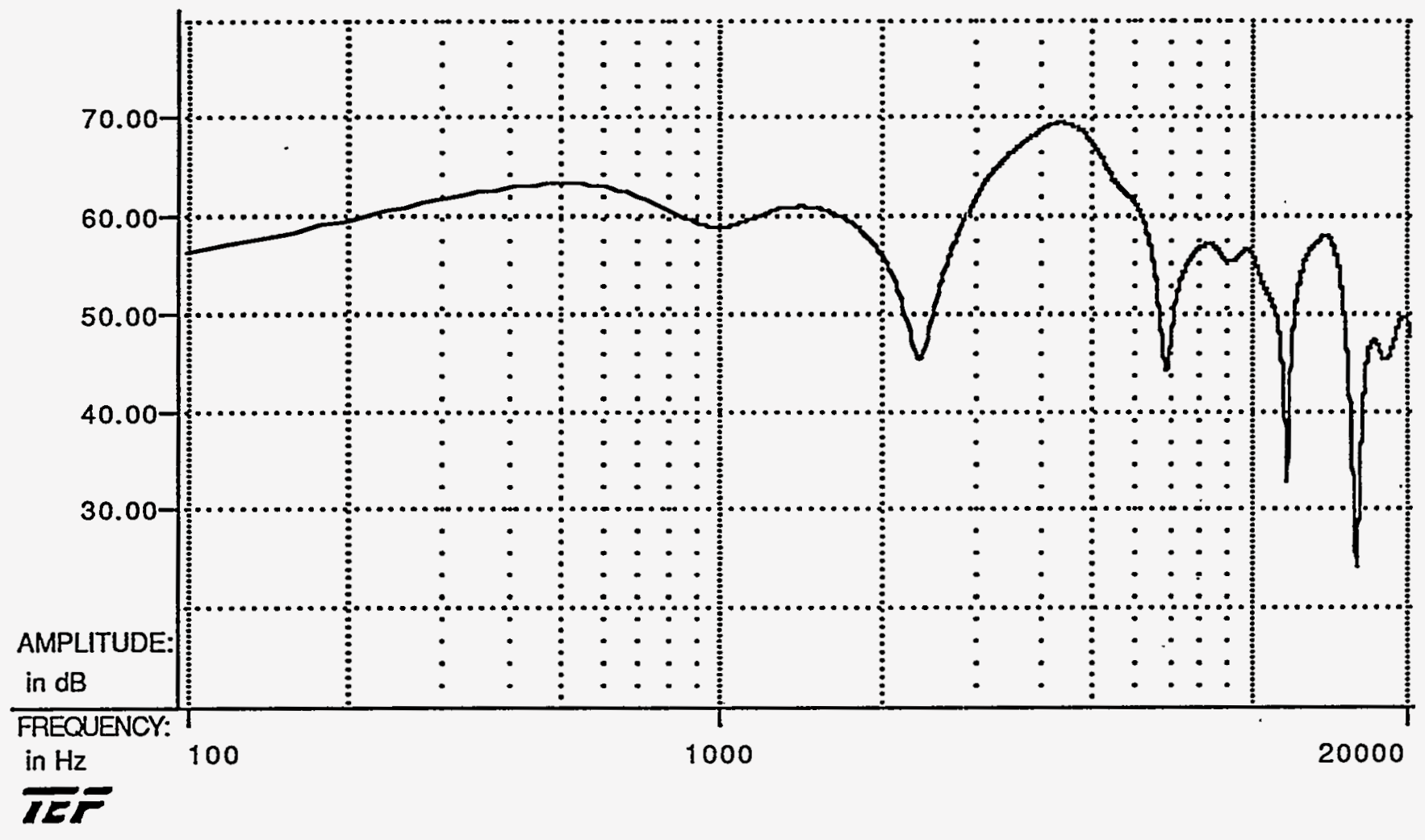

Test Parameters

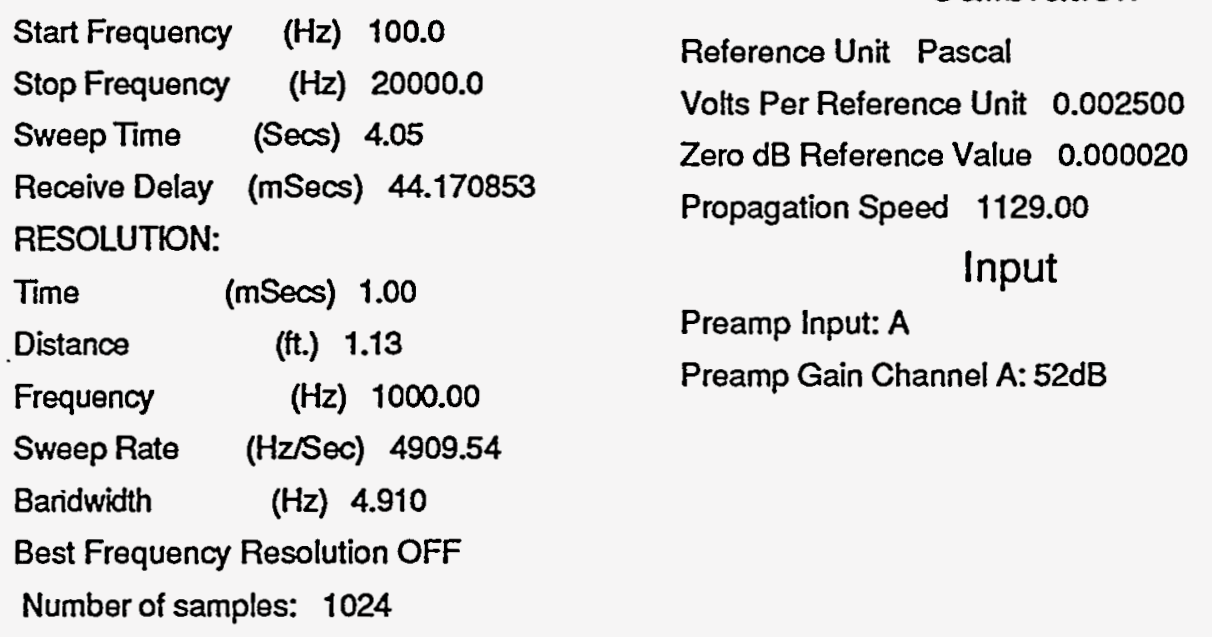


Test Title: Sound System Analysis

User Name: Doug Jones

Date: Thursday, October 12, 1995 at 8:19 PM

Location: Argonne

Job description: Balcony, center, stage right, no eq

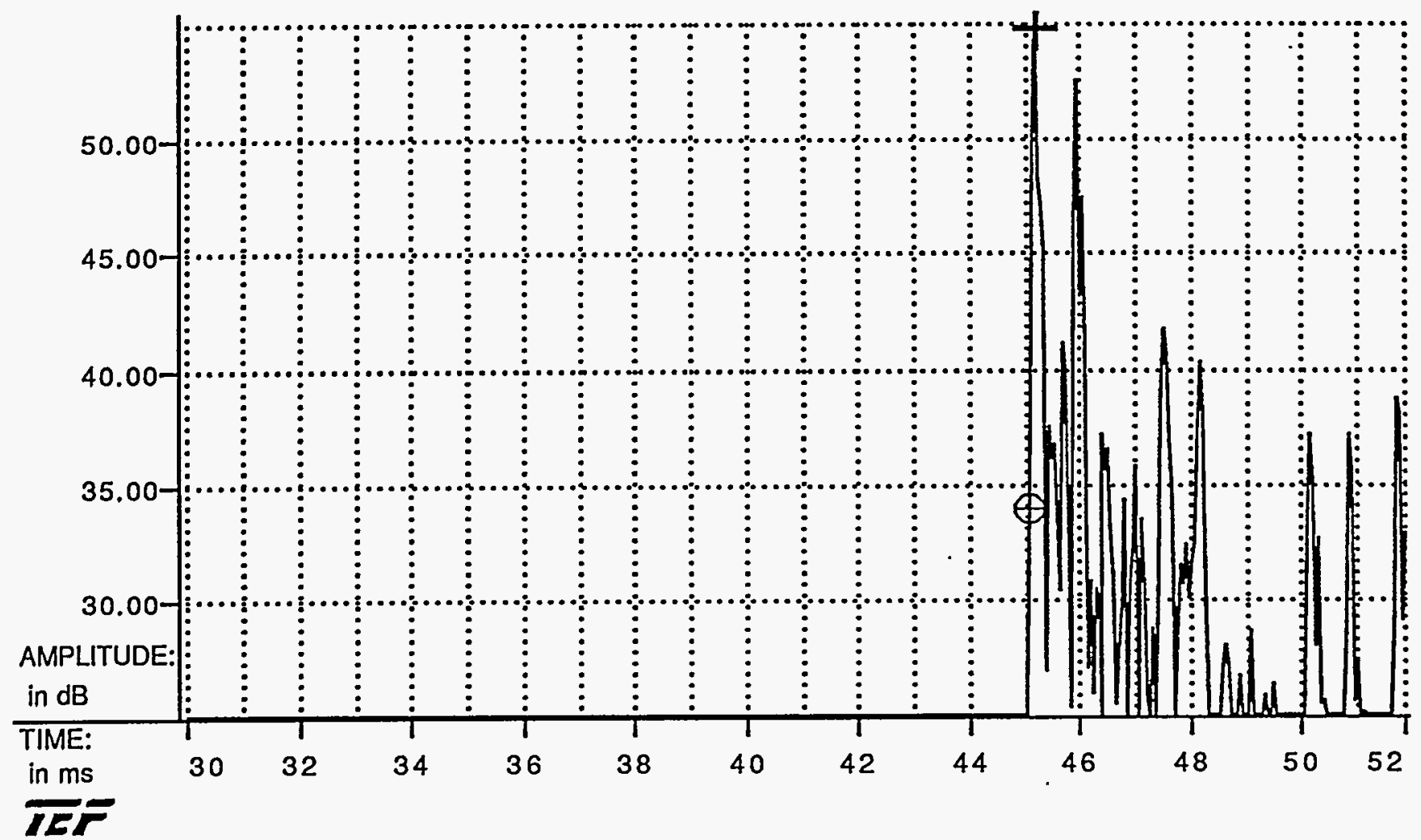

Test Parameters

\begin{tabular}{|c|c|}
\hline Start Frequency & $(\mathrm{Hz}) \quad 100.0$ \\
\hline Stop Frequency & $(\mathrm{Hz}) 20000.0$ \\
\hline Center Frequency & $(H z) \quad 10050.0$ \\
\hline Frequency Span & $(\mathrm{Hz}) \quad 19900.0$ \\
\hline Sweep Time & (Secs) 4.01 \\
\hline Receive Delay & (mSecs) 30.0000 \\
\hline ETC Time Span & (mSecs) 21.87 \\
\hline Number of Sample & les: $1024^{\circ}$, \\
\hline Window Type H & IING \\
\hline
\end{tabular}

Cursor

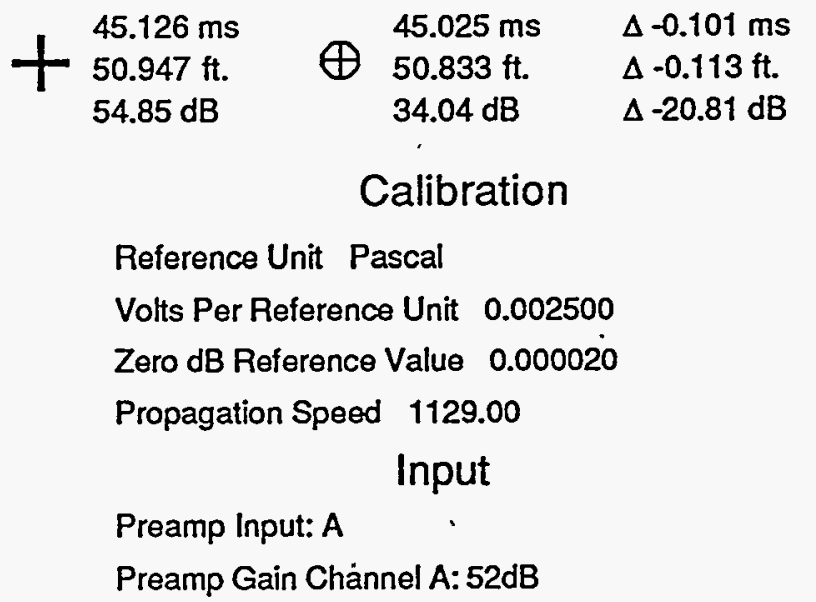


Test Title: Sound System Analysis

User Name: Doug Jones

Date: Thursday, October 12, 1995 at 8:22 PM

Location: Argonne

Job description: Balcony, center, stage right, no eq

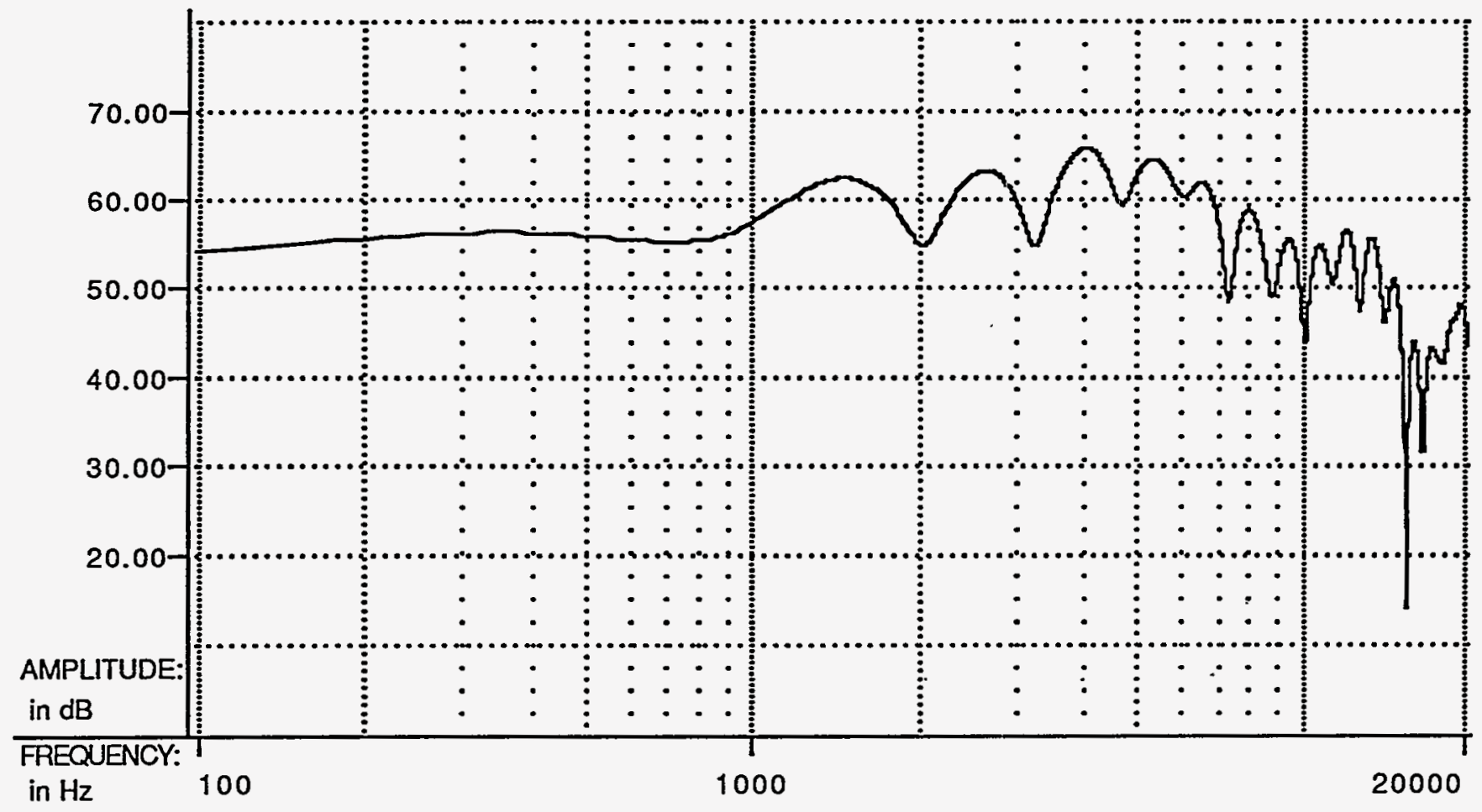

$\overline{T E F}$

Test Parameters

$\begin{array}{ll}\text { Start Frequency } & (\mathrm{Hz}) 100.0 \\ \text { Stop Frequency } & (\mathrm{Hz}) 20000.0 \\ \text { Sweep Time } & \text { (Secs) } 4.05 \\ \text { Receive Delay } & \text { (mSecs) } 45.125629 \\ \text { RESOLUTION: } & \\ \begin{array}{ll}\text { Time } & \text { (mSecs) } 1.00 \\ \text { Distance } & \text { (tt.) } 1.13 \\ \text { Frequency } & \text { (Hz) } 1000.00 \\ \text { Sweep Rate } & (\mathrm{Hz} / \mathrm{Sec}) 4909.54 \\ \text { Bandwidth } & \text { (Hz) } 4.910\end{array}\end{array}$

Best Frequency Resolution OFF

Number of samples: 1024

\section{Calibration}

Reference Unit Pascal

Volts Per Reference Unit 0.002500

Zero dB Reference Value 0.000020

Propagation Speed 1129.00

\section{Input}

Preamp Input: A

Preamp Gain Channel A: $\mathbf{5 2 d B}$ 
RASTI of Argonne. intel.1

Test Title: Intel tests

User Name: Doug Jones

Date: Thursday, October 12, 1995 at 8:28 PM

Location: Argonne APS

Job description: Balcony center stage right, no eq

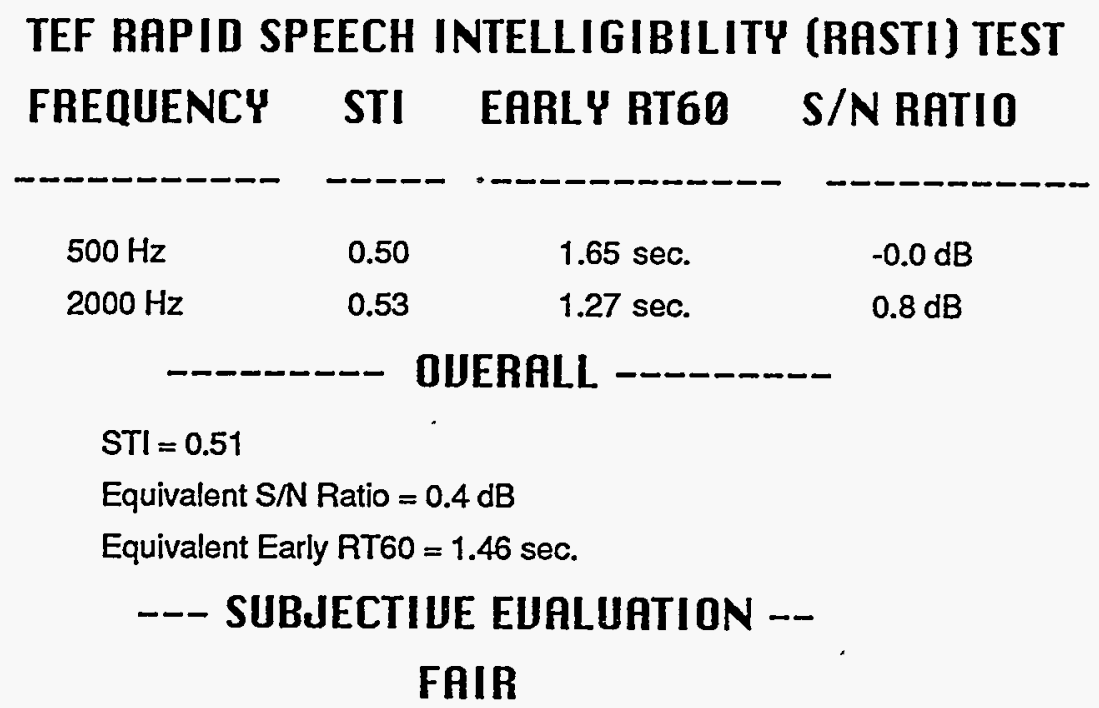

$\overline{\text { IEF }}$ 
RASTI of Argonne. intel.2

Test Title: Intel tests

User Name: Doug Jones

Date: Thursday, October 12, 1995 at 8:28 PM

Location: Argonne APS

Job description: Balcony center stage right, no eq

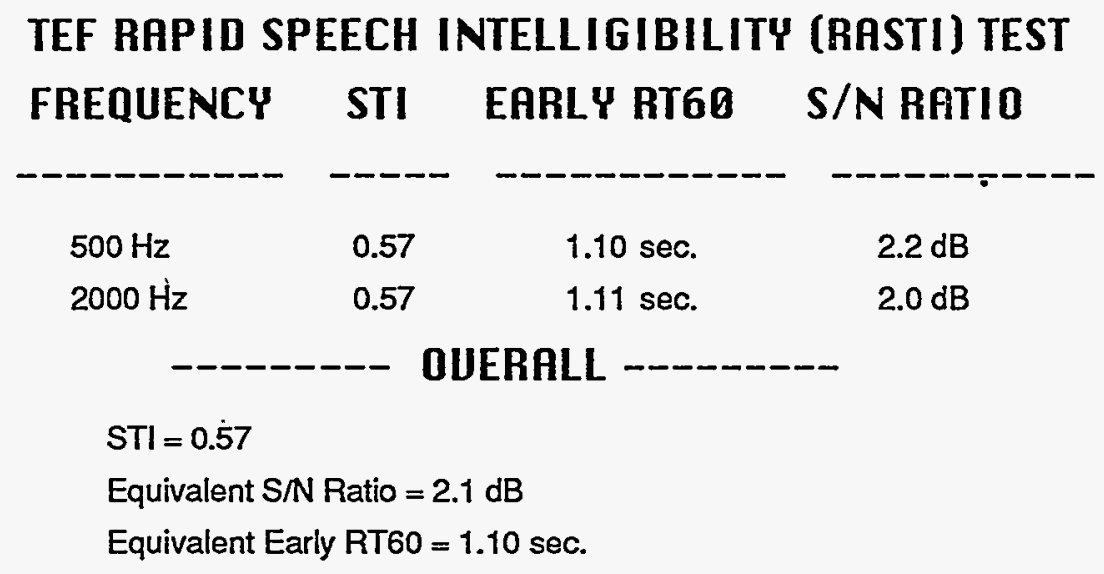

SUBJECTIUE EUALUATION --

FAIR

$\overline{\text { IEF }}$ 
Test Title: Intel tests

User Name: Doug Jones

Date: Thursday, October 12, 1995 at 8:37 PM

Location: Argonne APS

Job description: center, stage right, no eq

\section{TEF RAPID SPEECH INTELLIGIBILITY (RASTI) TEST}

\section{FREQUENCY STI EARLY RT6O S/N RATIO}

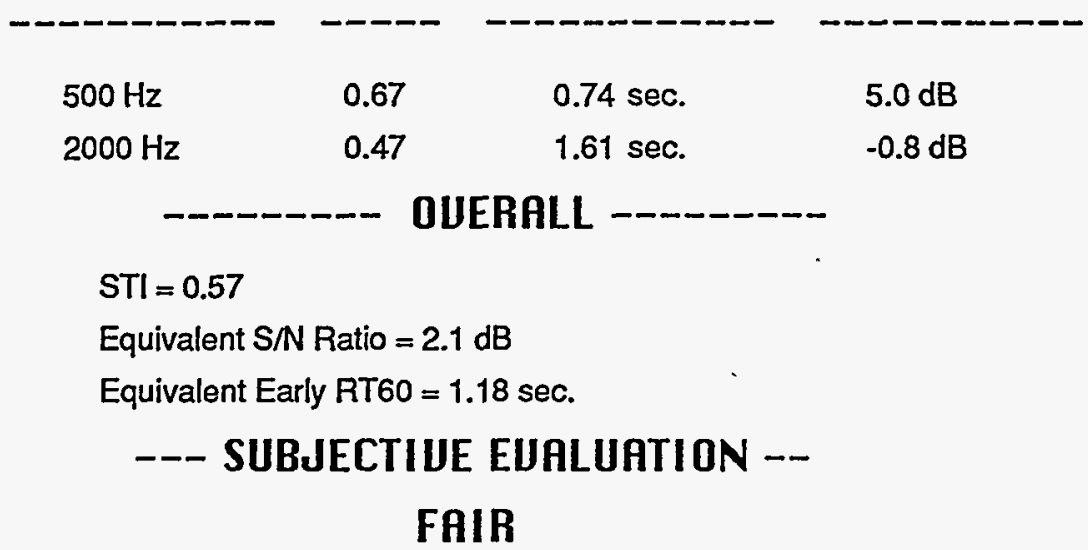

$\overline{\text { IEF }}$ 
RASTI of argonne.intel. 4

Test Title: Intel tests

User Name: Doug Jones

Date: Thursday, October 12, 1995 at 8:39 PM

Location: Argonne APS

Job description: center, rear, no eq

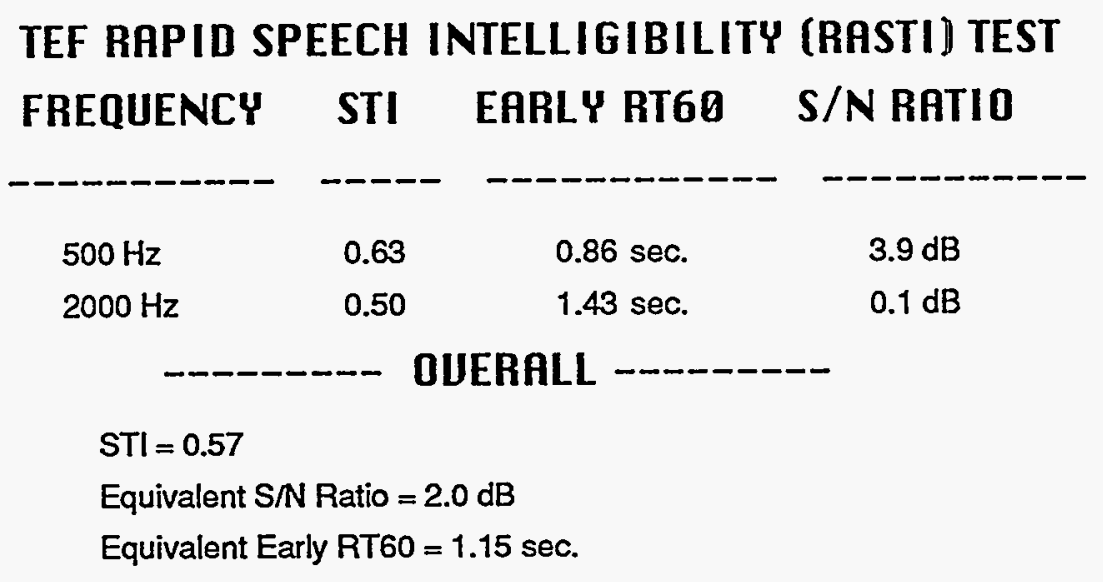

SUBJECTIUE EUALUATION --

FAIR

IEF 
RASTI of argonne. intel.5

Test Title: Intel Tests

User Name: Doug Jones

Date: Thursday, October 12, 1995 at 8:43 PM

Location: Argonne

Job description: Center front

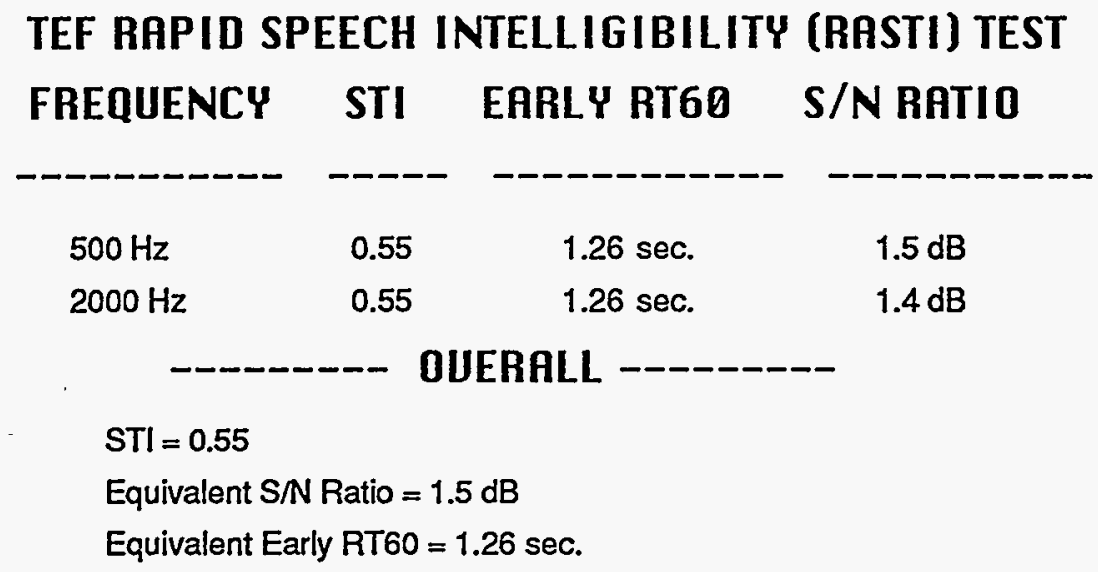

SUBJECTIUE EURLUATION --

FAIR

$\overline{\text { TEF }}$ 
Test Title:

User Name: Doug Jones

Date: Thursday, October 12, 1995 at 9:26 PM

Location:

Job description: MEASURED IN BALCONY, SPKR ON STAGE

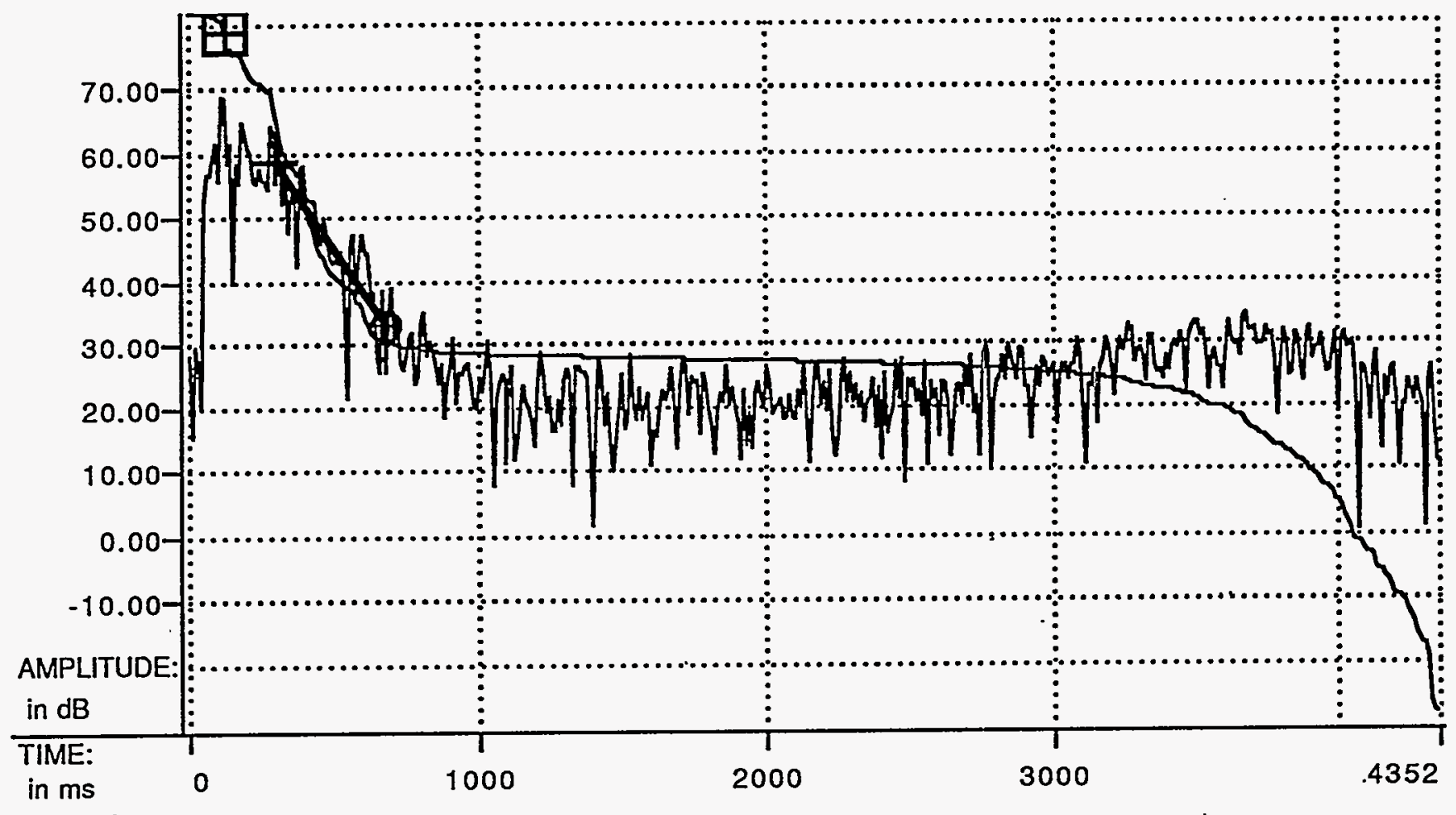

TEF

Test Parameters

\begin{tabular}{|c|c|c|}
\hline Start Frequency & $(\mathrm{Hz})$ & 100.0 \\
\hline Stop Frequency & $(\mathrm{Hz})$ & 200.0 \\
\hline Center Frequency & $(\mathrm{Hz})$ & 150.0 \\
\hline Frequency Span & $(H z)$ & 100.0 \\
\hline Sweep Time & (Secs) & 5.03 \\
\hline Recoive Delay & (mSecs) & 0.0000 \\
\hline ETC Time Span & (mSecs) & ) 4352.00 \\
\hline \multicolumn{3}{|c|}{ Number of Samples : 1024} \\
\hline ndow Ty? & & \\
\hline
\end{tabular}

Cursor

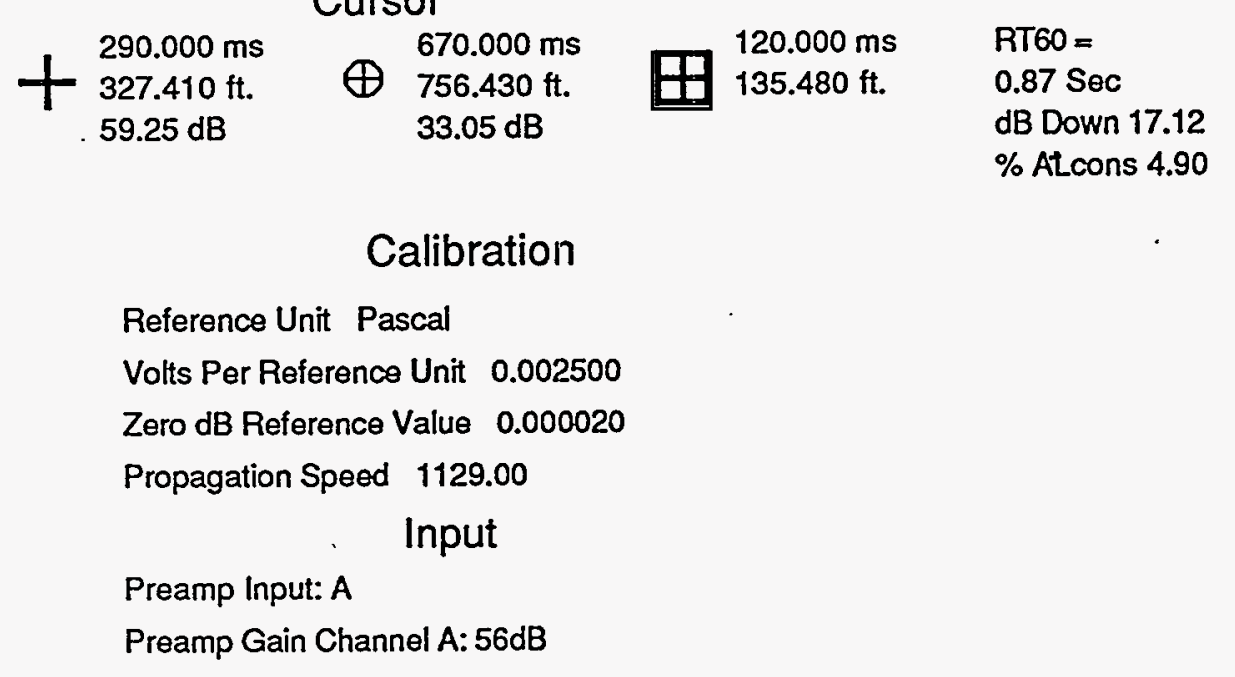


ETC Mag of ARGONNE RT 2

Test Title:

User Name: Doug Jones

Date: Thursday, October 12, 1995 at 9:26 PM

Location:

Job description: MEASURED IN BALCONY, SPKR ON STAGE

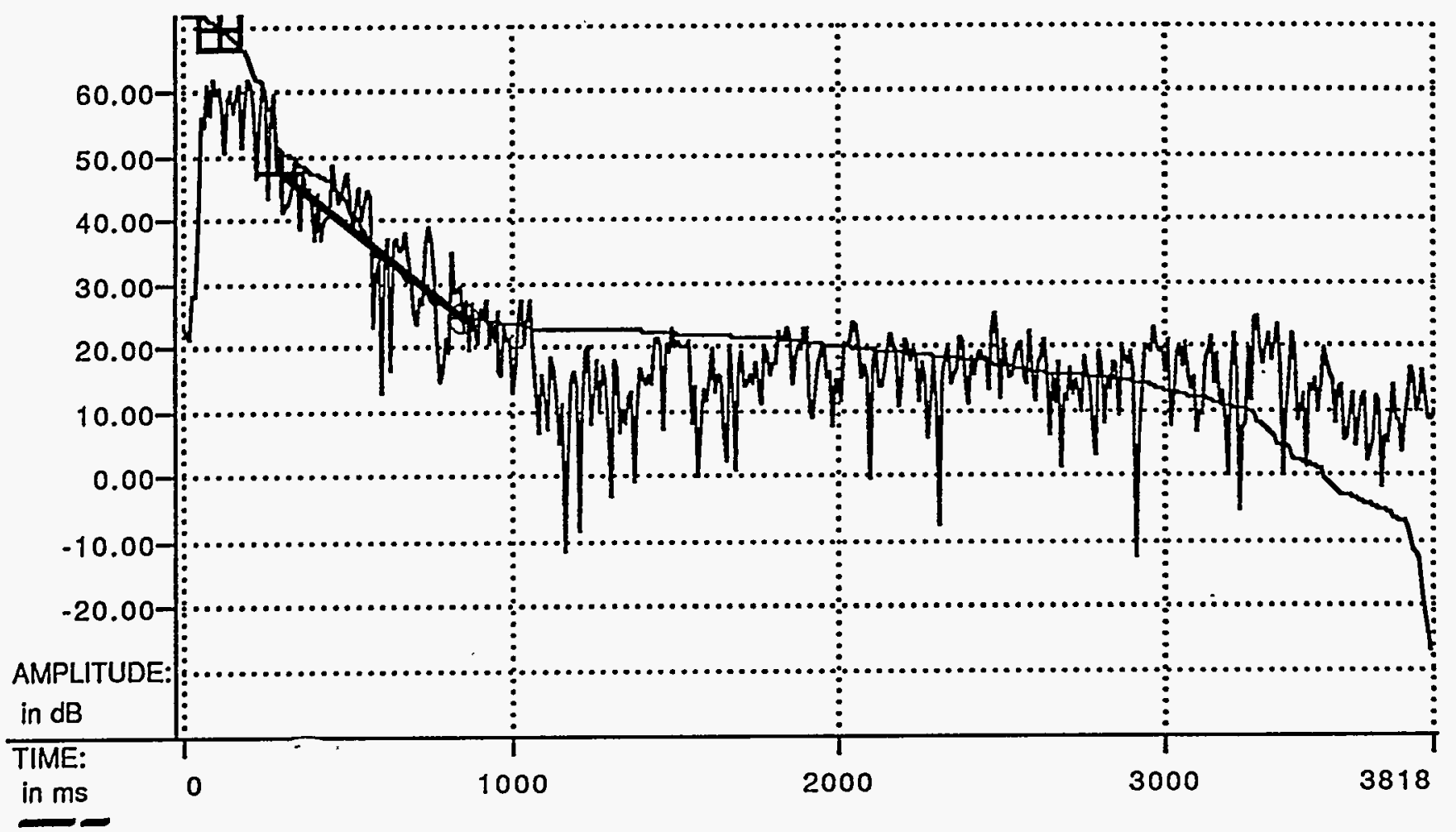

TEF.

Test Parameters

$\begin{array}{ll}\text { Start Frequency } & (\mathrm{Hz}) 186.0 \\ \text { Stop Frequency } & (\mathrm{Hz}) 300.0 \\ \text { Center Frequency } & (\mathrm{Hz}) 243.0 \\ \text { Frequency Span } & (\mathrm{Hz}) 114.0 \\ \text { Sweep Time } & (\mathrm{Secs}) 5.03 \\ \text { Receive Delay } & \text { (mSecs) } 0.0000 \\ \text { ETC Time Span } & \text { (mSecs) } 3817.54 \\ \text { Number of Samples: } 1024 \\ \text { Window Type HAMMING }\end{array}$

Cursor

\begin{tabular}{|c|c|c|c|c|}
\hline $\begin{array}{l}289.474 \mathrm{~ms} \\
326.816 \mathrm{ft} . \\
47.79 \mathrm{~dB}\end{array}$ & $\bigoplus$ & $\begin{array}{l}842.105 \mathrm{~ms} \\
950.737 \mathrm{ft} . \\
24.49 \mathrm{~dB}\end{array}$ & 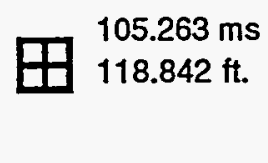 & $\begin{array}{l}\text { RT } 60= \\
1.42 \text { Sec } \\
\text { dB Down } 16.58 \\
\% \text { Alcons } 712\end{array}$ \\
\hline
\end{tabular}

Reference Unit Pascal

Volts Per Reference Unit $0.002500^{\circ}$

Zero dB Reference Value 0.000020

Propagation Speed 1129.00

Input

Preamp Input: A

Preamp Gain Channel A: 56dB 
Test Title:

User Name: Doug Jones

Date: Thursday, October 12, 1995 at 9:26 PM

Location:

Job description: MEASURED IN BALCONY, SPKR ON STAGE

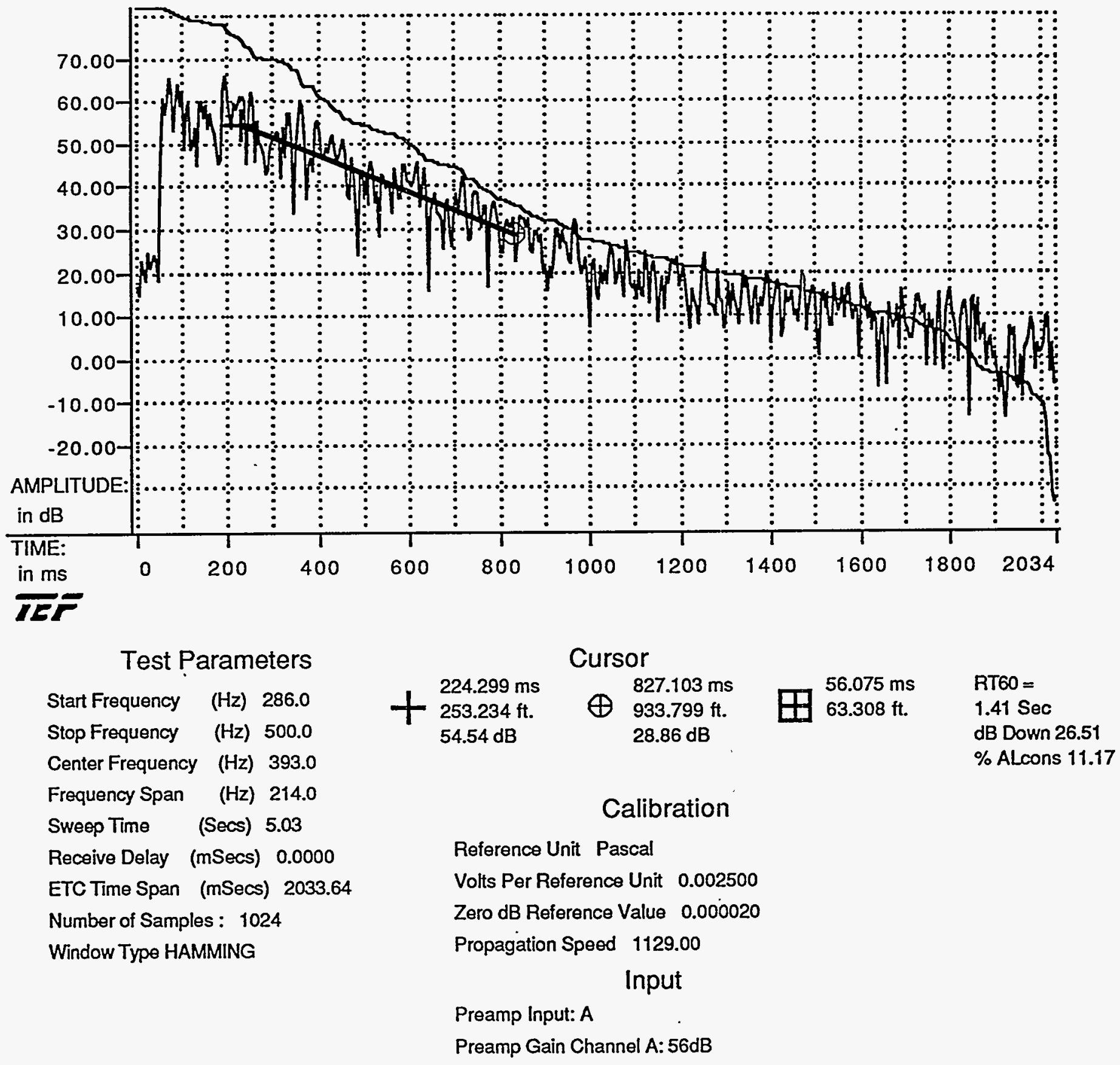


Test Title:

User Name: Doug Jones

Date: Thursday, October 12, 1995 at 9:26 PM

Location:

Job description: MEASURED IN BALCONY, SPKR ON STAGE

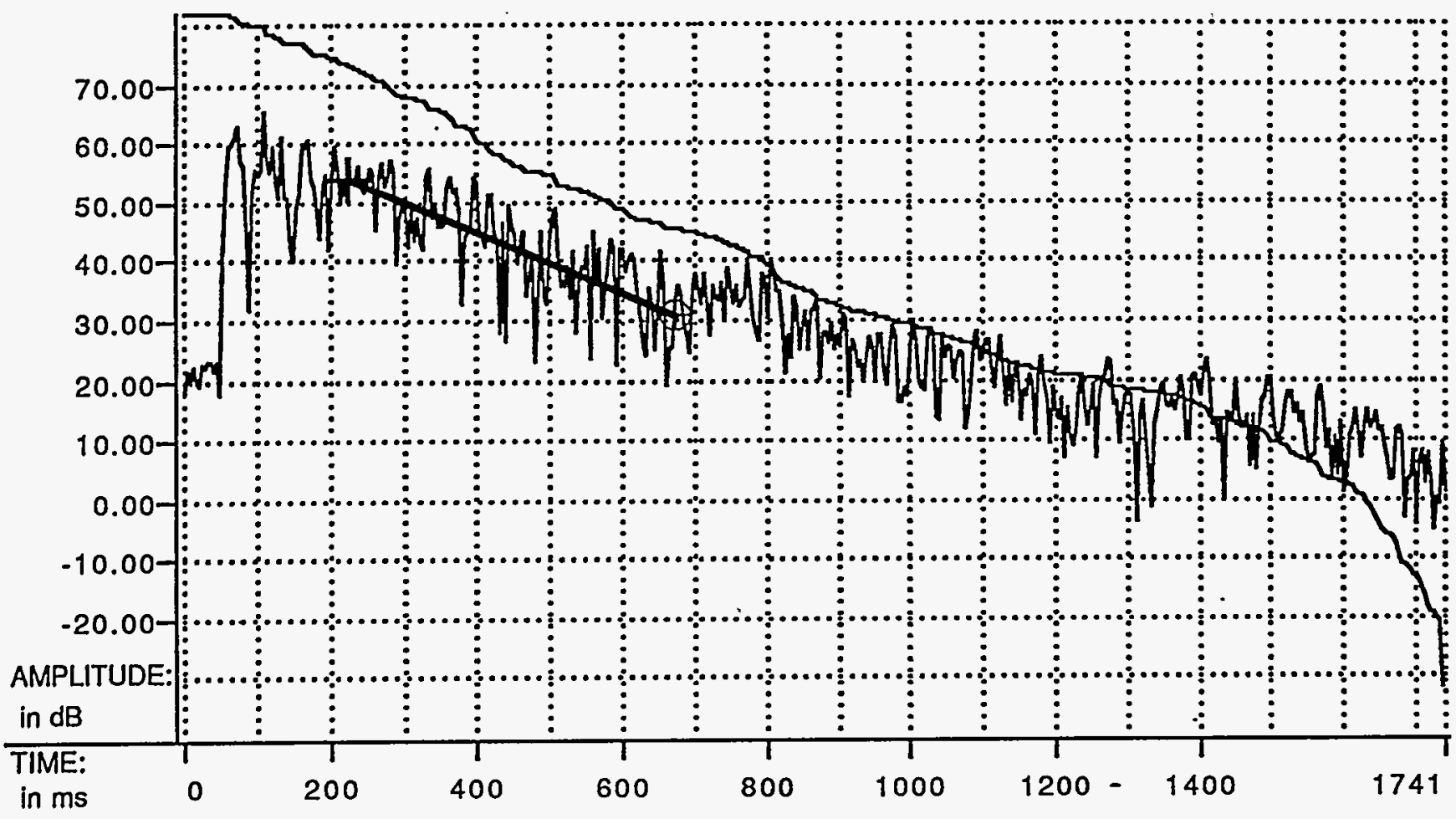

TEF

Test Parameters

\begin{tabular}{|c|c|}
\hline Start Frequency & $(H z) \quad 450.0$ \\
\hline Stop Frequency & $(\mathrm{Hz}) 700.0$ \\
\hline Center Frequency & $(H z) \quad 575.0$ \\
\hline Frequency Span & $(H z) 250.0$ \\
\hline Sweep Time & (Secs) 5.03 \\
\hline Recoive Delay & (mSecs) $\quad 0.0000$ \\
\hline ETC Time Span & (mSecs) 1740.80 \\
\hline Number of Sample & les: 1024 \\
\hline Window Type HAM & MMING \\
\hline
\end{tabular}

Cursor

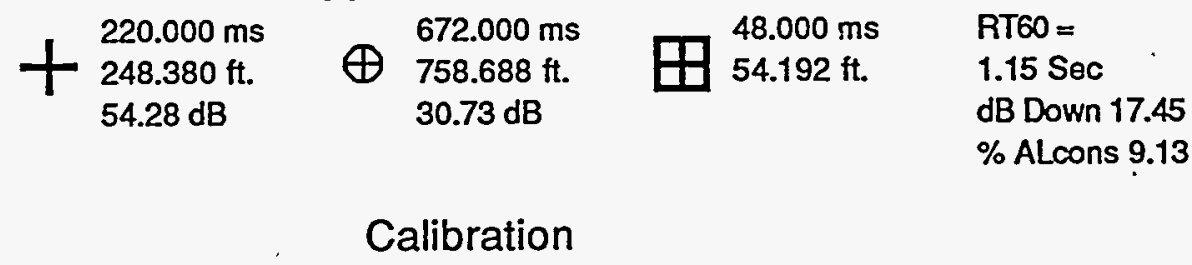

Reference Unit Pascal

Volts Per Reference Unit $\mathbf{0 . 0 0 2 5 0 0}$

Zero dB Reference Value 0.000020

Propagation Speed 1129.00

Input

Preamp Inpít: A

Preamp Gain Channel A: 56dB 
Test Title:

User Name: Doug Jones

Date: Thursday, October 12, 1995 at 9:26 PM

Location:

Job description: MEASURED IN BALCONY, SPKR ON STAGE

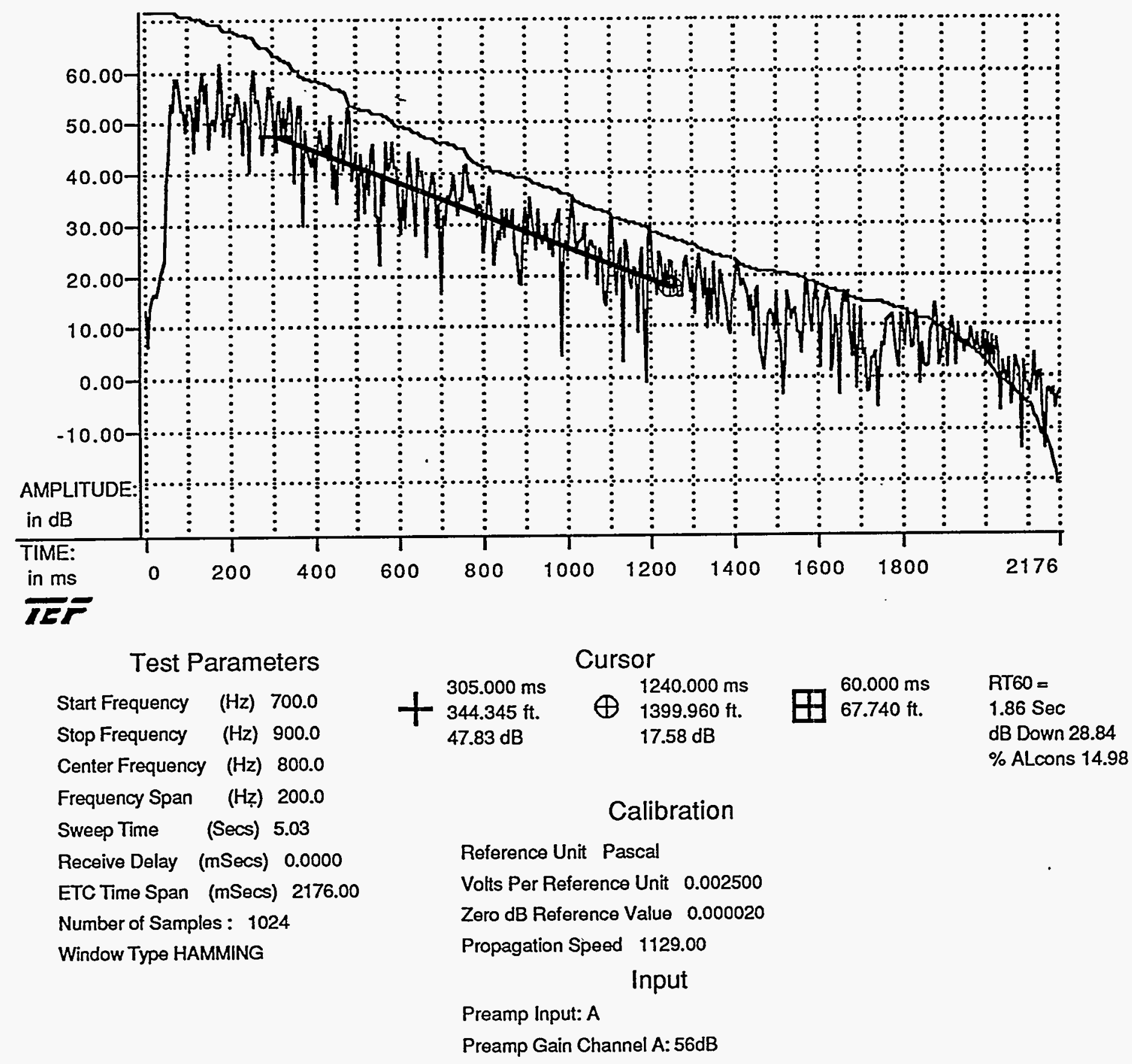


Test Title:

User Name:

Date:

Location:

Job description:

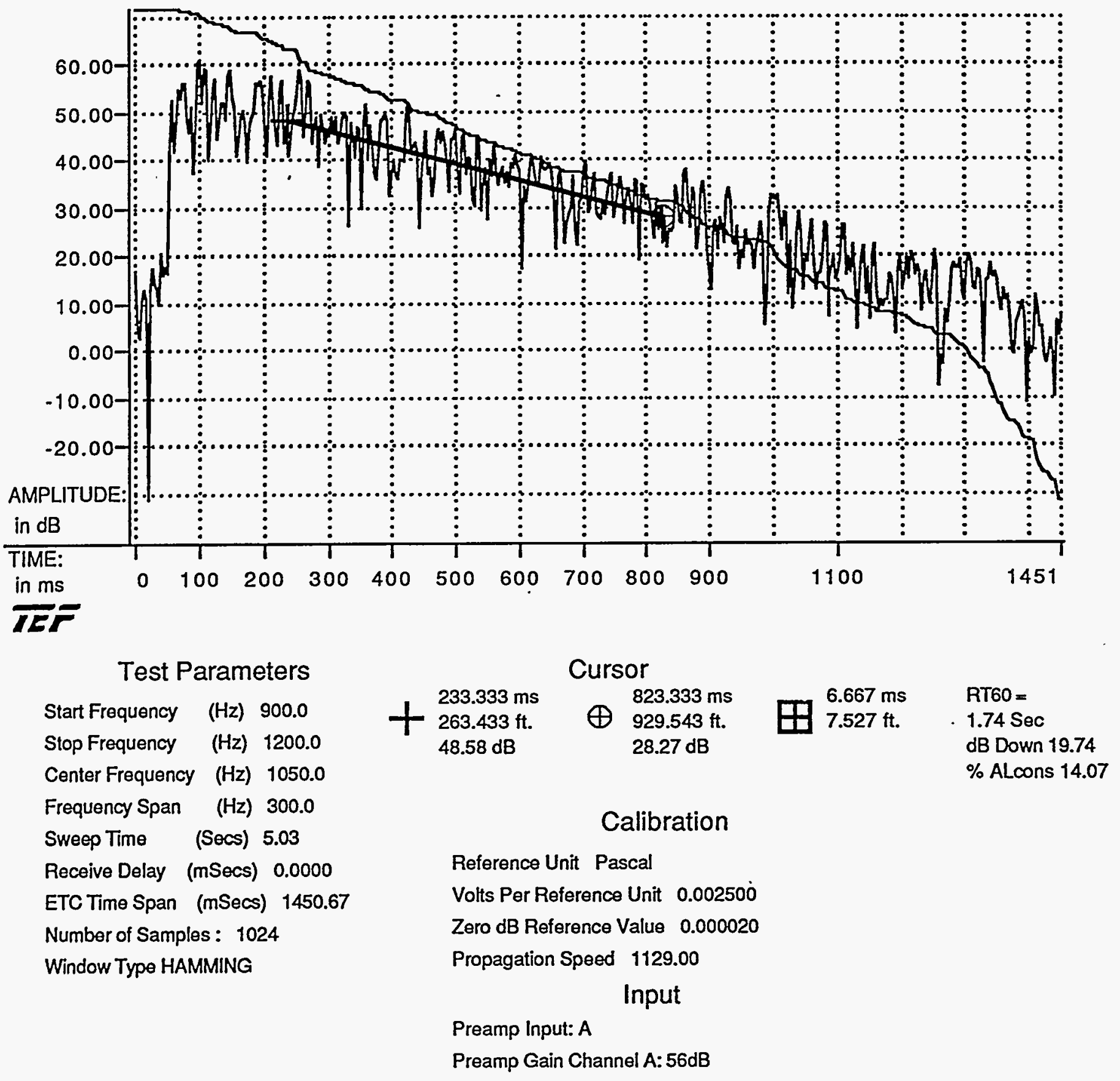


Test Title:

User Name:

Date:

Location:

Job description:

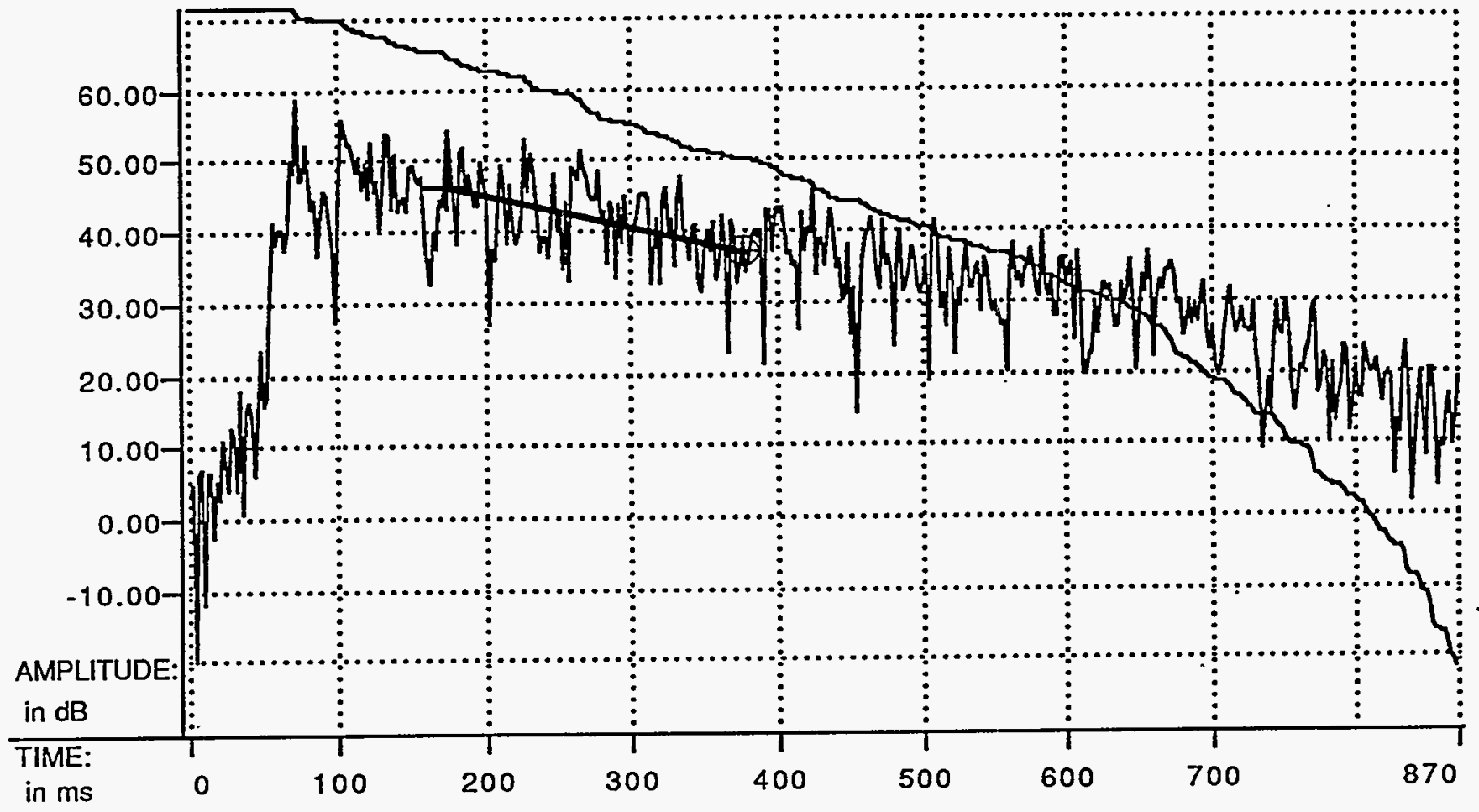

IEF

Test Parameters

Start Frequency

(Hz) 1500.0

Stop Frequency

(Hz) 2000.0

Center Frequency

Frequency Span

Sweep Time

(Hz) 1750.0

(Hz) 500.0

Receive Delay (mSecs) 0.0000

ETC Time Span (mSecs) 870.40

Number of Samples : 1024

Window Type HAMMING

\section{Cursor}

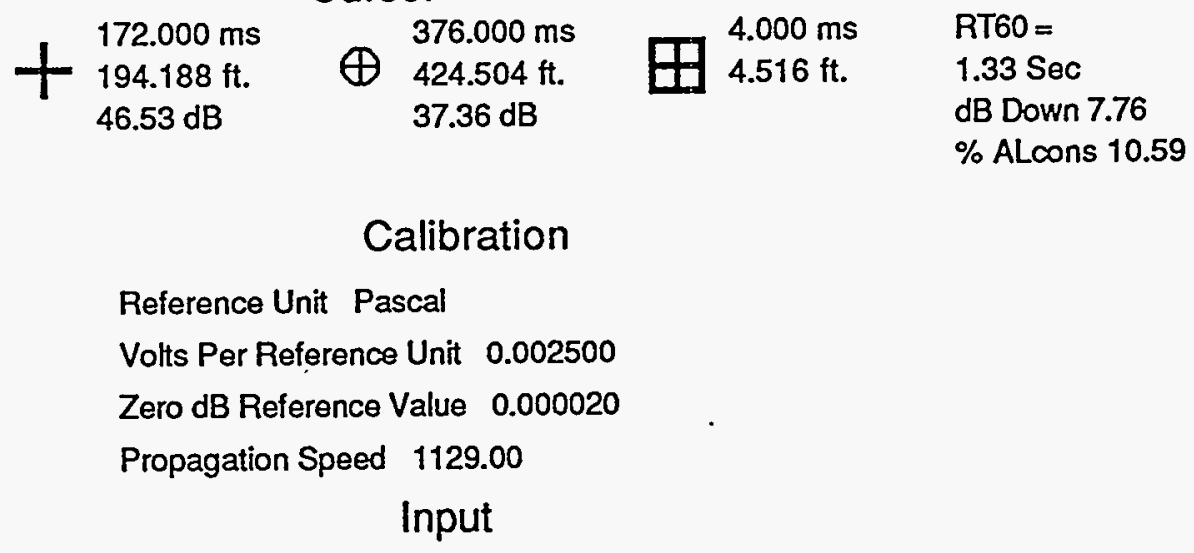

Preamp Input: $A$

Preamp Gain Channel A: 56dB 